\title{
Pharmacology and therapeutic implications of current drugs for type 2 diabetes mellitus
}

\begin{abstract}
Abd A. Tahrani 1,2, Anthony H. Barnett ${ }^{1,2}$ and Clifford J. Bailey ${ }^{3}$
Abstract | Type 2 diabetes mellitus (T2DM) is a global epidemic that poses a major challenge to health-care systems. Improving metabolic control to approach normal glycaemia (where practical) greatly benefits long-term prognoses and justifies early, effective, sustained and safety-conscious intervention. Improvements in the understanding of the complex pathogenesis of T2DM have underpinned the development of glucose-lowering therapies with complementary mechanisms of action, which have expanded treatment options and facilitated individualized management strategies. Over the past decade, several new classes of glucose-lowering agents have been licensed, including glucagon-like peptide 1 receptor (GLP-1R) agonists, dipeptidyl peptidase 4 (DPP-4) inhibitors and sodium/glucose cotransporter 2 (SGLT2) inhibitors. These agents can be used individually or in combination with well-established treatments such as biguanides, sulfonylureas and thiazolidinediones. Although novel agents have potential advantages including low risk of hypoglycaemia and help with weight control, long-term safety has yet to be established. In this Review, we assess the pharmacokinetics, pharmacodynamics and safety profiles, including cardiovascular safety, of currently available therapies for management of hyperglycaemia in patients with T2DM within the context of disease pathogenesis and natural history. In addition, we briefly describe treatment algorithms for patients with T2DM and lessons from present therapies to inform the development of future therapies.
\end{abstract}

Type 2 diabetes mellitus (T2DM) is a global epidemic with an estimated worldwide prevalence of 415 million people in 2015 , which is projected to rise to 642 million people by 2040 (REF. 1). The very considerable health, social and economic burdens caused by $\mathrm{T} 2 \mathrm{DM}^{1-3}$ present a major challenge to health-care systems around the world.

T2DM is a complex endocrine and metabolic disorder in which the interaction between genetic and environmental factors generates a heterogeneous and progressive pathology with varying degrees of insulin resistance and dysfunction of pancreatic $\beta$ cells and $\alpha$ cells, as well as other endocrine disturbances ${ }^{4-14}$ (FIC. 1). Insulin resistance results from deficits in signalling pathways at the level of the insulin receptor and downstream, and T2DM emerges when $\beta$ cells can no longer secrete sufficient insulin to overcome insulin resistance ${ }^{4,15-17}$. Overweight and obesity are major risk factors for the development of insulin resistance $e^{4,5,16,18-20}$.

Hyperglycaemia is the fundamental biochemical feature of T2DM, causing oxidative and nitrosative stress and activation of inflammatory pathways and endothelial dysfunction, as well as precipitating microvascular complications and contributing to macrovascular disease, which are major causes of morbidity and mortality ${ }^{21}$. The results of several randomized controlled trials (RCTs) have demonstrated the short-term and long-term benefits of improving glycaemic control in delaying the onset and reducing the severity of diabetes-related outcomes, particularly retinopathy, nephropathy, neuropathy and cardiovascular disease, and also mortality ${ }^{22-25}$. Attaining normal (or nearly normal) levels of blood glucose (where practical) is a major aim of T2DM treatment. Several strategies are available for this purpose: lifestyle changes, including dietary prudence, weight loss and physical activity, remain the cornerstones of management, but because of the progressive nature of T2DM and the difficulty in maintaining lifestyle changes in the long term, most patients also require oral therapies and (eventually) injectable treatments ${ }^{26}$.

For more than four decades, only two classes of oral glucose-lowering medications were available (biguanides and sulfonylureas), but in the past 20 years many more 


\section{Key points}

- Greater understanding of the complex and multifactorial pathogenesis of type 2 diabetes mellitus (T2DM) has informed the development of several new classes of glucose-lowering therapies

- Metformin remains the first-line pharmacotherapy for patients with T2DM, whereas the use of other well-established agents, such as sulfonylureas, meglitinides, pioglitazone and $\alpha$-glucosidase inhibitors, varies in different regions

- Agents that enhance incretin activity (DPP-4 inhibitors), supplement endogenous GLP-1 (GLP-1 receptor agonists) or increase urinary glucose elimination (SGLT2 inhibitors) have low risk of hypoglycaemia and can assist weight control

- Treatment with two or three agents with different modes of action can be required as T2DM advances, and insulin therapy is required if other agents are unable to maintain adequate glycaemic control

- Glycaemic targets and the choice of glucose-lowering agents should be customized to meet the needs and circumstances of individual patients, which could be facilitated by future developments in pharmacogenomics

- Although the balance of benefits and risks for different agents varies between individual patients, early, effective and sustained glycaemic control delays the onset and reduces the severity of hyperglycaemia-related complications

treatment options have been introduced ${ }^{26,27}$ (TABLE 1). In this Review, we provide an evaluation of the therapies available for the management of hyperglycaemia in patients with T2DM.

\section{Glycaemic control and targets in T2DM}

The treatment needs of patients with T2DM, and the responses to treatments, are highly variable, reflecting the complexity and variability of the pathogenic $\operatorname{process}^{28,29}$, so decisions must be made for each patient regarding the choice of therapy and glycaemic targets. Factors for consideration include patient age, weight, duration of T2DM, risk of hypoglycaemia, cardiovascular risk, concomitant treatments, presence of complications and concomitant life-limiting illness. Other aspects, which are more difficult to quantify in clinical practice, include the reserve capacity for insulin secretion, genetic factors that might affect responses to therapies, the risk of developing future complications and the rate of disease progression ${ }^{30}$.

The long-term benefits of intensive glycaemic control on T2DM-related complications and mortality are well known, particularly when initiated promptly after diagnosis in young patients who do not yet have comorbid complications ${ }^{22-25}$. However, intensive glycaemic control is not without risks, such as hypoglycaemia, weight gain and possible cardiovascular events and mortality in highrisk individuals. These risks might relate, at least in part, to the choice of glycaemic target and medications ${ }^{22,31-36}$, so an individualized management strategy is prefera$\mathrm{ble}^{36}$. The difficulty lies in the identification of patients in whom the risks associated with intensive glycaemic control outweigh the benefits. Stringent glycaemic control is not advised in elderly patients or in those with advanced disease, long T2DM duration or established cardiovascular disease ${ }^{27,36}$. An $\mathrm{HbA}_{1 \mathrm{c}}$ target of $7 \%$ is commonly given in guidelines, but a lower target might be appropriate for newly diagnosed, young patients with T2DM and no complications, and a higher target might be more realistic for an elderly or frail patient with a long duration of disease and established complications.

\section{Biguanides}

The only biguanide available in clinical practice is metformin (dimethylbiguanide) ${ }^{37}$. Other biguanides (phenformin and buformin) have been withdrawn because of risks of lactic acidosis ${ }^{38}$. Biguanides were derived from the guanidine-rich herb Galega officinalis (French lilac), which was used in traditional medicine in Europe ${ }^{37,39}$. Metformin was introduced into clinical practice in Europe in 1957 and in the USA in 1995, and has become the most prescribed agent for T2DM worldwide ${ }^{37,39}$.

\section{Mechanism of action}

Metformin enters cells mainly via solute carrier family 22 member 1 (also known as organic cation transporter 1 (hOCT1)) and exerts multiple insulindependent and insulin-independent actions according to the level of drug exposure and the control of nutrient metabolism within different tissues ${ }^{28,37,40-42}$ (FIG. 2). During treatment, the gut is exposed to high concentrations of metformin ${ }^{42}$, which interrupt the mitochondrial respiratory chain at complex I, and increase glucose utilization, anaerobic glycolysis and lactate production; some of the lactate can be converted back to glucose in the liver ${ }^{43}$. Lactate-glucose turnover causes energy dissipation, which might contribute to the weight neutrality (lack of weight gain or weight loss) observed in metformin-treated patients ${ }^{28,42}$. In the liver, metformin increases insulin signalling, reduces glucagon action and reduces gluconeogenesis and glycogenolysis ${ }^{28}$. Metformin can inhibit the mitochondrial redox shuttle enzyme glycerol-3-phosphate dehydrogenase, altering the hepatocellular redox state and resulting in reductions in the ATP:AMP ratio, hepatic gluconeogenesis and the conversion of lactate and glycerol to glucose, and activation of AMP-activated protein kinase $(\mathrm{AMPK})^{44}$. In addition, metformin treatment results in a shift toward the utilization of glucose relative to fatty acids as a cellular source of energy in the liver ${ }^{37}$. In muscle, metformin promotes insulinmediated glucose uptake via solute carrier family 2 , facilitated glucose transporter member 4 (GLUT- 4$)^{28}$.

As delayed-release formulations of metformin have achieved similar efficacies at lower doses compared with 'regular' formulations, it seems that the gut is a major site of metformin action at therapeutic doses ${ }^{45}$. Metformin can increase circulating levels of glucagon-like peptide-1 (GLP-1) from pretreatment levels, even in the absence of an oral glucose load and in individuals with and without $\mathrm{T}_{2} \mathrm{DM}^{46-50}$, by mechanisms that could include inhibition of sodium-dependent bile-acid transporters, which increase the availability of ileal bile acids to activate G-protein coupled bile acid receptor 1 (commonly known as TGR5) on enteroendocrine L cells. Compared with placebo, metformin reduces the activity of dipeptidyl peptidase 4 (DPP-4) ${ }^{46}$. Relative to pretreatment levels, metformin increases GLP-1 secretion in response to an oral glucose load, via muscarinic (M3) and gastrin-releasing peptide receptor (GRP-R)-dependent pathways ${ }^{47-51}$. In mice, metformin stimulates expression of GLP-1 receptor (Glp-1r) on pancreatic $\beta$ cells, mediated by peroxisome proliferator-activated receptor 


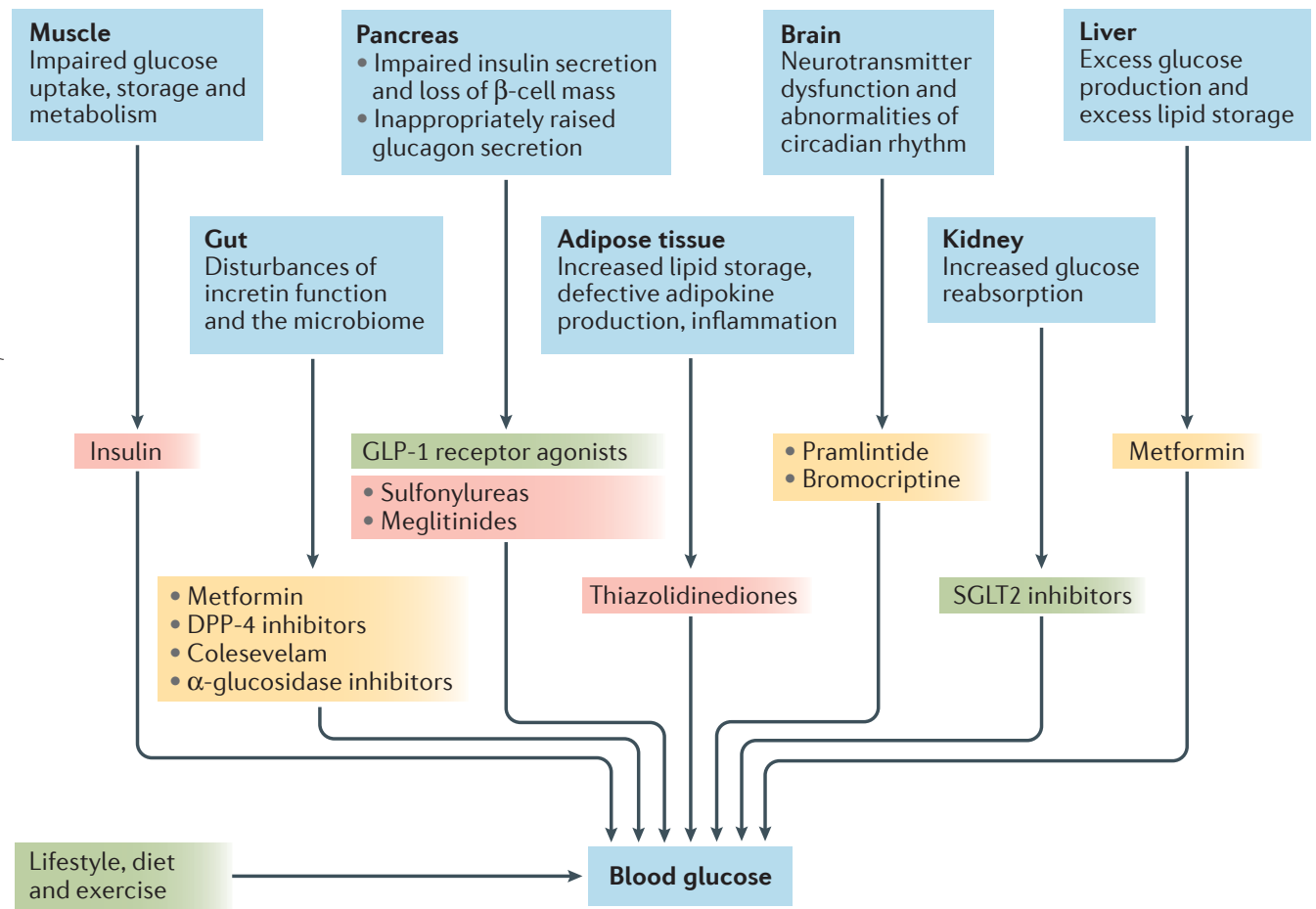

\begin{tabular}{|c|c|}
\hline $\begin{array}{c}\text { Tissue-specific effects in T2DM } \\
\text { Weight gain }\end{array}$ & Weight neutral \\
\hline
\end{tabular}

Figure 1 | Sites of action of glucose-lowering agents. Multiple genetic and environmental factors give rise to type 2 diabetes mellitus (T2DM) through insulin resistance with pancreatic $\beta$-cell failure. Overweight and obesity contribute to insulin resistance in association with increased inflammatory signals and disturbed lipid homeostasis, often preceding the onset of hyperglycaemia by many years and enhancing cardiovascular risk. When insulin secretion is no longer sufficient to overcome insulin resistance, glucose intolerance progresses to T2DM, usually accompanied by pancreatic $\alpha$-cell dysfunction that elevates glucagon secretion, reduced prandial secretion or activity of incretin hormones such as glucagon-like peptide 1 (GLP-1), alterations to the gut microbiome and disturbances of neural activities controlling hunger-satiety and the circadian regulation of glucose homeostasis. Insulin, sulfonylureas and meglitinides are associated with risk of hypoglycaemia. DPP-4, dipeptidyl peptidase 4; SGLT2, sodium/glucose cotransporter 2.

(PPAR) $a^{49}$. The effect of metformin on GLP-1 might contribute to its weight-neutral effect and to reduction in hepatic glucose output by inhibiting glucagon secretion $^{46-48}$. Metformin also affects the circadian control of glucose metabolism in liver and muscle ${ }^{42}$. Metformininduced AMPK activation results in phosphorylation of casein kinase I, which leads to degradation of the circadian clock component mPer2, thereby increasing expression of the CLOCK and BMAL1 circadian genes and causing phase advance in the circadian rhythm in treated rodents, compared with untreated controls ${ }^{52,53}$. The results of a study involving mice showed that metformin causes phase advance in the liver, but phase delay in muscle ${ }^{53}$, and the effects of metformin on circadian rhythm are blocked in mice with knock-out of Prkaa2, the gene encoding AMPK subunit $\alpha 2$ (REF. 52).

\section{Pharmacokinetics}

Metformin has an oral bioavailability of $40-60 \%$ and a plasma half-life of $4-9 \mathrm{~h}$, and is eliminated unchanged in the urine mostly via tubular secretion rather than glomerular filtration ${ }^{28,54}$.

\section{Pharmacodynamics}

Metformin is widely used as a first-line pharmacotherapy in patients with T2DM, because of its efficacy, long-term safety record, low risk of hypoglycaemia, weight neutrality and favourable effect on vascular disease ${ }^{36}$. Metformin treatment typically leads to a reduction in fasting plasma glucose (FPG) by $2-4 \mathrm{mmol} / \mathrm{l}$ and $\mathrm{HbA}_{1 \mathrm{c}}$ by $1-2 \%$, largely independent of age, weight and T2DM duration as long as some residual $\beta$-cell function remains ${ }^{28,39}$. In the 10 -year follow-up data from the UK Prospective Diabetes Study (UKPDS), patients who received metformin had significant risk reductions for any diabetes-related end point of $21 \%(P=0.01)$, diabetes-related death of $30 \%(P=0.01)$ and myocardial infarction of $33 \%(P=0.005)$ compared with overweight patients in the conventional therapy group $^{23,28,55}$. Metformin might also be associated with a reduction in the risk of cancer in patients with T2DM, particularly prostate, pancreas and breast cancer ${ }^{28,42}$.

The progressive nature of $\mathrm{T} 2 \mathrm{DM}$ can require the addition of other glucose-lowering treatments (including insulin) to metformin ${ }^{15,36,56}$. Many fixed-dose combinations of drugs that include metformin are, therefore, available. 
Table 1 | Summary of currently available glucose-lowering treatments in patients with type 2 diabetes mellitus ${ }^{28,36}$

\begin{tabular}{|c|c|c|c|c|c|c|c|c|}
\hline $\begin{array}{l}\text { Class and } \\
\text { examples }\end{array}$ & Dosing & $\begin{array}{l}\text { Mechanism of } \\
\text { action }\end{array}$ & $\begin{array}{l}\text { Physiological } \\
\text { effects }\end{array}$ & $\begin{array}{l}\text { Glucose- } \\
\text { lowering } \\
\text { efficacy }\end{array}$ & Advantages & Disadvantages & $\begin{array}{l}\text { Cardiovascular } \\
\text { safety }\end{array}$ & Cost"l \\
\hline \multicolumn{9}{|c|}{ Sulfonylureas (1956)* } \\
\hline $\begin{array}{l}\text { - Gliclazide }{ }^{\ddagger} \\
\text { - Glipizide } \\
\text { - Glimepiride } \\
\text { - Glyburide } \\
\text { (gliben- } \\
\text { clamide) }\end{array}$ & $\begin{array}{l}-\mathrm{OD} \\
\cdot \mathrm{BD}\end{array}$ & $\begin{array}{l}\text { Bind to SUR1 on } \\
\beta \text { cells, resulting } \\
\text { in closure of } \\
\mathrm{K}_{\text {ATP }} \text { channels, } \\
\text { depolarization } \\
\text { and calcium } \\
\text { influx }\end{array}$ & $\begin{array}{l}\text { Increase } \\
\text { insulin } \\
\text { secretion }\end{array}$ & High & $\begin{array}{l}\text { Good long-term } \\
\text { safety }\end{array}$ & $\begin{array}{l}\text { - Hypoglycaemia } \\
\text { - Weight gain } \\
\text { - Need for SMBG } \\
\text { - Need for dose } \\
\text { titration }\end{array}$ & $\begin{array}{l}\text { Conflicting } \\
\text { results from } \\
\text { database } \\
\text { studies, no } \\
\text { adverse } \\
\text { outcomes in } \\
\text { interventional } \\
\text { studies }\end{array}$ & Low \\
\hline \multicolumn{9}{|c|}{ Biguanides (1957)* } \\
\hline $\begin{array}{l}\text { Metformin } \\
\text { - Metformin } \\
\text { slow release }\end{array}$ & $\begin{array}{l}-\mathrm{OD} \\
\cdot \mathrm{BD}\end{array}$ & $\begin{array}{l}\text { - Activate } \\
\text { AMPK } \\
\text { - Improve } \\
\text { cellular insulin } \\
\text { signalling } \\
\text { - Reduce } \\
\text { respiratory } \\
\text { chain activity } \\
\text { - Alter gut } \\
\text { glucose- } \\
\text { lactate } \\
\text { metabolism }\end{array}$ & $\begin{array}{l}\text { - Reduce } \\
\text { hepatic } \\
\text { glucose } \\
\text { output } \\
\text { - Improve } \\
\text { insulin } \\
\text { sensitivity } \\
\text { - Increase } \\
\text { GLP-1 levels }\end{array}$ & High & $\begin{array}{l}\text { - Good } \\
\text { long-term } \\
\text { safety } \\
\text { - Weight neutral } \\
\text { - Low risk of } \\
\text { hypoglycaemia }\end{array}$ & $\begin{array}{l}\text { - Gastrointestinal } \\
\text { adverse effects } \\
\text { - Multiple possible } \\
\text { contraindications, } \\
\text { especially renal } \\
\text { impairment and } \\
\text { hypoxaemia }\end{array}$ & $\begin{array}{l}\text { Reduce } \\
\text { cardiovascular } \\
\text { disease }\end{array}$ & Low \\
\hline \multicolumn{9}{|c|}{ a-Glucosidase inhibitors (1995)* } \\
\hline $\begin{array}{l}\text { - Acarbose } \\
\text { - Miglitol } \\
\text { - Voglibose }\end{array}$ & $\begin{array}{l}\text { Up to } \\
\text { TDS } \\
\text { with } \\
\text { meals }\end{array}$ & $\begin{array}{l}\text { Inhibit } \\
\alpha \text {-glucosidase in } \\
\text { the gut }\end{array}$ & $\begin{array}{l}\text { Slow intestinal } \\
\text { carbohydrate } \\
\text { digestion } \\
\text { and delay } \\
\text { absorption }\end{array}$ & Modest & Weight neutral & $\begin{array}{l}\text { Gastrointestinal } \\
\text { adverse effects }\end{array}$ & $\begin{array}{l}\text { Unknown, } \\
\text { preliminary } \\
\text { evidence of } \\
\text { benefits }\end{array}$ & Moderate \\
\hline \multicolumn{9}{|c|}{ Meglitinides (1997)* } \\
\hline $\begin{array}{l}\text { - Nateglinide } \\
\text { - Repaglinide }\end{array}$ & $\begin{array}{l}\text { With } \\
\text { meals }\end{array}$ & $\begin{array}{l}\text { - Bind to SUR1 } \\
\text { on } \beta \text { cells } \\
\text { - Actions } \\
\text { more rapid } \\
\text { and shorter } \\
\text { duration than } \\
\text { sulfonylureas }\end{array}$ & $\begin{array}{l}\text { Increase } \\
\text { insulin } \\
\text { secretion }\end{array}$ & $\begin{array}{l}\text { Inter- } \\
\text { mediate } \\
\text { to high }\end{array}$ & $\begin{array}{l}\text { - Rapid onset, } \\
\text { short duration } \\
\text { - Suitable for } \\
\text { prandial use }\end{array}$ & $\begin{array}{l}\text { - Weight gain } \\
\text { - Hypoglycaemia } \\
\text { - Need for SMBG } \\
\text { (less than with } \\
\text { sulfonylureas) }\end{array}$ & $\begin{array}{l}\text { Cardiovascular } \\
\text { disease not } \\
\text { adversely } \\
\text { affected }\end{array}$ & Moderate \\
\hline \multicolumn{9}{|c|}{ Thiazolidinediones (1997)* } \\
\hline $\begin{array}{l}\text { - Pioglitazone } \\
\text { - Rosiglitazone }\end{array}$ & OD & PPAR- $\gamma$ agonists & $\begin{array}{l}\text { - Increase } \\
\text { insulin } \\
\text { sensitivity } \\
\text { - Reduce free } \\
\text { fatty acid } \\
\text { release }\end{array}$ & High & $\begin{array}{l}\text { - Low risk of } \\
\text { hypoglycaemia } \\
\text { - Might reduce } \\
\text { blood pressure } \\
\text { - Possible } \\
\text { effect on } \\
\text { nonalcoholic } \\
\text { steatohepatitis }\end{array}$ & $\begin{array}{l}\text { - Unresolved } \\
\text { long-term safety } \\
\text { - Fractures } \\
\text { - Weight gain } \\
\text { - Oedema and heart } \\
\text { failure }\end{array}$ & $\begin{array}{l}\text { - Oedema and } \\
\text { increased risk } \\
\text { of heart failure } \\
\text { - Debated } \\
\text { effect on } \\
\text { cardiovascular } \\
\text { disease } \\
\text { - Pioglitazone } \\
\text { reduced } \\
\text { composite } \\
\text { end point }\end{array}$ & Low \\
\hline \multicolumn{9}{|c|}{ DPP-4 inhibitors (2006)* } \\
\hline $\begin{array}{l}\text { - Sitagliptin } \\
\text { - Vildagliptin } \\
\text { - Saxagliptin } \\
\text { - Linagliptin } \\
\text { - Alogliptin }\end{array}$ & $\begin{array}{l}\cdot \mathrm{OD} \\
\cdot \mathrm{BD}\end{array}$ & $\begin{array}{l}\text { Inhibit DPP-4 } \\
\text { activity, increase } \\
\text { endogenous } \\
\text { incretin levels }\end{array}$ & $\begin{array}{l}\text { Glucose- } \\
\text { dependent } \\
\text { increase } \\
\text { in insulin } \\
\text { secretion and } \\
\text { inhibition } \\
\text { of glucagon } \\
\text { secretion }\end{array}$ & $\begin{array}{l}\text { Inter- } \\
\text { mediate }\end{array}$ & $\begin{array}{l}\text { - Weight neutral } \\
\text { - Low risk of } \\
\text { hypoglycaemia } \\
\text { (unless } \\
\text { combined with } \\
\text { sulfonylurea) } \\
\text { - Possible } \\
\text { benefit on } \\
\beta \text {-cell survival }\end{array}$ & $\begin{array}{l}\text { - Unknown } \\
\text { long-term safety } \\
\text { - Increased risk of } \\
\text { pancreatitis } \\
\text { - Possible increased } \\
\text { risk of liver } \\
\text { dysfunction with } \\
\text { vildagliptin }\end{array}$ & $\begin{array}{l}\text { No increase in } \\
\text { cardiovascular } \\
\text { disease risk } \\
\text { reported except } \\
\text { increased } \\
\text { hospitalization } \\
\text { with heart } \\
\text { failure with } \\
\text { saxagliptin }\end{array}$ & High \\
\hline
\end{tabular}


Table 1 (cont.) | Summary of currently available glucose-lowering treatments in patients with type 2 diabetes mellitus ${ }^{28,36}$

\begin{tabular}{|c|c|c|c|c|c|c|c|c|}
\hline $\begin{array}{l}\text { Class and } \\
\text { examples }\end{array}$ & Dosing & $\begin{array}{l}\text { Mechanism of } \\
\text { action }\end{array}$ & $\begin{array}{l}\text { Physiological } \\
\text { effects }\end{array}$ & $\begin{array}{l}\text { Glucose- } \\
\text { lowering } \\
\text { efficacy }\end{array}$ & Advantages & Disadvantages & $\begin{array}{l}\text { Cardiovascular } \\
\text { safety }\end{array}$ & Cost"l \\
\hline \multicolumn{9}{|c|}{ SGLT2 inhibitors (2012)* } \\
\hline $\begin{array}{l}\text { - Canagliflozin } \\
\text { - Dapagliflozin } \\
\text { - Empagliflozin }\end{array}$ & OD & $\begin{array}{l}\text { Inhibit SGLT2 } \\
\text { transporters in } \\
\text { proximal renal } \\
\text { tubules }\end{array}$ & $\begin{array}{l}\text { Increase } \\
\text { urinary } \\
\text { glucose } \\
\text { excretion }\end{array}$ & $\begin{array}{l}\text { Inter- } \\
\text { mediate to } \\
\text { high }\end{array}$ & $\begin{array}{l}\text { - Weight loss } \\
\text { - Blood pressure } \\
\text { reduction } \\
\text { - Low risk of } \\
\text { hypoglycaemia } \\
\text { (unless } \\
\text { combined } \\
\text { with insulin or } \\
\text { sulfonylurea) } \\
\text { - Possible } \\
\text { sustained } \\
\text { HbA }_{1 c} \\
\text { reduction }\end{array}$ & $\begin{array}{l}\text { - Unknown } \\
\text { long-term safety } \\
\text { - Association } \\
\text { with genital and } \\
\text { possibly urinary } \\
\text { tract infections } \\
\text { - Osmotic diuresis, } \\
\text { possible risk of } \\
\text { hypotension and } \\
\text { falls } \\
\text { - Possible increased } \\
\text { risk of fractures } \\
\text { - Small increased } \\
\text { risk of diabetic } \\
\text { ketoacidosis }\end{array}$ & $\begin{array}{l}\text { Empagliflozin } \\
\text { reduces } \\
\text { cardiovascular } \\
\text { disease }\end{array}$ & High \\
\hline
\end{tabular}

\section{Dopamine-2 agonist (2009)*}

\begin{tabular}{|c|c|c|c|c|c|c|c|}
\hline $\begin{array}{l}\text { Bromocriptine } \\
\text { quick release }\end{array}$ & OD & $\begin{array}{l}\text { Activates } \\
\text { hypothalamic } \\
\text { dopamine } \\
\text { receptors }\end{array}$ & $\begin{array}{l}\text { Suppression } \\
\text { of hepatic } \\
\text { glucose } \\
\text { output } \\
\text { - Increases } \\
\text { glucose } \\
\text { disposal }\end{array}$ & Modest & $\begin{array}{l}\text { - Weight neutral } \\
\text { - Low risk of } \\
\text { hypoglycaemia }\end{array}$ & $\begin{array}{l}\text { - Dizziness } \\
\text { - Nausea } \\
\text { - Fatigue }\end{array}$ & $\begin{array}{l}\text { Reduces } \\
\text { cardiovascular } \\
\text { disease risk }\end{array}$ \\
\hline
\end{tabular}

\begin{tabular}{|c|c|c|c|c|c|c|c|c|}
\hline \multicolumn{9}{|c|}{ Bile-acid sequestrant (2008)* } \\
\hline Colesevelam & $\begin{array}{l}\cdot \mathrm{OD} \\
\cdot \mathrm{BD}\end{array}$ & $\begin{array}{l}\text { - Increases } \\
\text { hepatic } \\
\text { bile-salt } \\
\text { production } \\
\text { - Increases } \\
\text { GLP-1 } \\
\text { secretion } \\
\text { - Activates liver } \\
\text { farnesoid } \\
\text { receptors }\end{array}$ & $\begin{array}{l}\text { Possibly } \\
\text { reduces } \\
\text { hepatic } \\
\text { glucose output } \\
\text { and increases } \\
\text { incretin } \\
\text { secretion }\end{array}$ & Modest & $\begin{array}{l}\text { - Low risk of } \\
\text { hypoglycaemia } \\
\text { - Weight neutral } \\
\text { - Reduces LDL } \\
\text { cholesterol, } \\
\text { increases HDL } \\
\text { cholesterol }\end{array}$ & $\begin{array}{l}\text { - Constipation } \\
\text { - Increases } \\
\text { triglycerides } \\
\text { - Could affect } \\
\text { absorption of some } \\
\text { drugs }\end{array}$ & $\begin{array}{l}\text { Reduces risk of } \\
\text { cardiovascular } \\
\text { disease } \\
\text { (licensed as cho- } \\
\text { lesterol-lower- } \\
\text { ing treatment) }\end{array}$ & High \\
\hline \multicolumn{9}{|l|}{ Insulin (1920s)* } \\
\hline $\begin{array}{l}\text { Rapid-acting } \\
\text { (aspart, lispro, } \\
\text { glulisine) } \\
\text { Short-acting } \\
\text { (humulin-S, } \\
\text { insuman rapid, } \\
\text { actrapid) } \\
\text { - Intermediate- } \\
\text { acting } \\
\text { (insulatard, } \\
\text { humulin-I, } \\
\text { insuman basal) } \\
\text { Long-acting } \\
\text { (glargine, } \\
\text { detemir, } \\
\text { degludec) } \\
\text { Biphasic } \\
\text { premixed }\end{array}$ & $\begin{array}{l}\text { OD to } \\
\text { QDS }\end{array}$ & $\begin{array}{l}\text { Directly activate } \\
\text { the insulin } \\
\text { receptor }\end{array}$ & $\begin{array}{l}\text { - Increase } \\
\text { glucose } \\
\text { disposal } \\
\text { - Reduce } \\
\text { hepatic } \\
\text { glucose } \\
\text { output } \\
\text { Decrease } \\
\text { lipolysis }\end{array}$ & High & $\begin{array}{l}\text { - Injectable } \\
\text { - Sustained } \\
\text { glycaemic } \\
\text { improvements } \\
\text { compared with } \\
\text { other agents }\end{array}$ & $\begin{array}{l}\text { - Weight gain } \\
\text { - Hypoglycaemia } \\
\text { - Need for SMBG } \\
\text { - Fluid retention }\end{array}$ & $\begin{array}{l}\text { Ongoing } \\
\text { debate, } \\
\text { increased risk } \\
\text { not shown in } \\
\text { RCTs }\end{array}$ & Variable \\
\hline
\end{tabular}


Table 1 (cont.) | Summary of currently available glucose-lowering treatments in patients with type 2 diabetes mellitus ${ }^{28,36}$

\begin{tabular}{|c|c|c|c|c|c|c|c|c|}
\hline $\begin{array}{l}\text { Class and } \\
\text { examples }\end{array}$ & Dosing & $\begin{array}{l}\text { Mechanism of } \\
\text { action }\end{array}$ & $\begin{array}{l}\text { Physiological } \\
\text { effects }\end{array}$ & $\begin{array}{l}\text { Glucose- } \\
\text { lowering } \\
\text { efficacy }\end{array}$ & Advantages & Disadvantages & $\begin{array}{l}\text { Cardiovascular } \\
\text { safety }\end{array}$ & Cost ${ }^{\|}$ \\
\hline \multicolumn{9}{|c|}{ GLP-1RAs (2005)* } \\
\hline $\begin{array}{l}\text { - Exenatide } \\
\text { - Liraglutide } \\
\text { - Lixisenatide } \\
\text { - Albiglutide } \\
\text { - Dulaglutide }\end{array}$ & $\begin{array}{l}\text { - OD } \\
\text { - BD } \\
\text { - } \mathrm{QW}\end{array}$ & $\begin{array}{l}\text { Activate the } \\
\text { GLP-1 receptor }\end{array}$ & $\begin{array}{l}\text { - Glucose- } \\
\text { dependent } \\
\text { increase } \\
\text { in insulin } \\
\text { secretion } \\
\text { and } \\
\text { inhibition } \\
\text { of glucagon } \\
\text { secretion } \\
\text { - Reduce } \\
\text { postprandial } \\
\text { glucose } \\
\text { excretion } \\
\text { - Increase } \\
\text { satiety }\end{array}$ & High & $\begin{array}{l}\text { - Weight loss } \\
\text { - Low risk of } \\
\text { hypoglycaemia } \\
\text { (unless } \\
\text { combined with } \\
\text { sulfonylurea) } \\
\text { - Possible effect } \\
\text { on } \beta \text {-cell } \\
\text { survival } \\
\text { - Possible } \\
\text { sustained } \\
\text { HbA } \\
\text { reduction }\end{array}$ & $\begin{array}{l}\text { - Injectable } \\
\text { - Gastrointestinal } \\
\text { adverse effects } \\
\text { - Unknown } \\
\text { long-term safety } \\
\text { - Unconfirmed } \\
\text { increased risk of } \\
\text { pancreatitis }\end{array}$ & $\begin{array}{l}\text { Possible } \\
\text { beneficial } \\
\text { effect in non- } \\
\text { randomized } \\
\text { studies } \\
\text { - Lixisenatide } \\
\text { did not alter } \\
\text { cardiovascular } \\
\text { disease risk in } \\
\text { RCT }\end{array}$ & High \\
\hline \multicolumn{9}{|c|}{ Amylin analogue (2005)* } \\
\hline Pramlintide ${ }^{\ddagger}$ & TDS & $\begin{array}{l}\text { Synthetic } \\
\text { soluble } \\
\text { analogue of } \\
\text { human amylin }\end{array}$ & $\begin{array}{l}\text { - Reduces } \\
\text { glucagon } \\
\text { secretion } \\
\text { - Increases } \\
\text { satiety } \\
\text { - Slows gastric } \\
\text { emptying }\end{array}$ & Modest & $\begin{array}{l}\text { Weight loss } \\
\text { Reduced } \\
\text { insulin dose }\end{array}$ & $\begin{array}{l}\text { - Injectable } \\
\text { - Unknown } \\
\text { long-term safety } \\
\text { - Increased risk of } \\
\text { hypoglycaemia } \\
\text { - Only used with } \\
\text { mealtime insulin }\end{array}$ & Unknown & High \\
\hline
\end{tabular}

\section{Safety and adverse effects}

The main adverse effects of metformin treatment are abdominal discomfort and other gastrointestinal effects, including diarrhoea ${ }^{37}$. Symptoms can diminish if the dose is reduced, but around $10 \%$ of patients cannot tolerate the drug at any dose ${ }^{37}$, possibly because of variants of hOCT1 that lead to an increased concentration of metformin in the intestine $\mathrm{e}^{57}$. The risk of metformin intolerance (defined as patients who stop metformin within the first 6 months of treatment) is increased by concomitant use of drugs that inhibit hOCT1 activity (including tricyclic antidepressants, citalopram, proton-pump inhibitors, verapamil, diltiazem, doxazosin, spironolactone, clopidogrel, rosiglitazone, quinine, tramadol and codeine; OR $1.63,95 \%$ CI $1.22-2.17, P=0.001)$ or the presence of two alleles of SLC22A1 associated with reduced function of hOCT1 rather than one allele or no deficient allele (OR 2.41, 95\% CI 1.48-3.93, $P<0.001)^{57}$.

Metformin is contraindicated in patients with advanced chronic kidney disease (CKD), notable liver disease or conditions that might predispose to hypoxia or reduced tissue perfusion. However, observational and database studies indicate that advantage can be taken of the broad therapeutic index with metformin ${ }^{38,58,59}$, and careful attention to dose has enabled its use even in patients with cardiovascular disease (including mild-to-moderate heart failure ${ }^{38,60}$ and chronic obstructive pulmonary disease ${ }^{61}$ ). Adjusting the dose and monitoring renal function to ensure adequate elimination are important considerations, and metformin therapy should be stopped if hypoxaemia occurs ${ }^{62,63}$.
Results of the UKPDS showed that, compared with sulfonylureas and insulin in patients with obesity and newly diagnosed T2DM, metformin use was associated with significantly reduced rates of myocardial infarction, stroke and all-cause mortality (by 39\%, $41 \%$ and $36 \%$, respectively ${ }^{64,65}$. The 10 -year follow-up of the UKPDS showed that the reductions in myocardial infarction and mortality persist ${ }^{23}$. Database analyses have consistently provided corroborating evidence for this effect ${ }^{65}$. Increasing levels of use of statins and renal-protective medications make it difficult to assess the effect of metformin on cardiovascular disease ${ }^{65}$, although several RCTs are ongoing to assess this effect ${ }^{65}$.

\section{Sulfonylureas}

Sulfonylureas were developed as variants of sulfonamides after the latter were reported to cause hypoglycaemia ${ }^{37,66}$. Sulfonylureas are classified as first-generation (such as tolbutamide and chlorpropamide) and second-generation (such as glibenclamide (glyburide), gliclazide, glipizide and glimepiride) $)^{37}$; the second-generation drugs have greater potency, enabling treatment with lower doses.

\section{Mechanism of action}

Sulfonylureas act directly on pancreatic $\beta$ cells by binding to the cytosolic face of ATP-binding cassette sub-family C member 8 (also known as sulfonylurea receptor 1 (SUR1)), which is part of the $\mathrm{K}_{\mathrm{ir}} 6.2$ ATP-sensitive potassium channel ${ }^{37,67}$. Binding closes the $\mathrm{K}_{\mathrm{ir}} 6.2$ channel, preventing potassium efflux and depolarizing the plasma membrane. 


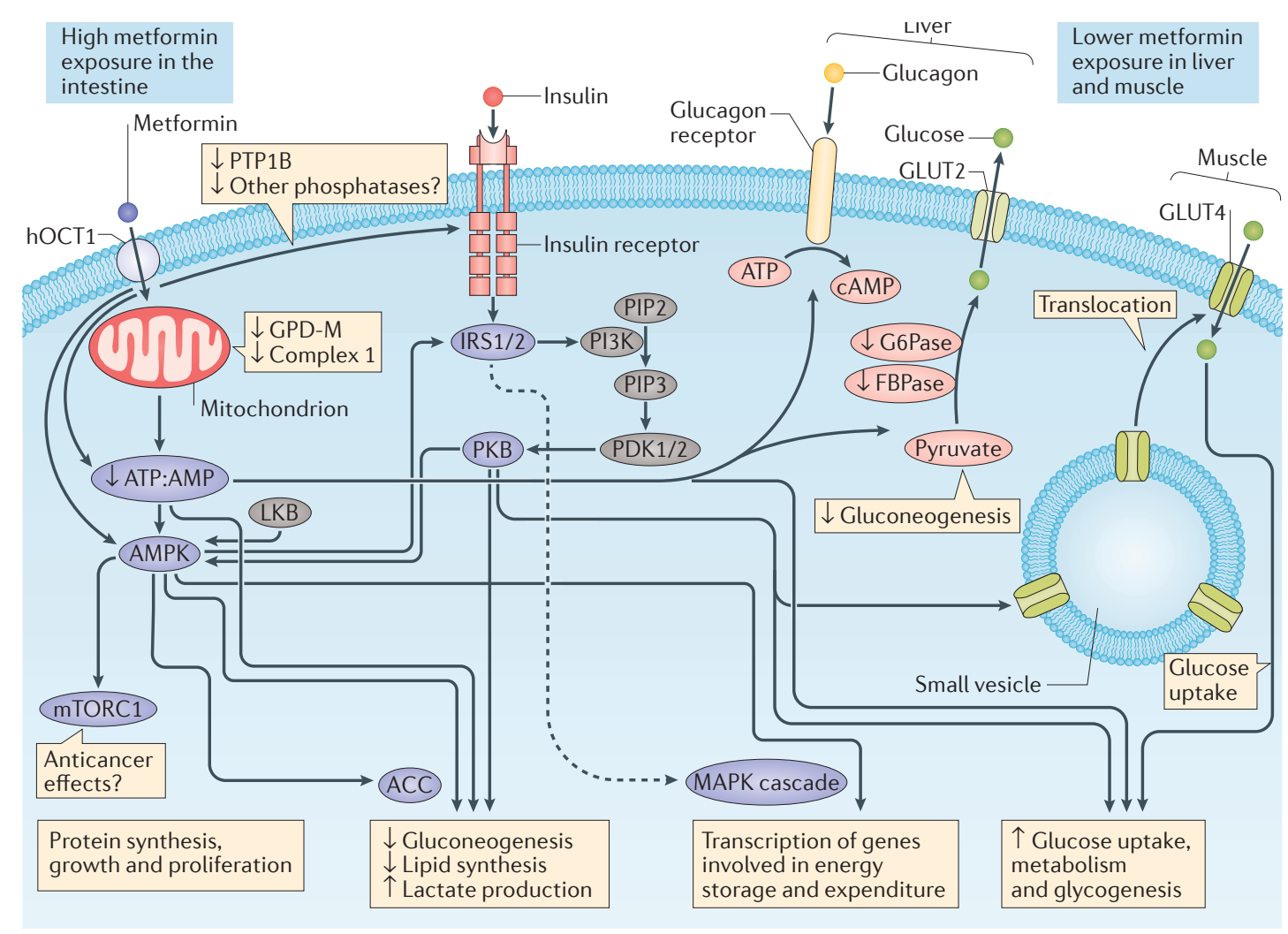

Figure 2 | Intracellular actions of metformin. Metformin alters nutrient metabolism through insulin-dependent and insulin-independent effects that vary with the amount of drug exposure and the activity of insulin within different tissues. The intestine is exposed to high levels of metformin, which have insulin-independent effects, whereas liver and muscle are exposed to lower concentrations of metformin that influence the metabolic effects of insulin. Metformin can improve insulin sensitivity via effects on insulin-receptor signalling and post-receptor signalling pathways of insulin action. Metformin can alter cellular nutrient metabolism and energy production independently of insulin via suppression of the mitochondrial respiratory chain and activation of 5' AMP-activated protein kinase (AMPK). ACC, acetyl-CoA carboxylase; FBPase, fructose-1,6-bisphosphatase; G6Pase, glucose-6-phosphatase; GLUT, glucose transporter isoform; hOCT1, organic cation transporter 1; IRS, insulin receptor substrate; LKB1, serine/threonine-protein kinase STK11; MAPK, mitogen-activated protein kinase; mTOR, mammalian target of rapamycin; PDK, 3-phosphoinositide-dependent protein kinase; PI3K, phosphatidylinositol 3-kinase; PIP2, phosphatidylinositol-3,4-bisphosphate; PIP3, phosphatidylinositol3,4,5-trisphosphate; PKB, protein kinase B; GPD-M, glycerol-3-phosphate dehydrogenase, mitochondrial.

This opens local voltage-dependent calcium channels, increasing the influx of calcium and activating calcium-dependent signalling proteins, leading to insulin exocytosis (FIG. 3). In vitro studies show that persistent exposure to sulfonylureas for several days can desensitize $\beta$ cells and reduce the insulin-secretory response. However, studies in patients with T2DM have shown that a $25 \%$ increase in $24-\mathrm{h}$ insulin secretion with the sulfonylurea glibenclamide is maintained for 6-10 weeks, although efficacy usually declines after 6-12 months of sulfonylurea therapy during clinical trials ${ }^{68}$.

\section{Pharmacokinetics}

Sulfonylureas vary considerably in their pharmacokinetic properties ${ }^{37,68-70}$ (see Supplementary information S1 (table)). They have high bioavailability and reach peak plasma concentrations within $1.5-4.0 \mathrm{~h}^{68}$. They are metabolized in the liver to varying extents to form a number of active and inactive metabolites that are eliminated along with unchanged drug via the bile and urine; caution is needed when treating patients with hepatic and/or renal impairment ${ }^{37}$. Half-lives are $<10 \mathrm{~h}$ for some sulfonylureas, but extend to $>24 \mathrm{~h}$ for others. Therapeutic effects are exerted for much longer than is indicated by the half-life if active metabolites are formed (as they are with glimepiride, glibenclamide and chlorpropamide $)^{68}$. In general, first-generation sulfonylureas should be avoided in patients with CKD stages 3 or 4 or those who are undergoing dialysis, in whom gliclazide and glipizide are suitable without extensive dose adjustment ${ }^{71-73}$. Glimepiride is an option for patients with CKD but not receiving dialysis, on the proviso of low-dose initiation and careful titration ${ }^{71,73}$.

More than $90 \%$ of sulfonylureas in the circulation are bound to plasma proteins, which can lead to interactions with other protein-bound drugs such as salicylates, sulfonamides and warfarin ${ }^{37,68}$. Some medications potentiate the glucose-lowering effects of sulfonylureas by inhibition of their hepatic metabolism (for example, some antifungals and monoamine oxidase inhibitors), displacing them from binding to plasma proteins (for example, coumarins, NSAIDs and sulfonamides), 
inhibiting their excretion (for example, probenecid) or antagonizing their mechanism of action (for example, diazoxide and other $\mathrm{K}_{\text {ATP }}$-channel openers) $)^{37}$. Drugs such as rifampicin that induce sulfonylurea metabolism inhibit glucose-lowering by sulfonylureas ${ }^{37}$.

Altered sulfonylurea formulations can enable rapid onset of action (as is the case with micronized glibenclamide) or prolonged activity (for example, 'Glipizide Extended Release' and 'Gliclazide Modified Release') while maintaining glucose-lowering efficacy ${ }^{37,74-76}$.

\section{Pharmacodynamics}

As monotherapy, sulfonylureas can lead to reductions in FPG by $2-4 \mathrm{mmol} / \mathrm{l}$ and $\mathrm{HbA}_{1 \mathrm{c}}$ by $1-2 \%{ }^{28,37,68,70}$. However, the failure rates of sulfonylureas as monotherapy are greater than those of metformin or rosiglitazone ${ }^{15}$. Sulfonylureas can be used as first-line treatment options in patients who are intolerant of metformin, and can be used in combination with most other glucose-lowering medications, except meglitinides, which have a similar mechanism of action ${ }^{28,37}$. The size and durability of the response to sulfonylureas is positively associated with the reserve of $\beta$-cell function ${ }^{37}$.

\section{Safety and adverse effects}

Hypoglycaemia and weight gain are the main adverse effects associated with sulfonylureas. Weight gain of $1-4 \mathrm{~kg}$ that stabilizes after about 6 months is common following drug initiation ${ }^{28}$. Weight gain is probably related to the anabolic effect of the increased insulin levels and reduction of glycosuria ${ }^{27,28,56}$.

Hypoglycaemia has been reported in $20-40 \%$ of patients receiving sulfonylureas, and severe hypoglycaemia (requiring third-party assistance) occurs in 1-7\% of patients ${ }^{28,37,77}$, depending on the population, the definition of hypoglycaemia and the type and pharmacokinetics of the sulfonylurea ${ }^{74}$. In a study involving six UK secondary care centres, self-reported hypoglycaemia prevalence was 39\% (95\% CI 30-49\%), similar to that in patients with T2DM treated with insulin for $<2$ years ${ }^{77}$. The prevalence of self-reported severe hypoglycaemia was $7 \%(95 \% \text { CI 3-13\%) })^{77}$. Continuous glucose monitoring (CGM) showed that $22 \%$ (95\% CI 15-31\%) of patients had at least one episode of interstitial glucose $<2.2 \mathrm{mmol} / \mathrm{l}$, similar to patients with T2DM treated with insulin for $<2$ years ${ }^{77}$. These results confirmed that the use of long-acting sulfonylureas with active metabolites is especially associated with hypoglycaemia ${ }^{28,37}$, and that the elderly, those living alone and those with renal or liver impairment, as well as car drivers, require extreme caution during treatment with sulfonylureas, as do those prescribing these drugs ${ }^{28,37}$. Education and glucose self-monitoring are essential in patients receiving sulfonylureas; the results of an $\mathrm{RCT}^{78}$ involving patients receiving Gliclazide Modified Release showed that self-monitoring of blood glucose reduced both the risk of symptomatic hypoglycaemia and the reduction in $\mathrm{HbA}_{1 \mathrm{c}}$, compared with no monitoring.

The cardiovascular safety of sulfonylureas is controversial. In the 1970s, the University Group Diabetes Program raised concerns regarding increased cardiovascular disease risk with tolbutamide ${ }^{/ 9}$, and since then many database studies, mostly retrospective, have suggested that sulfonylureas (particularly glibenclamide) are associated with less benefit than metformin against cardiovascular disease in patients with T2DM ${ }^{65}$. However, the results of RCTs such as UKPDS, ADVANCE and ACCORD did not show an increase in cardiovascular mortality or morbidity in sulfonylurea-treated patients ${ }^{65}$. The ongoing CAROLINA study ${ }^{80}$ comparing linaglitpin with glimepiride in patients with T2DM might help to define the cardiovascular safety of these drugs.

\section{Meglitinides}

The two main meglitinides (or glinides) are nateglinide and repaglinide. The class takes its name from the meglitinide moiety of glibenclamide, which exerts an insulin-releasing effect independently of the sulfonyl moiety ${ }^{26,28,81}$.

\section{Mechanism of action}

Meglitinides bind to the benzamido site of SUR1 on $\beta$ cells. This site is separate from the sulfonyl-binding site, but meglitinide binding has a similar effect to sulfonylurea binding on the $\mathrm{K}_{\mathrm{ir}} 6.2$ channels $^{37}$ (FIG. 3). However, the relatively rapid onset and short duration of action of meglitinides suits their use as prandial glucose-lowering agents $^{37}$.

\section{Pharmacokinetics}

Repaglinide is almost completely absorbed, with peak plasma concentrations after about $1 \mathrm{~h}$. Repaglinide binds to proteins in the circulation, and is rapidly metabolized in the liver (mostly by cytochrome P450 3A4 (CYP3A4)), producing inactive metabolites that are mostly excreted in the bile. A plasma half-life of around $1 \mathrm{~h}^{37,82,83}$ makes it suitable for patients with poor renal function. Taken approximately $15 \mathrm{~min}$ before a meal, repaglinide produces a prompt insulin response that lasts $4-6 h^{37}$. Bioavailability is unaffected by the ingestion of food. Repaglinide concentrations are positively affected by co-treatment with drugs that inhibit CYP3A4 (such as ketoconazole, antibacterial agents, steroids and cyclosporine), and negatively affected by drugs that induce CYP3A4 (such as rifampicin, carbamazepine and barbiturates) $)^{83,84}$.

Nateglinide has a slightly faster onset and shorter duration of action $(3-5 \mathrm{~h})$ than repaglinide, but is also protein-bound in the circulation and metabolized in the liver by CYP3A4, producing metabolites that are mostly excreted in the urine ${ }^{37,83}$.

\section{Pharmacodynamics}

Repaglinide (0.5-4.0 mg) or nateglinide $(60-180 \mathrm{mg}$ ) taken before meals produces dose-dependent increases in insulin concentrations and reduces postprandial and fasting hyperglycaemia ${ }^{37}$. Meglitinides are well-suited to patients with irregular meal patterns, or to elderly patients at high risk of hypoglycaemia ${ }^{37}$.

Meglitinides are usually used in combination with metformin, a thiazolidinedione or insulin, although they can be used as monotherapy. The results of RCTs have 


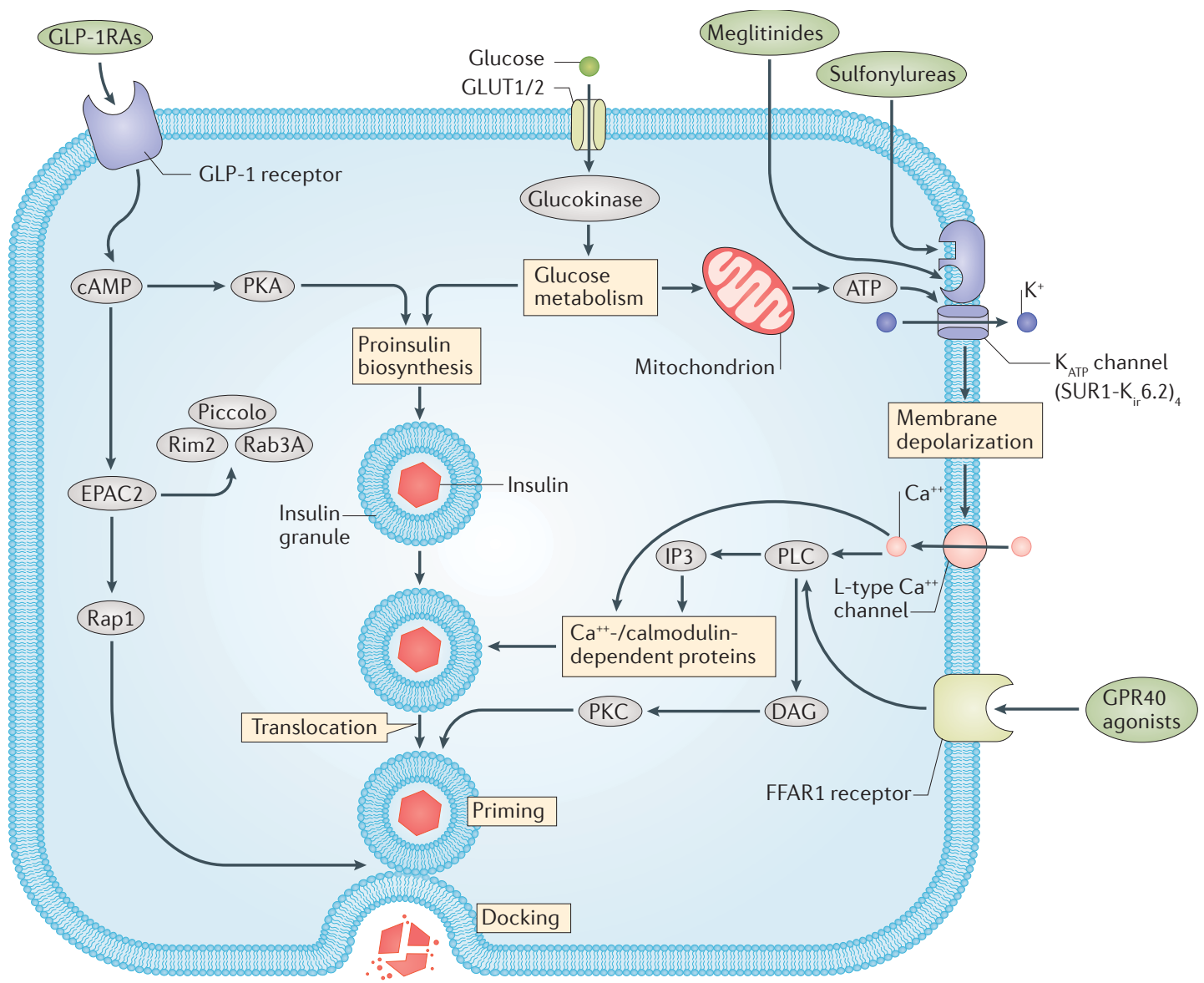

Figure 3 | Sulfonylureas, meglitinides and glucagon-like peptide 1 receptor agonists (GLP-1RAs) act on pancreatic $\beta$ cells to increase nutrient-induced insulin secretion. These agents bind to the cytosolic surface of the sulfonylurea receptor 1 (SUR1), which is part of the ATP-sensitive $\mathrm{K}_{\mathrm{ir}} 6.2$ potassium channel. Binding of the sulfonylurea or meglitinide closes the $\mathrm{K}_{\mathrm{ir}} 6.2$ channel, preventing potassium efflux and thereby depolarizing the plasma membrane. Depolarization opens local voltage-dependent calcium channels, increasing the influx of calcium and activating calcium-dependent signalling proteins that control insulin exocytosis. GLP-1RAs enhance nutrient-induced insulin release mainly via a cAMP-EPAC2-mediated potentiation of granule exocytosis. DAG, diacylglycerol; EPAC2, rap guanine nucleotide exchange factor 4; GLUT, glucose transporter isoform; IP3, inositol-1,4,5-trisphosphate; Rap1, Ras-related protein 1; PKA, protein kinase A; PKC, protein kinase C; PLC, phospholipase C.

shown that $\mathrm{HbA}_{1 \mathrm{c}}$ reductions are similar to, or slightly less than, those observed with sulfonylurea treatment when meglitinides are used as monotherapy or as an add-on to metformin ${ }^{37,83}$. Repaglinide can be used effectively in conjunction with basal and biphasic insulins ${ }^{85,86}$. In an $\mathrm{RCT}^{86}$ with treatment for 12 months, nonobese patients with long-term T2DM $(n=102)$ were randomly assigned to receive either repaglinide or metformin, both in combination with biphasic insulin aspart 30/70 (30\% soluble insulin aspart and 70\% intermediate-acting insulin aspart), which was titrated to achieve an $\mathrm{HbA}_{1 \mathrm{c}}$ level of $<6.5 \%$. At the end of treatment, $\mathrm{HbA}_{1 \mathrm{c}}$ reductions were similar in both treatment groups (baseline versus studyend $\mathrm{HbA}_{1 \mathrm{c}} 8.15 \pm 1.32$ versus $6.72 \pm 0.66 \%$ with metformin and $8.07 \pm 1.49 \%$ versus $6.90 \pm 0.68 \%$ with repaglinide, $P=0.2$ for between-groups difference ${ }^{86}$.

In a head-to-head $\mathrm{RCT}^{87}$ in which 150 drug-naive patients were randomly assigned to receive either repaglinide $(0.5 \mathrm{mg}$ per meal, maximum dose $4 \mathrm{mg}$ per meal) or nateglinide (60 mg per meal, maximum dose $120 \mathrm{mg}$ per meal) for 16 weeks, $\mathrm{HbA}_{1 \mathrm{c}}$ reductions from an average of $8.9 \%$ at baseline were greater with repaglinide than nateglinide $(-1.57 \%$ versus $-1.04 \%$, $P=0.002)$. Reductions in FPG were also greater with repaglinide than nateglinide $(-57 \mathrm{mg} / \mathrm{dl}$ versus $-18 \mathrm{mg} / \mathrm{dl}, P<0.001)^{87}$.

\section{Safety and adverse effects}

Results of studies with repaglinide and nateglinide have shown variable rates of hypoglycaemia, and generally less weight gain than with sulfonylureas ${ }^{83,88-92}$. In a head-to-head $\mathrm{RCT}^{87}$, hypoglycaemia (blood glucose $<50 \mathrm{mg} / \mathrm{dl}$ ) was more commonly associated with treatment with repaglinide than with nateglinide ( $7 \%$ versus $0 \%)$. Weight gain was also slightly greater in the repaglinide group ( $1.8 \mathrm{~kg}$ versus $0.7 \mathrm{~kg})^{87}$. As co-treatments with biphasic insulin, repaglinide and metformin resulted in similar rates of hypoglycaemia, but weight gain was less with metformin (difference in mean body weight $=-2.51 \mathrm{~kg}, 95 \% \mathrm{CI}-4.07 \mathrm{~kg}$ to $-0.95 \mathrm{~kg})^{86}$. 
Meglitinides can bind to the sulfonylurea receptor 2 splice variants SUR2A and SUR2B, which are expressed by cardiovascular tissues ${ }^{83,93}$. In the large NAVIGATOR $\mathrm{RCT}^{94}$, nateglinide did not alter cardiovascular outcomes in people with impaired glucose tolerance who either had, or were at high risk of, cardiovascular disease. No association has been demonstrated between repaglinide and either cardiovascular disease or cardiovascular risk ${ }^{65,83,95}$.

\section{a-Glucosidase inhibitors (AGls)}

Acarbose was the first AGI to be introduced, in the early 1990s; subsequently, miglitol and voglibose were introduced in some countries. AGIs are widely used in Asian populations that have diets in which complex carbohydrates predominate $^{37}$.

\section{Mechanism of action}

AGIs competitively inhibit $\alpha$-glucosidase enzymes in the brush border of enterocytes lining the intestinal villi, preventing the enzymes from cleaving disaccharides and oligosaccharides into monosaccharides ${ }^{37,96}$. This action delays carbohydrate digestion and defers absorption distally along the intestinal tract, reducing blood-glucose excursions and lowering prandial insulin levels ${ }^{37}$. Compared with controls, AGI treatment can also increase postprandial GLP-1 secretion and reduce secretion of glucose-dependent insulinotropic polypeptide (GIP) ${ }^{97,98}$. The affinities of AGIs vary for different a-glucosidase enzymes, resulting in specific activity profiles (for example, acarbose has greater affinity for glycoamylase than for other glucosidases, whereas miglitol is a stronger inhibitor of sucrase) $)^{37}$.

\section{Pharmacokinetics}

Acarbose is degraded by amylases and bacteria in the small intestine; $<2 \%$ of the unchanged drug is absorbed (along with some of the intestinal degradation products). Absorbed material is mostly eliminated in the urine within $24 \mathrm{~h}^{37}$. Miglitol is almost completely absorbed, and is eliminated unchanged in the urine ${ }^{37}$.

\section{Pharmacodynamics}

Typical $\mathrm{HbA}_{1 \mathrm{c}}$ reductions with AGI treatment are $\sim 0.5 \%$, mostly through reductions in postprandial glycaemia; reductions depend upon the amount of complex carbohydrate in the $\operatorname{diet}^{28}$. In a noninferiority RCT ${ }^{99}$ of Chinese patients $(n=784)$ with newly diagnosed T2DM and mean $\mathrm{HbA}_{1 \mathrm{c}}$ of $7.5 \%$, acarbose resulted in $\mathrm{HbA}_{1 \mathrm{c}}$ reductions similar to those with metformin $(-1.1 \%$, within groups difference $0.01 \%, 95 \%$ CI $-0.12 \%$ to $0.14 \%$ ). However, the sulfonylurea tolbutamide resulted in greater $\mathrm{HbA}_{1 c}$ reductions compared with acarbose $(-1.8 \%$ versus $-1.1 \%$; mean difference $0.6 \%, 95 \%$ CI $0.2-1.0 \%)$ in newly diagnosed drug-naive patients with T2DM $(n=96$, mean baseline $\left.\mathrm{HbA}_{1 \mathrm{c}} \sim 8 \%\right)^{100}$. Tolbutamide had a greater effect on FPG than acarbose, whereas their effects on postprandial glucose were similar ${ }^{100}$.

\section{Safety and adverse effects}

Gastrointestinal adverse effects of AGIs (flatulence, abdominal discomfort and diarrhoea) are commonly encountered and can lead to treatment withdrawal. Hypoglycaemia is uncommon. AGIs do not cause weight gain, and they have no clinically significant drug interactions.

The results of the STOP-NIDDM RCT showed that acarbose reduces the risk of developing T2DM, delays the onset of hypertension and reduces macrovascular events by $49 \%$ compared with placebo, but the total number of events was too small $(n=47)$ to draw firm conclusions ${ }^{65,101,102}$. A large $\mathrm{RCT}^{103}$ assessing the impact of acarbose on cardiovascular outcomes is ongoing.

\section{Thiazolidinediones}

Drugs derived from thiazolidinedione include pioglitazone, rosiglitazone and troglitazone. Troglitazone was introduced in 1997 and withdrawn soon after because of hepatotoxicity ${ }^{28}$. Rosiglitazone and pioglitazone were introduced in 1999. Rosiglitazone was discontinued in Europe and its use was restricted in the USA in 2008 after reports of an association with cardiovascular risk; the FDA lifted the restrictions in 2013. Pioglitazone was discontinued in 2011 in some European countries pending enquires into a possible risk of bladder cancer.

\section{Mode of action}

Thiazolidinediones are agonists of the peroxisome proliferator-activated receptor gamma (PPAR- $\gamma$ ), a nuclear receptor that is highly expressed in adipose tissue, and to a lesser extent in muscle, liver, $\beta$ cells, vascular endothelium and macrophages ${ }^{37,104}$. PPAR- $\gamma$ activation alters gene expression, promoting adipogenesis, insulin sensitivity and tissue glucose uptake, reducing inflammation and altering energy balance ${ }^{104,105}$ in a tissuespecific manner. PPAR- $\gamma$ activation reduces hepatic gluconeogenesis, modifies the blood lipid profile and possibly improves $\beta$-cell viability ${ }^{104,105}$. Differentiation of pre-adipocytes into new small insulin-sensitive adipocytes by PPAR- $\gamma$ activation reduces circulating levels of free fatty acids, which reduces ectopic lipid accumulation in skeletal muscle and liver and rebalances the Randle (glucose-fatty acid) cycle in favour of glucose utilization by restricting availability of free fatty acids as an energy source for hepatic gluconeogenesis ${ }^{28}$.

\section{Pharmacokinetics}

Thiazolidinediones reach peak plasma levels within $1-2 \mathrm{~h}^{37}$. In the circulation, thiazolidinediones are almost entirely bound to plasma proteins, but their concentrations are not sufficient to interfere with other proteinbound drugs ${ }^{37}$. Pioglitazone is metabolized by cytochrome P450 2C8 (CYP2C8) and CYP3A4 to weakly active metabolites that are eliminated via bile, whereas rosiglitazone is metabolized by CYP2C9 and CYP2C8 to inactive metabolites that are excreted via urine $\mathrm{e}^{37,106}$. Rifampicin induces expression of CYP3A4, resulting in a reduction in levels of rosiglitazone and pioglitazone, whereas the lipid-lowering fibrate gemfibrozil inhibits CYP2C8, leading to accumulation of rosiglitazone and pioglitazone $e^{106}$. 


\section{Pharmacodynamics}

Maximal doses of thiazolidinediones can reduce $\mathrm{HbA}_{1 \mathrm{c}}$ by $0.7-1.6 \%$ when used as monotherapy or in combination with metformin, sulfonylureas or insulin ${ }^{104,107}$. In an $\mathrm{RCT}^{108}$, patients with T2DM receiving metformin $(n=630$, mean age $\sim 56$ years, mean diabetes duration $\sim 5.5$ years, baseline mean $\mathrm{HbA}_{1 \mathrm{c}} 8.5-8.7 \%$ ) were randomly assigned to either pioglitazone or gliclazide as an add-on treatment. After 2 years, the changes in $\mathrm{HbA}_{1 \mathrm{c}}$ were similar in the two arms $(-0.89 \%$ with pioglitazone and $-0.77 \%$ with gliclazide, $P=0.2$ for between-groups difference), whereas pioglitazone resulted in greater reductions in FPG $(-1.8 \mathrm{mmol} / \mathrm{l} \text { versus }-1.1 \mathrm{mmol} / \mathrm{l}, P<0.001)^{108}$. In another $\mathrm{RCT}^{108}$, patients with T2DM receiving a sulfonylurea ( $n=639$, mean age $\sim 60$ years, mean T2DM duration $\sim 7$ years, baseline mean $\mathrm{HbA}_{1 \mathrm{c}} 8.8 \%$ ) were randomly assigned to either pioglitazone or metformin as an add-on treatment. After 2 years, the changes in $\mathrm{HbA}_{1 \mathrm{c}}$ were similar in the two arms $(-1.03 \%$ with pioglitazone versus $-1.16 \%$ with gliclazide, $P=0.17$ for between-groups difference); reductions in FPG (around $\sim 2 \mathrm{mmol} / \mathrm{l}$ ) were also similar in the two arms ${ }^{108}$. Onset of the glucose-lowering effect of thiazolidinediones is gradual, taking 2-3 months to reach maximum effect ${ }^{37}$. The ADOPT trial ${ }^{15}$, in which 4,360 patients with T2DM (mean age $56-58$ years, baseline $\mathrm{HbA}_{1 c} 7.4 \%$, mostly $<2$ years $\mathrm{T} 2 \mathrm{DM}$ duration) were randomly assigned to glyburide, metformin or rosiglitazone, showed that rosiglitazone as monotherapy has a more prolonged effect on glycaemic control (measured by $\mathrm{HbA}_{1 \mathrm{c}}$ and $\mathrm{FPG}$ ) than metformin or glyburide over 5 years. The glucose-lowering efficacy of thiazolidinediones is generally gradual in onset over several weeks, varies considerably between individuals, and no definite predictors are known to identify responders versus nonresponders ${ }^{29}$.

\section{Safety and adverse effects}

Thiazolidinediones do not affect the risk of hypoglycaemia when used as monotherapy or in combination with metformin. Oedema (often identified by rapid weight gain) has been reported in $4-6 \%$ of patients receiving thiazolidinediones ${ }^{104}$; the observed fluid retention is the result of renal sodium reabsorption mediated by increased expression of sodium channel proteins in collecting duct epithelium $^{28}$. Thiazolidinediones are associated with weight gain of $2-3 \mathrm{~kg}$ for each $1 \%$ drop in $\mathrm{HbA}_{1 \mathrm{c}}$, whether used as monotherapy or in combination with metformin or insulin ${ }^{104}$. The weight gain is usually in subcutaneous adipose tissue, whereas visceral fat is either reduced or unaltered ${ }^{104,109}$. In the ADOPT trial ${ }^{15}$, the weight gain with rosiglitazone over 5 years was greater than with glibenclamide (glyburide; treatment difference $2.5 \mathrm{~kg}$, 95\% CI $2.0-3.1 \mathrm{~kg}, P<0.001$ ), whereas no difference was observed in waist circumference (treatment difference $0.77 \mathrm{~cm}$, $95 \% \mathrm{CI}-0.21 \mathrm{~cm}$ to $1.76 \mathrm{~cm}, P=0.12$ ).

The results of RCTs and observational studies show that, compared with control groups, long-term treatment with thiazolidinediones lowers bone density and doubles the risk of fractures in patients with T2DM, particularly in women ${ }^{110}$. In the ACCORD trial ${ }^{111}$, women who received a thiazolidinedione had double the risk of nonspinal fracture compared with those not using a thiazolidinedione; this risk was reduced after discontinuation of the thiazolidinedione. A meta-analysis of RCTs showed that, compared with metformin, sulfonylureas or placebo, thiazolidinediones reduce bone mineral density at the lumbar spine (difference $-1.1 \%, 95 \% \mathrm{CI}-1.6 \%$ to $-0.7 \%, P<0.0001)$, total hip $(-1.0 \%, 95 \% \mathrm{CI}-1.4 \%$ to $-0.6 \%, P<0.0001)$, forearm $(-0.9 \%, 95 \% \mathrm{CI}-1.6 \%$ to $-0.3 \%, P=0.007)$ and femoral neck $(-0.7 \%, 95 \% \mathrm{CI}$ $-1.4 \%$ to $0.0 \%, P=0.06)$, effects that were not reversed after 1 year of stopping treatment in some studies ${ }^{112}$.

The cardiovascular safety of thiazolidinediones was questioned in a controversial meta-analysis that showed increased adverse cardiovascular outcomes in patients treated with rosiglitazone compared with controls without rosiglitazone, prompting withdrawal of rosiglitazone in Europe and restricted use in the USA ${ }^{65,113}$. However, when the FDA re-examined the data from the RECORD study, no significant effect on cardiovascular risk was found ${ }^{65,114}$.

Pioglitazone is a ligand for PPAR- $\alpha$ (as well as PPAR- $\gamma$ ), and through PPAR- $\alpha$ it mitigates cardiovascular risk by positive effects on plasma levels of HDL cholesterol, reductions in plasma triglycerides and small dense LDL cholesterol particles, with the production of larger, more buoyant particles $^{115}$. Thiazolidinediones can also have beneficial effects on blood pressure and endothelial function ${ }^{65}$, but compared with pioglitazone, rosiglitazone increases levels of plasma LDL cholesterol and triglycerides ${ }^{65}$.

In the PROACTIVE trial ${ }^{32}$, compared with placebo, pioglitazone was associated with a numerical but nonsignificant reduction in the composite outcome of all-cause mortality, nonfatal myocardial infarction, stroke, acute coronary syndrome, endovascular or surgical intervention in the coronary or leg arteries and amputation above the ankle (HR 0.90, 95\% CI 0.80-1.02, $P=0.095$ ). However, pioglitazone significantly lowered the occurrence of the secondary end point, a composite of all-cause mortality, nonfatal myocardial infarction and stroke (HR 0.84, $95 \%$ CI $0.72-0.98, P=0.027)^{32}$. In addition, pioglitazone reduced the risks of subsequent myocardial infarction and recurrent stroke by $16 \%$ and $47 \%$, respectively ${ }^{65,116,117}$. Nonetheless, the risk of heart failure was higher in the pioglitazone group than the placebo group in the PROACTIVE trial, although this risk was not associated with increased mortality ${ }^{65}$.

However, both rosiglitazone and pioglitazone can cause congestive heart failure in patients who already have diastolic dysfunction, because of the propensity for oedema ${ }^{65}$. The effects of rosiglitazone on coronary artery disease are not clear, but pioglitazone might be beneficial ${ }^{65,118-122}$.

\section{DPP-4 inhibitors}

The currently available DPP-4 inhibitors (sitagliptin, vildagliptin, saxagliptin, linagliptin and alogliptin $)^{123}$ are licensed as monotherapy, dual therapy, triple therapy and in combination with insulin, but there are some minor variations in licensing between agents. In addition, once-weekly DPP-4 inhibitors (omarigliptin and trelagliptin) are licensed in Japan ${ }^{124,125}$. 


\section{Mechanism of action}

The action of DPP-4 inhibitors causes elevation of circulating levels of incretin hormones, notably GLP-1 and GIP. The incretin effect is the ability of intestinal factors to enhance nutrient-induced insulin responses during feeding by $50-70 \%$ in healthy individuals ${ }^{126,127}$; this effect is much diminished in T2DM. GIP is secreted by $\mathrm{K}$ cells in the duodenum and jejunum in response to ingestion of carbohydrates and lipids ${ }^{128-130}$. In addition to its incretin effect, GIP reduces gastric acid secretion and has roles in adipogenesis and possibly $\beta$-cell proliferation ${ }^{128,130-133}$. GLP-1 is secreted by L cells mainly in the distal ileum and colon ${ }^{128,130}$, and accounts for most of the incretin effect ${ }^{128,134}$, including insulin biosynthesis ${ }^{135,136}$. Additionally, GLP-1 causes a reduction in glucagon secretion, and has extrapancreatic actions that enhance satiety and delay gastric emptying (see Supplementary information S2 (box) $)^{127,134,137-139}$.

GIP and GLP-1 are rapidly degraded by DPP-4 (REF. 128), which acts on peptides to cleave N-terminal dipeptides with alanine (as in the incretins) or proline at position N2 (REF. 130). DPP-4 exists free in the circulation and also attached to endothelial cells ${ }^{130,140}$, and is widely expressed in human tissues, including the intestine and portal system ${ }^{130}$. GLP-1 and GIP are generally inactivated almost immediately following secretion, and have half-lives of $<2 \mathrm{~min}$ and 5-7 min, respectively ${ }^{128,130,141,142}$. Compared with placebo treatment, DPP-4 inhibition results in a 2-3-fold increase in postprandial active GLP-1 levels ${ }^{143,144}$. Unlike GLP-1 receptor agonists (GLP-1RAs), which can have an effect equivalent to a $>10$-fold increase in GLP-1, DPP-4 inhibitors do not delay gastric emptying or increase satiety and weight loss, but they do avoid initial nausea and vomiting ${ }^{145,146}$.

\section{Pharmacokinetics}

Currently available DPP-4 inhibitors can produce 77-99\% inhibition of DPP-4 activity and are appropriate for once-daily dosing, except for vildagliptin (twicedaily), and omarigliptin and trelagliptin (once-weekly). They are predominantly excreted in the urine, except for linagliptin, which does not require dose adjustment in patients with CKD (see Supplementary information S3 (table) $)^{123,147-151}$.

DPP-4 inhibitors have little or no interaction with other glucose-lowering agents or drugs commonly used in patients with T2DM ${ }^{123,152}$, possibly because DPP-4 inhibitors are neither inducers nor inhibitors of cytochrome P450 isoforms, and are not appreciably bound to plasma proteins ${ }^{152}$. However, saxagliptin is metabolized to an active metabolite by CYP3A4 and CYP3A5 (REFS 123,152).

\section{Pharmacodynamics}

On average, DPP- 4 inhibitors reduce postprandial glucose excursions by $\sim 3 \mathrm{mmol} / 1$, and FPG by $\sim 1.0-1.5 \mathrm{mmol} / \mathrm{1}^{28,123}$. A meta-analysis ${ }^{153}$ that assessed the efficacy of DPP-4 inhibitors as monotherapy or as add-on therapy to other oral agents included placebo-controlled or activecontrolled RCTs of DPP- 4 inhibitors ( $n=98$ trials, 24,163 patients) of 12-54 weeks duration, with $\geq 30$ patients in each treatment arm. The mean ages of the participants in all but two of these studies were $50-62$ years; 88 of the 98 trials included were double-blinded and 10 were openlabel design ${ }^{153}$. The results showed that DPP-4 inhibitors reduce $\mathrm{HbA}_{1 \mathrm{c}}$ by $-0.77 \%$ ( $95 \% \mathrm{CI}-0.82 \%$ to $-0.72 \%$ ) from an average baseline of $8.05 \%{ }^{153}$. In 18 RCTs with a duration of 52-54 weeks, DPP-4 inhibitors resulted in $\mathrm{HbA}_{1 \mathrm{c}}$ reductions of $-0.84 \%$ ( $95 \% \mathrm{CI}-0.99 \%$ to $-0.68 \%$, $P<0.0001$ ), whereas in 26 RCTs of $12-18$ weeks duration, the $\mathrm{HbA}_{1 \mathrm{c}}$ reduction was $-0.68 \%$ (95\% CI $-0.75 \%$ to $-0.61 \%, P<0.0001)^{153}$. The $\mathrm{HbA}_{1 \mathrm{c}}$ reductions were largely similar across the class, but results from direct head-to-head trials are limited. In this meta-analysis, the $\mathrm{HbA}_{1 \mathrm{c}}$ reductions according to DPP-4 inhibitor were: vildagliptin $50 \mathrm{mg}\left(n=26\right.$, age 56.3 years, baseline $\mathrm{HbA}_{1 \mathrm{c}}$ $8.06 \%)-0.88 \%$ ( $95 \% \mathrm{CI}-1.00 \%$ to $-0.75 \%, P<0.0001)$; sitagliptin $100 \mathrm{mg}\left(n=37\right.$, age 55.2 years, baseline $\mathrm{HbA}_{1 \mathrm{c}}$ $8.05 \%)-0.79 \%$ ( $95 \% \mathrm{CI}-0.87 \%$ to $-0.71 \%, P<0.0001)$; saxagliptin $5 \mathrm{mg}\left(n=13\right.$, age 55.4 years, baseline $\mathrm{HbA}_{1 \mathrm{c}}$ $8.01 \%)-0.70 \%$ (95\% CI $-0.79 \%$ to $-0.62 \%, P<0.0001$ ); linagliptin $5 \mathrm{mg}\left(n=13\right.$, age 59.0 years, baseline $\mathrm{HbA}_{1 \mathrm{c}}$ $8.05 \%)-0.55 \%$ ( $95 \% \mathrm{CI}-0.65 \%$ to $-0.45 \%, P<0.0001$ ); alogliptin $25 \mathrm{mg}\left(n=11\right.$, age 55.2 years, baseline $\mathrm{HbA}_{1 \mathrm{c}}$ $8.14 \%)-0.76 \%$ ( $95 \%$ CI $-0.86 \%$ to $-0.66 \%, P<0.0001)^{153}$. Reductions in $\mathrm{HbA}_{1 \mathrm{c}}$ were greater in patients with baseline $\mathrm{HbA}_{1 \mathrm{c}}>9.0 \%$, compared with $\mathrm{HbA}_{1 \mathrm{c}} \leq 9.0 \%{ }^{153}$. For RCTs with basal $\mathrm{HbA}_{1 \mathrm{c}}<7.5 \%(n=8$, age 57.4 years, baseline $\left.\mathrm{HbA}_{1 \mathrm{c}} 7.32 \%\right)$ the $\mathrm{HbA}_{1 \mathrm{c}}$ reduction was $-0.63 \%$ (95\% CI $-0.78 \%$ to $-0.48 \%, P<0.0001$ ); for basal $\mathrm{HbA}_{1 \mathrm{c}} 7.5-8.0 \%(n=28$, age 57.6 years, baseline $\left.\mathrm{HbA}_{1 \mathrm{c}} 7.82 \%\right)$ the reduction was $-0.70 \%$ (95\% CI -0.76 to $-0.63, P<0.0001)$; for basal $\mathrm{HbA}_{1 \mathrm{c}} 8.0-8.5 \%(n=34$, age 55.9 years, baseline $\left.\mathrm{HbA}_{1 \mathrm{c}} 8.15 \%\right)$ the reduction was $-0.72 \%$ ( $95 \% \mathrm{CI}-0.79 \%$ to $-0.64 \%, P<0.0001)$; for basal $\mathrm{HbA}_{1 \mathrm{c}}>9.0 \%$ ( $n=30$, age 54.2 years, baseline $\mathrm{HbA}_{1 \mathrm{c}}$ $8.63 \%)$ the reduction was $-0.93 \%$ (95\% CI $-1.02 \%$ to $-0.84 \%, P<0.0001)^{153}$.

A meta-analysis of 27 reports of 19 studies, including 7,136 patients, showed that DPP-4 inhibitor monotherapy was associated with a smaller decline in $\mathrm{HbA}_{1 \mathrm{c}}$ than metformin monotherapy (weighted mean difference (WMD) $0.20 \%, 95 \%$ CI $\left.0.08-0.32 \%, P_{\text {overall effect }}=0.001\right)$. DPP-4 inhibitors combined with metformin produced smaller declines than GLP-1RAs combined with metformin (WMD $0.49 \%, 95 \%$ CI $0.31-0.67 \%, P_{\text {overall effect }}<0.001$ ) and sulfonylureas combined with metformin (WMD 0.07\%, $95 \%$ CI $\left.0.03-0.11 \%, P_{\text {overall effect }}<0.001\right)$, but similar declines to pioglitazone combined with metformin (WMD 0.09\%, $95 \%$ CI $-0.07 \%$ to $\left.0.24 \%, P_{\text {overall effect }}=0.28\right)^{154}$. In the studies comparing monotherapies, trial durations were 24-206 weeks, and participants had mean T2DM duration of 1.0-4.4 years and mean $\mathrm{HbA}_{1 \mathrm{c}}$ of $7.2-9.6 \%$. In the trials of combination therapies, mean T2DM duration was 5.0-7.3 years and mean $\mathrm{HbA}_{1 \mathrm{c}}$ was $7.3-8.5 \%{ }^{154}$.

The comparison of the efficacy of DPP-4 inhibitors with sulfonylureas is complicated by multiple factors including study duration, renal function and the choice of sulfonylurea for the active comparator ${ }^{155}$. In a meta-analysis ${ }^{155}$ of 12 RCTs of $\geq 18$ weeks duration that compared sulfonylureas head-to-head with DPP-4 inhibitors, the mean changes from baseline in $\mathrm{HbA}_{1 \mathrm{c}}$ were modestly but significantly smaller with DPP-4 inhibitors 
than with sulfonylureas (difference of mean changes in $\mathrm{HbA}_{1 \mathrm{c}}$ 0.105, 95\% CI 0.103-0.107, $P<0.0001$ ). However, several RCTs of $1-3$ years duration showed similar $\mathrm{HbA}_{1 \mathrm{c}}$ reductions for DPP-4 inhibitors and sulfonylureas ${ }^{150,155-164}$.

The glucose-lowering efficacy of DPP-4 inhibitors is greater in Asian patients with T2DM than in other ethnic groups (between-group $\mathrm{HbA}_{1 \mathrm{c}}$ difference $-0.26 \%$, 95\% CI $-0.36 \%$ to $-0.17 \%, P<0.001)$, and might be affected by genetic factors such as a TCF7L2 gene variant ${ }^{165,166}$. A meta-analysis of RCTs of $\geq 76$ weeks duration suggested that the effect of DPP-4 inhibitors is not durable and lessens during the second year of treatment ${ }^{167}$.

\section{Head-to-head comparisons of DPP-4 inhibitors}

The number of head-to-head trials comparing DPP-4 inhibitors is limited. The results of an RCT ${ }^{168}$ comparing saxagliptin and sitagliptin as add-on treatment to metformin in 810 patients (age 58.4 years, diabetes duration 6.3 years, baseline $\mathrm{HbA}_{1 \mathrm{c}}$ 7.7\%) showed that $\mathrm{HbA}_{1 \mathrm{c}}$ reductions over 18 weeks are similar with both treatments (adjusted mean changes in $\mathrm{HbA}_{1 \mathrm{c}}-0.52$ and $-0.62 \%$, respectively; between-group difference $0.09 \%$, $95 \%$ CI $-0.01 \%$ to $0.20 \%$ ). However, sitagliptin resulted in a slightly greater reduction in FPG $(-0.60 \mathrm{mmol} / \mathrm{l}$ for saxagliptin versus $-0.90 \mathrm{mmol} / \mathrm{l}$ for sitagliptin; treatment difference $0.30 \mathrm{mmol} / 1,95 \%$ CI $0.08-0.53 \mathrm{mmol} / \mathrm{l})^{168}$.

In another $\mathrm{RCT}^{169}, 148$ patients with T2DM and estimated glomerular filtration rate (eGFR) $<30 \mathrm{ml} /$ $\mathrm{min} / 1.73 \mathrm{~m}^{2}$, who were either drug-naive or treated with any glucose-lowering agents were randomly allocated to vildagliptin $50 \mathrm{mg}$ or sitagliptin $25 \mathrm{mg}$ once daily. The treatments resulted in similar reductions in $\mathrm{HbA}_{1 \mathrm{c}}$ over 24 weeks (adjusted mean change in $\mathrm{HbA}_{1 \mathrm{c}}-0.54 \%$ from a baseline of $7.52 \%$ with vildagliptin versus $-0.56 \%$ from a baseline of $7.80 \%$ with sitagliptin, $P=0.874$ ). Vildagliptin lowered FPG by $0.47 \pm 0.37 \mathrm{mmol} / \mathrm{l}$, whereas FPG increased in the sitagliptin group by $0.16 \pm 0.43 \mathrm{mmol} / \mathrm{l}$, but the difference between groups was not significant $(P=0.185)^{169}$.

In a phase III, noninferiority $\mathrm{RCT}^{170}, 243$ patients with T2DM that was inadequately controlled by diet and exercise were randomly assigned to receive trelagliptin (100 mg once weekly), alogliptin (25 mg daily) or placebo for 24 weeks. Trelagliptin was noninferior to alogliptin and resulted in similar reductions in $\mathrm{HbA}_{1 \mathrm{c}}$ ( $-0.33 \%$ versus $-0.45 \%$, respectively; least-squares mean difference (LSMD) $0.11 \%, 95 \%$ CI $-0.054 \%$ to $0.281 \%$ ). Both trelagliptin and alogliptin significantly reduced mean $\mathrm{HbA}_{1 \mathrm{c}}$ compared with placebo $(P<0.0001)^{170}$.

In another $\mathrm{RCT}^{171}, 412$ patients with $\mathrm{T} 2 \mathrm{DM}$, who were drug-naive or on oral glucose-lowering treatments, were randomly assigned to receive omarigliptin $25 \mathrm{mg}$ weekly, sitagliptin $50 \mathrm{mg}$ daily or placebo, for 24 weeks. At baseline, patients had mean $\mathrm{HbA}_{1 \mathrm{c}}$ of $7.9 \%, 8.0 \%$ and $8.1 \%$, respectively, in the omarigliptin, sitagliptin and placebo groups ${ }^{171}$. Omarigliptin treatment resulted in $\mathrm{HbA}_{1 \mathrm{c}}$ reduction of $-0.66 \%$ ( $95 \% \mathrm{CI}-0.76 \%$ to $-0.57 \%$ ), which was significantly greater than with placebo $(P<0.001)$ and similar to sitagliptin (LSMD $-0.02 \%$, $95 \% \mathrm{CI}-0.15 \%$ to $0.12 \%)$, meeting the prespecified noninferiority criterion ${ }^{171}$.

\section{Safety and adverse effects}

DPP-4 inhibitors are generally well tolerated, and the incidence of adverse effects is similar to placebo and lower than other glucose-lowering agents ${ }^{154,172}$. The incidence of gastrointestinal symptoms is lower with DPP-4 inhibitors than with metformin or a GLP-1RA ${ }^{154}$. The risk of hypoglycaemia in patients treated with a DPP-4 inhibitor is very low except when combined with sulfonylureas or insulin ${ }^{123,154,172}$.

DPP-4 has many substrates other than incretins, including bradykinin, encephalins, neuropeptide Y, peptide YY1-36, gastrin-releasing polypeptide, substance $\mathrm{P}$, insulin-like growth factor 1 , vasostatin 1 , the a chains of thyrotropin, luteinizing hormone, chorionic gonadotropin and several chemokines, such as $\mathrm{C}$-C motif chemokine 2 (monocyte chemotactic protein 1$)^{173}$; however, no adverse effects relating to these substrates have been observed in clinical trial ${ }^{28,123,148}$. In addition, DPP-4 is the T-cell activation antigen CD26, but no untoward immune-related effects have been demonstrated, either in Dpp4 knockout mice or with the use of DPP-4 inhibitors in animals or humans ${ }^{28}$.

Several meta-analyses and pooled analyses have shown that DPP-4 inhibitors (individually and as a class) are associated with reductions in cardiovascular events ${ }^{65,174}$. However, these studies were retrospective and not specifically designed to examine the effect of DPP-4 inhibitors on the incidence of cardiovascular disease ${ }^{65}$. The results of three RCTs (SAVOR-TIMI ${ }^{175,176}$, EXAMINE ${ }^{177}$ and TECOS ${ }^{178}$ ) demonstrated that saxagliptin, alogliptin and sitagliptin are not associated with the risk of adverse cardiovascular outcomes ${ }^{65,175-178}$. The populations of patients in these trials were each slightly different. SAVOR-TIMI ${ }^{175,176}$ included patients with T2DM with either a history of, or a risk of, cardiovascular events. EXAMINE ${ }^{177}$ included patients with T2DM and an acute myocardial infarction or hospitalization for unstable angina in the preceding 15-90 days. TECOS ${ }^{178}$ included patients with T2DM who were $>50$ years old and had established cardiovascular disease.

These studies were designed to look specifically at the effects of DPP- 4 inhibitors on cardiovascular safety so that patients in the placebo arms received other glucose-lowering therapies to minimize any differences in $\mathrm{HbA}_{1 \mathrm{c}}$ between arms. In the SAVOR-TIMI study ${ }^{175,176}$, saxagliptin treatment was associated with a $3.5 \%$ incidence of hospitalization for heart failure, compared with $2.8 \%$ in the placebo arm $(P=0.007)$, with no increase in mortality, and this difference was independent of baseline renal function, although compared with placebo, saxagliptin reduced the development and progression of microalbuminuria ${ }^{65,175,176}$. No effect on heart failure was observed in the EXAMINE ${ }^{177}$ or TECOS ${ }^{178}$ trials, and the mechanism underlying the effect that was seen with saxagliptin is unclear. An ongoing study (CAROLINA ${ }^{80}$ ) has been designed to examine the effect of linagliptin on cardiovascular outcomes with an active comparator (glimepiride) rather than placebo.

The individual results of the SAVOR-TIMI, EXAMINE and TECOS trials did not show any increased risk of pancreatitis or pancreatic cancer ${ }^{175-179}$, but a meta-analysis of 
these RCTs did demonstrate a significantly increased risk of acute pancreatitis in patients using DPP-4 inhibitors compared with those receiving standard care (OR 1.82, 95\% CI 1.17-2.82, $P=0.008)^{180}$.

\section{GLP-1RAs}

Exenatide (twice daily) was the first GLP-1RA, and was introduced in 2005. Two once daily GLP-1RAs (liraglutide and lixisenatide) and three once weekly GLP-1RAs (exenatide, albiglutide and dulaglutide) are also now available for combination therapy with oral glucose-lowering agents and basal insulin (except exenatide once weekly, which is not licensed to be used with basal insulin). Dulaglutide and albiglutide are also licensed as monotherapy in patients who are intolerant to metformin.

Exenatide (synthetic exendin-4), a peptide originally isolated from saliva of the lizard Heloderma suspectum (Gila monster) ${ }^{128,181}$, has 53\% homology with human GLP-1 and contains an Ala8Gly substitution that confers resistance to degradation by DPP-4 (REFS 128,182). Exenatide once weekly sustained-release formulation consists of exenatide embedded within biodegradable polymeric microspheres of poly(DL-lactic-co-glycolic acid $)^{183}$. Liraglutide is a true analogue of GLP-1 with the addition of a 16-carbon fatty acid chain attaching Lys 26 to albumin, to mask the DPP-4 cleavage site ${ }^{184}$. Albiglutide has two copies of GLP-1 in series, each with an Ala8Gly substitution, and this molecule is fused to albumin ${ }^{185}$. Lixisenatide is an exendin- 4 analogue with six Lys residues added at the $\mathrm{C}$ terminus to confer resistance to DPP-4 (REF. 186). Dulaglutide has two copies of a GLP-1 analogue (with amino acid substitutions Ala8Gly, Gly22Glu and Arg36Gly) covalently linked to an Fc fragment of human IgG4 (REF. 187).

\section{Mechanism of action}

GLP-1RAs mimic GLP-1 and activate the GLP-1 receptor, potentiating nutrient-induced insulin secretion (FIG. 3), contributing to reductions in fasting glycaemia and postprandial glycaemia, and to weight loss ${ }^{188}$ (see Supplementary information S2,S4,S5 (box, table, table)). Therapeutic concentrations of GLP-1RAs are far higher than physiological levels of GLP-1, and although GLP-1 deficiency has been described in patients with T2DM, this deficiency is not a universal characteristic of the disease $\mathrm{e}^{188}$.

\section{Pharmacokinetics}

GLP-1RAs are delivered by subcutaneous injection. Exenatide is rapidly absorbed ${ }^{189} . \mathrm{T}_{\max }$ is $\sim 2 \mathrm{~h}$, half-life is $3-4 \mathrm{~h}^{189}$ and elimination is mostly renal by glomerular filtration and proteolytic degradation ${ }^{190-192}$ (see Supplementary information S6 (table)). Relative to patients with normal renal function, exenatide clearance is decreased by $36 \%$ in patients with moderate renal disease (in whom it should be used with caution) and by $84 \%$ in those with severe renal disease (in whom it should not be used $)^{193}$. The once weekly exenatide reaches therapeutic levels within 2 weeks and maximum concentrations by 6 weeks ${ }^{194}$. The half-life of liraglutide is $10-15 \mathrm{~h}$, with a $\mathrm{T}_{\max }$ of 9-12 $\mathrm{h}^{195-197}$. Lixisenatide has a half-life of $2-4 \mathrm{~h}$ and a $\mathrm{T}_{\max }$ of $1-2 \mathrm{~h}^{198}$, and exerts its main effect on the meal immediately after injection. Albiglutide has a $\mathrm{T}_{\max }$ of 3-5 days and a half-life of 6-7 days ${ }^{199}$. Dulaglutide has a $\mathrm{T}_{\max }$ of $12-72 \mathrm{~h}$, a half-life of $\sim 4$ days and reaches steady-state levels by 2 weeks ${ }^{200}$ (see Supplementary information S6 (table)). GLP-1RAs are not recommended in severe renal disease; they have limited drug interactions, but can affect the availability of other medicines, such as acetaminophen (paracetamol) and statins because of the delay in gastric emptying (except for exenatide once weekly, which has a minor effect on gastric emptying) ${ }^{27,201}$.

\section{Pharmacodynamics}

The efficacy of GLP-1RAs has been explored in large programmes of placebo-controlled and active-comparator RCTs ${ }^{202-238}$ (see Supplementary information S4,S5 (tables)).

Effect on glycaemic measures. Exenatide (twice daily) significantly reduces measures of glycaemic control when used as monotherapy or add-on therapy (see Supplementary information S4 (table) $)^{239-243}$. A meta-analysis ${ }^{244}$ of RCTs in which exenatide was an add-on to existing metformin therapy for 16-30 weeks showed that exenatide lowers $\mathrm{HbA}_{1 \mathrm{c}}$ by $0.8 \%$ from an average baseline of $8.1 \pm 0.6 \%$. The effect of exenatide on $\mathrm{HbA}_{1 \mathrm{c}}$ reduction was greater in patients with baseline $\mathrm{HbA}_{1 \mathrm{c}}>9 \%$ than in those with $\mathrm{HbA}_{1 \mathrm{c}} \leq 9 \%{ }^{239}$, and was maintained at 3 years ${ }^{240}$ and only deteriorated modestly through 6 years ${ }^{245,246}$.

Liraglutide improves glycaemic control when used as monotherapy or add-on therapy ${ }^{239,241,247,248}$ (see Supplementary information S4 (table)). Compared with glimepiride $8 \mathrm{mg}$ daily, liraglutide $1.2-1.8 \mathrm{mg}$ daily monotherapy resulted in greater reductions in $\mathrm{HbA}_{1 \mathrm{c}}$ from an average baseline of $8.3 \%$ (glimepiride $-0.6 \%$, liraglutide $1.2 \mathrm{mg}-0.9 \%$ and liraglutide $1.8 \mathrm{mg}-1.1 \%$; treatment difference for liraglutide $1.2 \mathrm{mg}-0.31 \%, 95 \% \mathrm{CI}-0.54 \%$ to $-0.08 \%, P=0.008$; treatment difference for liraglutide $1.8 \mathrm{mg}-0.60 \%, 95 \% \mathrm{CI}-0.83 \%$ to $-0.38 \%, P<0.0001)$. A similar effect was seen for reductions in FPG (treatment difference for liraglutide $1.2 \mathrm{mg}-0.63 \mathrm{mmol} / \mathrm{l}$, $95 \% \mathrm{CI}-1.17 \mathrm{mmol} / 1$ to $-0.09 \mathrm{mmol} / \mathrm{l}, P=0.02$; treatment difference for liraglutide $1.8 \mathrm{mg}-0.99 \mathrm{mmol} / \mathrm{l}$, $95 \% \mathrm{CI}-1.53 \mathrm{mmol} / \mathrm{l}$ to $-0.45 \mathrm{mmol} / \mathrm{l}, P<0.001)$ and also postprandial glucose over 104 weeks $^{247}$. In pooled patient data from seven phase III RCTs from the liraglutide development programme, with 26 weeks of liraglutide $1.8 \mathrm{mg}, \mathrm{HbA}_{1 \mathrm{c}}$ reductions were less in patients with baseline $\mathrm{HbA}_{1 \mathrm{c}} \leq 7.5 \%$ than in those with $\mathrm{HbA}_{1 \mathrm{c}}>9.0 \%(-0.7 \% \text { versus }-1.8 \%)^{249}$.

Lixisenatide significantly decreases $\mathrm{HbA}_{1 \mathrm{c}}$ and postprandial glucose when used as monotherapy or add-on therapy ${ }^{210-215,250-257}$. In a meta-analysis of RCTs, compared with placebo, lixisenatide treatment produced reductions in $2 \mathrm{~h}$ postprandial glucose from baseline (LSMD $-4.9 \mathrm{mmol} / \mathrm{l}, P<0.001$ ), glucose excursion (LSMD $-4.5 \mathrm{mmol} / \mathrm{l}, P<0.001$ ) and postprandial glucagon (LSMD $-19.0 \mathrm{ng} / \mathrm{l}, P<0.001)^{256}$. Compared with placebo, lixisenatide also reduced $\mathrm{HbA}_{1 \mathrm{c}}$ and postprandial glucose, but not FPG, when added to basal insulin ${ }^{257}$. 
Exenatide once weekly reduces $\mathrm{HbA}_{1 c}$, FPG and postprandial glucose when used as monotherapy or add-on treatment ${ }^{218,239,241,258}$. Exenatide once weekly monotherapy has been noninferior to metformin, superior to sitagliptin and similar to pioglitazone with regard to $\mathrm{HbA}_{1 \mathrm{c}}$ reduction in RCTs at 26 weeks ${ }^{239,258}$. Addition of exenatide once weekly to metformin is more effective for the achievement of glucose control than addition of either sitagliptin or pioglitazone to metformin ${ }^{218,239}$. In a study involving 456 patients with T2DM treated with metformin alone or with a sulfonylurea, addition of exenatide once weekly resulted in similar $\mathrm{HbA}_{1 \mathrm{c}}$ reductions to addition of insulin glargine; the effect of exenatide once weekly persisted at 3 years $^{222,236,239}$. Similarly, addition of exenatide once weekly to oral glucose-lowering medication resulted in greater $\mathrm{HbA}_{1 \mathrm{c}}$ reductions over 26 weeks than addition of once daily or twice daily insulin detemir ${ }^{239,259}$. In the extension phase of the DURATION-1 trial ${ }^{260}$, patients received exenatide once weekly for up to 5 years, and improvements in $\mathrm{HbA}_{1 \mathrm{c}}$ and FPG were maintained over this period. However, $40 \%$ of patients did not complete the study. Most of the loss of follow-up was because of withdrawal of consent, and only eight patients withdrew because of "loss of glucose control". No differences were identified in baseline characteristics between those who completed and did not complete the study, and $\mathrm{HbA}_{1 \mathrm{c}}$ reduction at 5 years was evident in the intention-to-treat analysis $(-1.2 \% \pm 0.1 \%)$ and the analysis of patients who completed the extension $(-1.6 \% \pm 0.1 \%)$.

Albiglutide has beneficial effects on glycaemic control when used as monotherapy or add-on therapy in phase III studies ${ }^{250,261,262}$. In an RCT lasting 104 weeks, treatments were added to metformin, and albiglutide provided significantly greater reductions in $\mathrm{HbA}_{1 \mathrm{c}}$ and FPG than placebo, sitagliptin or glimepiride ${ }^{226}$. As an add-on to treatment with metformin and sulfonylurea, albiglutide did not meet the prespecified noninferiority margin for the difference in the change of $\mathrm{HbA}_{1 \mathrm{c}}$ of $0.3 \%$ compared with pioglitazone over 52 weeks ${ }^{223}$. As an add-on to metformin (with or without sulfonylurea), albiglutide resulted in similar $\mathrm{HbA}_{1 \mathrm{c}}$ reductions to insulin glargine over 52 weeks ${ }^{224}$. As an add-on to insulin glargine, albiglutide was noninferior to insulin lispro at 26 weeks, but did not meet the noninferiority margin at 52 weeks ${ }^{250,263}$.

Dulaglutide $0.75 \mathrm{mg}$ and $1.5 \mathrm{mg}$ weekly treatments were more effective than metformin and sitagliptin when used as monotherapy or as add-on therapy to other oral glucose-lowering treatments over 52 weeks ${ }^{232,234,250}$. In addition to metformin and sulfonylureas over 52 weeks, compared with daily insulin glargine, dulaglutide $1.5 \mathrm{mg}$ weekly was more effective and dulaglutide $0.75 \mathrm{mg}$ was noninferior for the reduction of $\mathrm{HbA}_{1 \mathrm{c}}$ from baseline ${ }^{237}$.

A meta-analysis of RCTs of $\geq 12$ weeks duration in which information about ethnicity was available showed that the WMD in $\mathrm{HbA}_{1 \mathrm{c}}$ for GLP-1RA treatment compared with placebo was $-1.16 \%$ (95\% CI $-1.48 \%$ to $-0.85 \%$ ) in the pool of studies involving $\geq 50 \%$ Asian participants, and $-0.83 \%$ ( $95 \% \mathrm{CI}-0.97 \%$ to $-0.70 \%)$ in the studies with $<50 \%$ Asian participants (between-group difference $-0.32 \%, 95 \% \mathrm{CI}-0.64 \%$ to $-0.01 \%, P=0.04)^{264}$.
Effect on weight. GLP-1RAs are associated with reductions in body weight and waist circumference, but with much variation in individual responses and within-class differences $^{250,265-268}$ (see Supplementary information S5 (table)). In a meta-analysis ${ }^{266}$ of 15 RCTs, the combination of GLP-1RAs with basal insulin was shown to result in mean weight loss of $-3.22 \mathrm{~kg}(95 \% \mathrm{CI}-4.90 \mathrm{~kg}$ to $-1.54 \mathrm{~kg}$ ).

Effect on blood pressure. Results from individual RCTs and meta-analyses have shown that GLP-1RAs result in modest, but significant, reductions in systolic blood pressure, compared with placebo or insulin ${ }^{269-271}$ (see Supplementary information S5 (table)). This effect is independent of baseline blood pressure and the influence of the GLP-1RA on $\mathrm{HbA}_{1 \mathrm{c}}$ or body weight ${ }^{269}$. A reduction in diastolic blood pressure compared with placebo has also been observed with exenatide twice daily $(-1.08 \mathrm{mmHg}$, $95 \% \mathrm{CI}-1.78 \mathrm{mmHg}$ to $-0.33 \mathrm{mmHg})^{270}$.

Other effects. A meta-analysis has shown that GLP-1RAs modestly reduce levels of total cholesterol, LDL cholesterol and triglycerides, but do not improve HDL cholesterol levels, in comparison with placebo or active comparators $^{272}$.

\section{Safety and adverse effects}

GLP-1RAs are generally well tolerated; the most common adverse effect is nausea, which is usually transient, resolving over 4-8 weeks, and which can be minimized by progressively increasing the dose $\mathrm{e}^{27,28,239,250}$. The risk of hypoglycaemia in patients receiving GLP-1RAs is low, unless they are combined with insulin or sulfonylureas $^{27,28,239,250}$. Injection-site reactions are common with some GLP-1RAs, including exenatide once weekly $(\leq 17.6 \%)$ and albiglutide $(\leq 22 \%)^{250}$. The occurrence of antibodies is also commonly associated with GLP-1RA treatment, but with little apparent clinical relevance, and generally with no influence on glycaemic control, except very occasionally in patients receiving exenatide once weekly who have high antibody titres ${ }^{28,194,239,250}$.

The possible association between GLP-1RAs and the risk of pancreatitis and pancreatic cancer has received much attention, but to date no definite causal link has been found ${ }^{273}$. Meta-analyses have shown no significant increase in acute pancreatitis with GLP-1RA treatment in patients with $\mathrm{T} 2 \mathrm{DM}^{179,274,275}$. In addition, results from cardiovascular safety trials have not shown a significant increase in pancreatitis with GLP-1RAs ${ }^{276}$. The recommendation in the product labelling for GLP-1RAs to avoid therapy in patients with a history of pancreatitis and to discontinue treatment if pancreatitis develops is considered appropriate ${ }^{28}$. Thyroid C-cell hyperplasia and medullary cell carcinoma were also raised as possible concerns in preclinical studies in rodents, but clinical studies have not identified any substantial problems with GLP-1RA treatment ${ }^{28,239,250}$.

The results of preclinical studies showed that GLP-1RAs have cardioprotective effects in heart failure and following myocardial ischaemia ${ }^{65}$. GLP-1RAs can have favourable effects on many cardiovascular risk 
factors, such as weight loss, blood pressure, endothelial function, inflammation, plasminogen activator inhibitor-1, postprandial lipaemia and LDL cholesterol ${ }^{65}$. Results of studies in patients with and without T2DM have shown a beneficial effect of GLP-1RAs on left ventricular function in patients with heart failure and on myocardial function and the myocardial salvage index following ischaemia ${ }^{65,277}$. However, GLP-1RAs often stimulate the resting heart rate by $\sim 3 \mathrm{bpm}$, most likely by activating GLP-1R in the sinoatrial node ${ }^{65}$. In an $\mathrm{RCT}^{271}$ with 24 -h ambulatory heart-rate monitoring, dulaglutide $1.5 \mathrm{mg}$ was associated with increased heart rate compared with placebo (LSMD $2.8 \mathrm{bpm}$, 95\% CI 1.5-4.2 bpm), unlike dulaglutide $0.75 \mathrm{mg}$ and exenatide ${ }^{271,278}$. Large RCTs assessing the cardiovascular safety of liraglutide, semaglutide, exenatide once weekly and dulaglutide are ongoing ${ }^{65}$. No adverse cardiovascular outcomes have been reported in patients with T2DM and established cardiovascular disease who were treated with lixisenatide ${ }^{276}$.

\section{Head-to-head comparisons of GLP-1RAs}

As several GLP-1RAs are available, with different chemical structures and formulations, the different pharmacokinetic and pharmacodynamic profiles seen in head-to-head trials could influence clinical decisionmaking ${ }^{205,216,219-221,227,230,231,238,279}$ (TABLE 2). Overall, liraglutide $1.8 \mathrm{mg}$ and dulaglutide $1.5 \mathrm{mg}$ seem to have the greatest effects on $\mathrm{HbA}_{1 \mathrm{c}}$, and liraglutide $1.8 \mathrm{mg}$ and exenatide once weekly have the largest effect on weight reduction. Albiglutide has less effect on $\mathrm{HbA}_{1 \mathrm{c}}$ and weight reduction than other GLP-1RAs, but is associated with fewer gastrointestinal adverse effects. Once weekly preparations are associated more with injection-site reactions than once daily or twice daily agents.

In general, longer-acting GLP-1RAs produce greater reductions in FPG, but have less effect on postprandial glucose excursions, compared with shorter-acting GLP-1RAs ${ }^{280,281}$. The effect on postprandial glucose is at least partly mediated by delayed gastric emptying, and occurs more with short-acting GLP-1RAs than with long-acting GLP-1RAs, which are subject to tachyphylaxis brought on by chronic elevation of plasma GLP-1 (REF. 280). In addition, lixisenatide, in contrast to liraglutide, strongly suppresses postprandial glucagon secretion $^{280}$. Patient satisfaction is greater in those receiving exenatide once weekly or liraglutide, compared with exenatide twice daily ${ }^{279}$.

\section{GLP-1RAs versus insulin}

In a meta-analysis ${ }^{282}$ of RCTs that compared GLP-1RAs with basal insulin progressively titrated to achieve FPG targets in patients with T2DM, GLP-1RAs resulted in greater reductions in $\mathrm{HbA}_{1 \mathrm{c}}$ (mean net change $-0.14 \%$, $95 \% \mathrm{CI}-0.27 \%$ to $-0.02 \%, P=0.03)$ and weight $(-4.40 \mathrm{~kg}$, $95 \% \mathrm{CI}-5.23 \mathrm{~kg}$ to $-3.56 \mathrm{~kg}, P<0.01)$, but less reduction in FPG (1.18 mmol/l, 95\% CI 0.43-1.93 mmol/l, $P<0.01)$. GLP-1RAs were also associated with greater reductions in postprandial glucose compared with insulin ${ }^{282}$. Hypoglycaemia was reported to reduce in the GLP-1RA group (HR $0.45,95 \%$ CI $0.27-0.76, P<0.01)^{282}$. In a separate $\mathrm{RCT}^{283}$, dulaglutide resulted in greater reduction in $\mathrm{HbA}_{1 \mathrm{c}}$ than insulin glargine, when added to insulin lispro.

\section{Insulin-GLP-1RA combination}

To simplify the co-administration of basal insulin and GLP-1RAs, these two agents have been combined into a single injection, a fixed-ratio combination (IDegLira), which was launched in the UK in 2014 (REF. 147). IDegLira combines $50 \mathrm{U}$ of insulin degludec with $1.8 \mathrm{mg}$ of liraglutide ${ }^{147}$; the combination is titrated in the same way as insulin alone $\mathrm{e}^{147}$.

In a 26 -week $\mathrm{RCT}^{284}$ involving insulin-naive patients, $\mathrm{HbA}_{1 \mathrm{c}}$ decreased by $1.9 \% \pm 1.1 \%$ with IDegLira, compared with $1.4 \% \pm 1.0 \%$ with insulin degludec and $1.3 \% \pm 1.1 \%$ with liraglutide. The IDegLira group had fewer reports of nausea than the liraglutide group and lower incidence of hypoglycaemia than the insulin degludec group ${ }^{284}$. These benefits were maintained at 52 weeks, with $\mathrm{HbA}_{1 \mathrm{c}}$ reductions of $1.84 \%, 1.40 \%$ and $1.21 \%$ for IDegLira, insulin degludec and liraglutide, respectively ${ }^{285}$. FPG was similar with IDegLira $(5.7 \mathrm{mmol} / \mathrm{l})$ and insulin degludec $(6.0 \mathrm{mmol} / \mathrm{l})$ by the end of the study, but higher with liraglutide $\left(7.3 \mathrm{mmol} / \mathrm{l}^{285}\right.$. The improvements in glycaemic control were achieved with $37 \%$ less daily insulin dose with IDegLira than with insulin degludec ${ }^{285}$. IDegLira was associated with a significantly greater decrease in body weight (estimated treatment difference $-2.80 \mathrm{~kg}, P<0.0001$ ) and a $37 \%$ lower rate of hypoglycaemia compared with insulin degludec ${ }^{285}$. In patients who were already receiving basal insulin, $\mathrm{HbA}_{1 \mathrm{c}}$ decreased by $1.9 \%$ with IDegLira versus $0.9 \%$ with insulin degludec (treatment difference $-1.1 \%, 95 \%$ CI $-1.3 \%$ to $-0.8 \%, P<0.0001)$. Mean weight reduction with IDegLira was $2.7 \mathrm{~kg}$ versus no weight change with insulin degludec, and the incidence of hypoglycaemia was similar (24\% for IDegLira versus $25 \%$ for insulin degludec) ${ }^{286}$. Another fixed-ratio combination of lixisenatide and insulin glargine has completed phase III trials and a regulatory submission has been made to the $\mathrm{FDA}^{287,288}$.

\section{SGLT2 inhibitors}

SGLT2 inhibitors currently available in Europe and North America are dapagliflozin, canagliflozin and empagliflozin. They can be used as monotherapy when diet and exercise are inadequate, and when metformin is not tolerated, and can also be used as add-on to other glucose-lowering agents, including insulin ${ }^{289}$. As their efficacy is dependent on the renal filtration of glucose, SGLT2 inhibitors should not be initiated in patients with eGFR $<60 \mathrm{ml} / \mathrm{min} / 1.73 \mathrm{~m}^{2}$, but in patients who are already receiving, and are tolerant of, canagliflozin or empagliflozin, these medications can be continued in patients with eGFR as low as $45 \mathrm{ml} / \mathrm{min} / 1.73 \mathrm{~m}^{2}$ (REF. 290).

\section{Mechanism of action}

SGLTs are secondary active membrane symporters that transfer sodium down its concentration gradient, usually into the cell, in conjunction with the transfer of specific hexose sugars or other molecules against their 
Table 2 | Head-to-head trials of glucagon-like peptide 1 receptor agonists (GLP-1RAs) $166,177,179,180,182,194,195,204,215,218-220,225,228,229,235-237$

\begin{tabular}{|c|c|c|c|c|c|c|c|}
\hline Study & Design & $\begin{array}{l}\text { Baseline } \\
\text { characteristics }\end{array}$ & $\begin{array}{l}\text { Background } \\
\text { therapy }\end{array}$ & $\begin{array}{l}\text { Active } \\
\text { comparators }\end{array}$ & $\begin{array}{l}\mathrm{HbA}_{1 \mathrm{c}} \text { change } \\
\text { from baseline } \\
(\%)\end{array}$ & $\begin{array}{l}\text { Weight } \\
\text { change from } \\
\text { baseline }(\mathrm{kg})\end{array}$ & $\begin{array}{l}\text { Comments on } \\
\text { adverse effects }\end{array}$ \\
\hline $\begin{array}{l}\text { - DURATION-1 } \\
\text { Exenatide } \\
\text { QW versus } \\
\text { exenatide BD }\end{array}$ & $\begin{array}{l}\text { - } \mathrm{R}, \mathrm{OL}, \mathrm{AC}, \mathrm{NI} \\
\cdot n=295, \\
30 \text { weeks }\end{array}$ & $\begin{array}{l}\text { Mean age } 55 \text { years, } \\
\mathrm{HbA}_{1 \mathrm{c}} 8.3 \% \text {, weight } \\
102 \mathrm{~kg}, \mathrm{BMI} 35 \mathrm{~kg} / \\
\mathrm{m}^{2}, 6.7 \text { years } \mathrm{T} 2 \mathrm{DM}\end{array}$ & $\begin{array}{l}\text { Drug naive or } \\
\text { metformin, } \\
\text { SU, TZD or a } \\
\text { combination } \\
\text { of two of those } \\
\text { agents }\end{array}$ & $\begin{array}{l}\text { - Exenatide } \\
2 \text { mg QW } \\
\text { - Exenatide } \\
10 \mu \mathrm{BD}\end{array}$ & $\begin{array}{l}-1.9 \text { versus }-1.5 \\
P=0.0023\end{array}$ & $\begin{array}{l}-3.7 \text { versus } \\
-3.6, P=0.89\end{array}$ & $\begin{array}{l}\text { Higher } \\
\text { incidence of } \\
\text { nausea and } \\
\text { vomiting with } \\
\text { exenatide } \\
\mathrm{BD} \text {, more } \\
\text { injection-site } \\
\text { reactions with } \\
\text { exenatide QW }\end{array}$ \\
\hline $\begin{array}{l}\text { - LEAD-6 } \\
\text { - Liraglutide } \\
\text { versus } \\
\text { exenatide BD }\end{array}$ & $\begin{array}{l}\cdot \mathrm{R}, \mathrm{OL}, \mathrm{AC}, \mathrm{NI} \\
\text { - }=464, \\
26 \text { weeks }\end{array}$ & $\begin{array}{l}\text { Mean age } 57 \text { years, } \\
\mathrm{HbA}_{1 \mathrm{c}} 8.1 \% \text {, weight } \\
93 \mathrm{~kg}, \mathrm{BMI} 32.9 \mathrm{~kg} / \\
\mathrm{m}^{2}, 8.2 \text { years } \mathrm{T} 2 \mathrm{DM}\end{array}$ & $\begin{array}{l}\text { Metformin, SU } \\
\text { or both }\end{array}$ & $\begin{array}{l}\text { - Liraglutide } \\
1.8 \text { mg QD } \\
\text { - Exenatide } \\
10 \mu \mathrm{gBD}\end{array}$ & $\begin{array}{l}-1.12 \text { versus } \\
-0.79, P<0.0001\end{array}$ & $\begin{array}{l}-3.24 \text { versus } \\
-2.87, P=0.22\end{array}$ & $\begin{array}{l}\text { Fewer adverse } \\
\text { effects with } \\
\text { liraglutide, but } \\
\text { often more } \\
\text { severe than with } \\
\text { exenatide }\end{array}$ \\
\hline $\begin{array}{l}\text { - DURATION-5 } \\
\text { Exenatide } \\
\text { QW versus } \\
\text { exenatide BD }\end{array}$ & $\begin{array}{l}-\mathrm{R}, \mathrm{OL}, \mathrm{AC}, \mathrm{NI} \\
\text { - }=252 \\
24 \text { weeks }\end{array}$ & $\begin{array}{l}\text { Mean age } 56 \text { years, } \\
\mathrm{HbA}_{1 \mathrm{c}} 8.4 \% \text {, weight } \\
96 \mathrm{~kg}, \mathrm{BMI} 33.3 \mathrm{~kg} / \\
\mathrm{m}^{2}, 7 \text { years T2DM }\end{array}$ & $\begin{array}{l}\text { Drug naive or } \\
\text { metformin, } \\
\text { SU, TZD or any } \\
\text { combination }\end{array}$ & $\begin{array}{l}\text { - Exenatide } \\
2 \mathrm{mg} \mathrm{QW} \\
\text { - Exenatide } \\
10 \mu \mathrm{BD}\end{array}$ & $\begin{array}{l}-1.6 \text { versus }-0.9 \\
P<0.0001\end{array}$ & $\begin{array}{l}-2.3 \text { versus } \\
-1.4, \\
\text { nonsignificant }\end{array}$ & $\begin{array}{l}\text { Similar to } \\
\text { DURATION-1 }\end{array}$ \\
\hline $\begin{array}{l}\text { - DURATION-6 } \\
\text { - Liraglutide } \\
\text { versus } \\
\text { exenatide QW }\end{array}$ & $\begin{array}{l}\text { - } \mathrm{R}, \mathrm{OL}, \mathrm{AC}, \mathrm{NI} \\
\text { n=911, } \\
26 \text { weeks }\end{array}$ & $\begin{array}{l}\text { Mean age } 57 \text { years, } \\
\mathrm{HbA}_{1 \mathrm{c}} 8.5 \% \text {, weight } \\
91 \mathrm{~kg}, \mathrm{BMI} 32.3 \mathrm{~kg} / \\
\mathrm{m}^{2}, 8.5 \text { years } \mathrm{T} 2 \mathrm{DM}\end{array}$ & $\begin{array}{l}\text { Metformin, } \\
\text { SU, both or } \\
\text { metformin }+ \\
\text { pioglitazone }\end{array}$ & $\begin{array}{l}\text { - Liraglutide } \\
1.8 \text { mg QD } \\
\text { - Exenatide } \\
2 \text { mg QW }\end{array}$ & $\begin{array}{l}-1.48 \text { versus } \\
-1.28, P=0.02 \\
\text { (predefined } \\
\text { noninferiority } \\
\text { criteria were not } \\
\text { met) }\end{array}$ & $\begin{array}{l}-3.57 \text { versus } \\
-2.68 \\
P=0.0005\end{array}$ & $\begin{array}{l}\text { Higher rates } \\
\text { of nausea, } \\
\text { vomiting and } \\
\text { diarrhoea with } \\
\text { liraglutide, more } \\
\text { injection-site } \\
\text { reactions with } \\
\text { exenatide QW }\end{array}$ \\
\hline $\begin{array}{l}\text { - GetGoal-X } \\
\text { - Lixisenatide } \\
\text { versus } \\
\text { exenatide BD }\end{array}$ & $\begin{array}{l}\text { - } \mathrm{R}, \mathrm{OL}, \mathrm{AC}, \mathrm{NI} \\
\text { - } n=634, \\
24 \text { weeks }\end{array}$ & $\begin{array}{l}\text { Mean age } 57 \text { years, } \\
\mathrm{HbA}_{1 \mathrm{c}} 8.0 \% \text {, weight } \\
95 \mathrm{~kg}, \mathrm{BMl} 33.6 \mathrm{~kg} / \\
\mathrm{m}^{2}, 6.8 \text { years } \mathrm{T} 2 \mathrm{DM}\end{array}$ & Metformin & $\begin{array}{l}\text { - Lixisenatide } \\
20 \mu g \text { QD } \\
\text { Exenatide } \\
10 \mu \mathrm{gBD}\end{array}$ & $\begin{array}{l}-0.79 \text { versus } \\
-0.96, \text { predefined } \\
\text { noninferiority } \\
\text { criteria were met }\end{array}$ & $\begin{array}{l}-2.96 \text { versus } \\
-3.98\end{array}$ & $\begin{array}{l}\text { Lower } \\
\text { incidences of } \\
\text { nausea and } \\
\text { hypoglycaemia } \\
\text { with lixisenatide } \\
\text { treatment }\end{array}$ \\
\hline $\begin{array}{l}\text { - HARMONY-7 } \\
\text { - Liraglutide } \\
\text { versus } \\
\text { albiglutide }\end{array}$ & $\begin{array}{l}\text { - } \mathrm{R}, \mathrm{OL}, \mathrm{AC}, \mathrm{NI} \\
\text { n= } 841 \text {, } \\
32 \text { weeks }\end{array}$ & $\begin{array}{l}\text { Mean age } 56 \text { years, } \\
\mathrm{HbA}_{1 \mathrm{c}} 8.2 \% \text {, weight } \\
92 \mathrm{~kg}, \mathrm{BMI} 32.8 \mathrm{~kg} / \\
\mathrm{m}^{2}, 8.4 \text { years } \mathrm{T} 2 \mathrm{DM}\end{array}$ & $\begin{array}{l}\text { Metformin, } \\
\text { pioglitazone, } \\
\text { SU or any } \\
\text { combination }\end{array}$ & $\begin{array}{l}\text { - Liraglutide } \\
1.8 \text { mg QD } \\
\text { - Albiglutide } \\
50 \text { mg QW }\end{array}$ & $\begin{array}{l}0.99 \text { versus } \\
0.78, P=0.0846, \\
\text { predefined } \\
\text { noninferiority } \\
\text { criteria were not } \\
\text { met }\end{array}$ & $\begin{array}{l}-2.16 \text { versus } \\
-0.64 \\
P<0.0001\end{array}$ & $\begin{array}{l}\text { Slightly higher } \\
\text { incidence of } \\
\text { nausea and } \\
\text { vomiting with } \\
\text { liraglutide, more } \\
\text { injection-site } \\
\text { reactions with } \\
\text { albiglutide }\end{array}$ \\
\hline $\begin{array}{l}\text { - AWARD-1 } \\
\text { - Dulaglutide } \\
1.5 \text { mg versus } \\
\text { dulaglutide } \\
0.75 \text { mg versus } \\
\text { exenatide } \\
\text { BD versus } \\
\text { placebo }\end{array}$ & $\begin{array}{l}-\mathrm{R}, \mathrm{OL}, \mathrm{PC}, \\
\mathrm{AC}, \mathrm{S}, \mathrm{NI} \\
-n=978, \\
26 \text { weeks }\end{array}$ & $\begin{array}{l}\text { Mean age } 56 \text { years, } \\
\mathrm{HbA}_{1 \mathrm{c}} 8.1 \% \text {, weight } \\
96 \mathrm{~kg}, \mathrm{BMI} 33 \mathrm{~kg} / \\
\mathrm{m}^{2}, 9 \text { years } T 2 \mathrm{DM}\end{array}$ & $\begin{array}{l}\text { Metformin+ } \\
\text { pioglitazone }\end{array}$ & $\begin{array}{l}\text { Dulaglutide } \\
1.5 \text { mg QW } \\
\text { Dulaglutide } \\
0.75 \text { mg QW } \\
\text { Exenatide } \\
10 \mu \mathrm{BDD} \\
\text { Placebo }\end{array}$ & $\begin{array}{l}-1.51 \text { versus } \\
-1.30 \text { versus } \\
-0.99 \text { versus } \\
-0.46, P<0.001 \\
\text { for both } \\
\text { dulaglutide } \\
\text { doses versus } \\
\text { exenatide }\end{array}$ & $\begin{array}{l}-1.30 \text { versus } \\
+0.2 \text { versus } \\
-1.07 \text { versus } \\
+1.24 \text {, } \\
P=0.47 \text { for } \\
\text { dulaglutide } \\
1.5 \text { mg versus } \\
\text { exenatide }\end{array}$ & $\begin{array}{l}\text { No differences } \\
\text { between } \\
\text { dulaglutide and } \\
\text { exenatide }\end{array}$ \\
\hline $\begin{array}{l}\text { - AWARD-6 } \\
\text { - Dulaglutide } \\
\text { versus } \\
\text { liraglutide }\end{array}$ & $\begin{array}{l}\cdot \mathrm{R}, \mathrm{OL}, \mathrm{AC}, \mathrm{NI} \\
\cdot n=599, \\
26 \text { weeks }\end{array}$ & $\begin{array}{l}\text { Mean age } 57 \text { years, } \\
\mathrm{HbA}_{1 \mathrm{c}} 8.1 \% \text {, weight } \\
94 \mathrm{~kg}, \mathrm{BMI} 33.5 \mathrm{~kg} / \\
\mathrm{m}^{2}, 72 \text { years } \mathrm{T} 2 \mathrm{DM}\end{array}$ & Metformin & $\begin{array}{l}\text { - Dulaglutide } \\
1.5 \text { mg QW } \\
\text { - Liraglutide } \\
1.8 \text { mg QD }\end{array}$ & $\begin{array}{l}-1.42 \text { versus } \\
-1.36, \text { predefined } \\
\text { noninferiority } \\
\text { criteria were met }\end{array}$ & $\begin{array}{l}-2.90 \text { versus } \\
-3.61 \\
P=0.011\end{array}$ & $\begin{array}{l}\text { No differences } \\
\text { between groups }\end{array}$ \\
\hline
\end{tabular}

*Superiority testing was versus placebo, noninferiority testing was versus exenatide. AC, active comparator; BD, twice-daily; NI, noninferiority; OL, open label; PC, placebo controlled; QD, once-daily; QW, once-weekly; R, randomized; S, superiority; SU, sulfonylurea; T2DM, type 2 diabetes mellitus; TZD, thiazolidinedione.

concentration gradient ${ }^{291}$. SGLTs in the intestine and kidneys transfer glucose across the luminal membrane into enterocytes or ductal epithelial cells; glucose transporters (GLUTs) mediate passive transfer of glucose across basolateral membranes down its concentration gradient ${ }^{289,292,293}$.
The main SGLTs are SGLT1 and SGLT2, which are primarily responsible for intestinal glucose absorption and for reabsorption of most of the filtered glucose in the kidney, respectively ${ }^{291,294}$. SGLT2 is a low-affinity, high-capacity glucose transporter in the S1 segment of the proximal tubules, which is suited to reabsorption 
of a high concentration of filtered glucose entering the tubules. SGLT1, which is also expressed in the kidneys, is a high-affinity, low-capacity glucose transporter that is suited to reabsorption of glucose at low concentration in the S3 segment of the proximal tubules ${ }^{294-296}$.

Competitively inhibiting SGLT2 can eliminate 60-90 g glucose per day ${ }^{297}$, but this amount can vary considerably depending on renal function and the degree of hyperglycaemia ${ }^{289}$. The effects of SGLT2 inhibition are self-limiting, as the efficacy decreases as hyperglycaemia lessens (and less glucose is filtered in the kidney). The effects of SGLT2 inhibition are insulin-independent, and efficacy is not affected by declining $\beta$-cell function or insulin resistance ${ }^{28,289}$. However, insulin is still required, as SGLT2 inhibition does not treat the underlying endocrinopathies that contribute to the pathogenesis of T2DM, except by reducing the effects of glucotoxicity ${ }^{28,289}$. SGLT2 inhibition and the associated glycosuria result in mild diuresis and calorie loss, leading to modest reductions in blood pressure and body weight ${ }^{28,289}$. However, the weight loss associated with SGLT2 inhibitors is less than expected from the degree of glycosuria; patients typically have one-quarter to one-third of the weight loss predicted by their glycosuria. This effect is partly accounted for by an elevation of calorie intake, which correlates negatively with baseline BMI and positively with baseline eGFR ${ }^{298}$. In an $\mathrm{RCT}^{299}$ that included 95 patients who were taking a GLP-1RA (which should counter increased calorie intake), addition of canagliflozin $300 \mathrm{mg}$ resulted in significant weight loss compared with placebo (LSMD for change in weight $-3.2 \%$, $95 \% \mathrm{CI}-4.5 \%$ to $-2.0 \%$ ) over 18 weeks.

\section{Pharmacokinetics}

The currently available SGLT2 inhibitors have half-lives of $10.6 \mathrm{~h}$ to $13.3 \mathrm{~h}^{289,300-304}$ (see Supplementary information S7 (box)). Empagliflozin is the most specific. SGLT2 inhibition by dapagliflozin (10 mg per day), canagliflozin (300 mg per day) or empagliflozin (25 mg per day) increases urinary glucose excretion by $60-90 \mathrm{~g}$ per day ${ }^{289,302,303}$. SGLT2 inhibitors are metabolized by uridine diphosphate glucuronosyl transferases, and no significant interactions with other drugs have been reported ${ }^{289,305,306}$.

\section{Pharmacodynamics}

Dapagliflozin. In a 24-week RCT ${ }^{307}$ involving drug-naive patients with T2DM, compared with placebo, dapagliflozin $5-10 \mathrm{mg}$ per day reduced $\mathrm{HbA}_{1 \mathrm{c}}$ by $0.8-0.9 \%$, and reduced body weight by $2.8-3.2 \mathrm{~kg}$. A meta-analysis ${ }^{308}$ of RCTs of 12-104 weeks duration showed that dapagliflozin (2.5-10.0 mg per day) improved $\mathrm{HbA}_{1 \mathrm{c}}$, FPG and weight compared with placebo when used as an add-on therapy to metformin, insulin, thiazolidinediones, sulfonylureas or metformin \pm sitagliptin (mean difference between groups $-0.52 \%, 95 \% \mathrm{CI}-0.60 \%$ to $-0.45 \%$, $-1.52 \mathrm{mmol} / \mathrm{l}, 95 \% \mathrm{CI}-1.75 \mathrm{mmol} / \mathrm{l}$ to $-1.29 \mathrm{mmol} / \mathrm{l}$ and $-1.61 \mathrm{~kg}, 95 \% \mathrm{CI}-1.97 \mathrm{~kg}$ to $-1.26 \mathrm{~kg}$, respectively). The reductions in $\mathrm{HbA}_{1 \mathrm{c}}$ and FPG compared with placebo were generally similar with different background treatments, but were greatest when dapagliflozin was added to a sulfonylurea $(-0.96 \%, 95 \% \mathrm{CI}-0.86 \%$ to $-0.52 \%$ and
$-1.47 \mathrm{mmol} / \mathrm{l}, 95 \% \mathrm{CI}-1.86 \mathrm{mmol} / \mathrm{l}$ to $-1.08 \mathrm{mmol} / \mathrm{l})^{300}$. The largest between-group difference in weight change was seen when dapagliflozin was added to insulin $(-2.45 \mathrm{~kg}, 95 \% \mathrm{CI}-2.99 \mathrm{~kg} \text { to }-1.92 \mathrm{~kg})^{308}$.

Dapagliflozin and glipizide were compared in a 52-week RCT with a 156-week extension ${ }^{309}$; dapagliflozin resulted in lesser $\mathrm{HbA}_{1 \mathrm{c}}$ reductions in the initial 18-week titration phase, but the 18-104-week coefficient of failure was lower with dapagliflozin $(0.13 \%$ per year) than with glipizide $\left(0.59 \%\right.$ per year). $\mathrm{HbA}_{1 \mathrm{c}}$ reductions were greater with dapagliflozin by week 104 (difference from glipizide $-0.18 \%, 95 \% \mathrm{CI}-0.33 \%$ to $-0.03 \%, P=0.021)^{309}$. Dapagliflozin also resulted in sustained reductions in weight and systolic blood pressure (104-week differences from glipizide $-5.1 \mathrm{~kg}, 95 \% \mathrm{CI}-5.7 \mathrm{~kg}$ to $-4.4 \mathrm{~kg}$ and $-3.9 \mathrm{mmHg}$, $95 \% \mathrm{CI}-6.1 \mathrm{mmHg}$ to $-1.7 \mathrm{mmHg}$, respectively $)^{309}$. In an RCT $^{310}$ involving 180 patients with T2DM inadequately controlled by metformin, a modest level of weight loss with dapagliflozin add-on compared with placebo was associated with significant improvements in health-related quality of life over 102 weeks. In an RCT ${ }^{311}$ involving 18 men with T2DM, in comparison with placebo dapagliflozin resulted in increased glucagon secretion from as early as $1 \mathrm{~h}$ after administration, reaching a peak after $4 \mathrm{~h}$. After 3 days of dapagliflozin treatment, the fasting plasma glucagon concentration was $32 \%$ higher than on day 1 , compared with no change in the placebo group $^{311}$. The increase in glucagon was associated with increased endogenous glucose production ${ }^{311}$. The mechanism underlying this apparently compensatory change is not known, although SGLT2 expression has been noted in pancreatic a cells $s^{312}$.

Canagliflozin. In a meta-analysis of RCTs, canagliflozin was found to reduce $\mathrm{HbA}_{1 \mathrm{c}}$ when used as monotherapy (WMD $-1.08 \%, 95 \% \mathrm{CI}-1.25 \%$ to $-0.90 \%, P<0.00001$ ) or add-on treatment $(-0.73 \%, 95 \% \mathrm{CI}-0.84 \%$ to $-0.61 \%$, $P<0.00001)$, compared with placebo ${ }^{313}$. Relative to active comparators, canagliflozin reduced $\mathrm{HbA}_{1 \mathrm{c}}$ by $-0.21 \%$ (95\% CI $-0.33 \%$ to $-0.08 \%, P=0.001)^{313}$. Canagliflozin also reduced $\mathrm{HbA}_{1 \mathrm{c}}$ in comparison with sitagliptin $(-0.24 \%, 95 \%$ CI $-0.40 \%$ to $-0.09 \%, P=0.002)$ and glimepiride $(-0.12 \%, 0.95 \%$ CI $-0.23 \%$ to $-0.01 \%$, $P=0.03)^{313}$, and reduced FPG in comparison with placebo $(-33.50 \mathrm{mg} / \mathrm{dl}, 95 \% \mathrm{CI}-39.22 \mathrm{mg} / \mathrm{dl}$ to $-27.78 \mathrm{mg} / \mathrm{dl}$, $P<0.00001)$ and active comparators $(-15.86 \mathrm{mg} / \mathrm{dl}$, $95 \% \mathrm{CI}-23.17 \mathrm{mg} / \mathrm{dl}$ to $-8.56 \mathrm{mg} / \mathrm{dl}, P<0.00001)^{313}$. Canagliflozin resulted in greater weight loss than placebo $(-2.81 \mathrm{~kg}, 95 \% \mathrm{CI}-3.26 \mathrm{~kg}$ to $-2.37 \mathrm{~kg})$ or active comparators $(-3.49 \mathrm{~kg}, 95 \% \mathrm{CI}-4.86 \mathrm{~kg}$ to $-2.12 \mathrm{~kg})$, particularly when compared with glimepiride $(-5.40 \mathrm{~kg}$, $95 \% \mathrm{CI}-5.95 \mathrm{~kg}$ to $-4.85 \mathrm{~kg}, P<0.00001)^{313}$.

Addition of canagliflozin to insulin treatment (generally by a basal-bolus regimen) has been shown to result in a significant reduction in $\mathrm{HbA}_{1 \mathrm{c}}$ at 18 weeks (and sustained up to 52 weeks) compared with placebo, from a baseline of $8.3 \%(-0.62 \%, 95 \%$ CI $-0.69 \%$ to $-0.54 \%, P<0.001$ with $100 \mathrm{mg}$ canagliflozin and $-0.73 \%$, $95 \%$ CI $-0.81 \%$ to $-0.65 \%, P<0.001$ with $300 \mathrm{mg}$ canagliflozin) $)^{314}$. In an RCT involving 37 patients, following an initial dose of canagliflozin, a second dose of 
$300 \mathrm{mg}$ canagliflozin administered immediately before a mixed-meal tolerance test reduced postprandial glucose (compared with placebo) without causing further increases in urinary glucose excretion, which suggests the induction of mechanisms such as SGLT1 inhibition in the gut ${ }^{315}$. Glucose lowering and weight loss with canagliflozin are more durable than with sulfonylureas at 104 weeks $^{316}$.

Reductions in systolic and diastolic blood pressure have been demonstrated for canagliflozin compared with placebo (systolic $-5.05 \mathrm{mmHg}$, 95\% CI $-6.81 \mathrm{mmHg}$ to $-3.28 \mathrm{mmHg}, P<0.00001$, diastolic $-2.43 \mathrm{mmHg}$, 95\% CI $-3.29 \mathrm{mmHg}$ to $-1.57 \mathrm{mmHg}, P<0.0001$ ) or active comparators (systolic $-4.34 \mathrm{mmHg}, 95 \% \mathrm{CI}-5.31 \mathrm{mmHg}$ to $-3.36 \mathrm{mmHg}, P<0.00001$, diastolic $-2.17 \mathrm{mmHg}$, $95 \% \mathrm{CI}-2.79 \mathrm{mmHg}$ to $-1.54 \mathrm{mmHg}, P<0.00001)^{313}$.

Empagliflozin. In 24-week RCTs ${ }^{317-320}$, empagliflozin (as monotherapy or added to metformin, to metformin with sulfonylurea or to pioglitazone with or without metformin) resulted in reductions in $\mathrm{HbA}_{1 \mathrm{c}}$, body weight and systolic blood pressure of $0.7-0.8 \%$, $1.5-2.5 \mathrm{~kg}$ and $2.9-4.1 \mathrm{mmHg}$ respectively, which were significant in comparison with placebo. Reductions in $\mathrm{HbA}_{1 \mathrm{c}}$ and weight were maintained in trial extensions up to 76 weeks $^{321-324}$.

Compared with sitagliptin monotherapy for 24 weeks, empagliflozin monotherapy resulted in similar $\mathrm{HbA}_{1 \mathrm{c}}$ reductions, but greater reductions in FPG, body weight and systolic blood pressure ${ }^{317}$. Over 104 weeks, empagliflozin was noninferior to glimepiride as an add-on to metformin treatment, and resulted in less hypoglycaemia ${ }^{325}$.

In patients receiving basal insulin (with or without the additional regimen of metformin with or without sulfonylurea), empagliflozin resulted in $\mathrm{HbA}_{1 \mathrm{c}}$ reduction of $2.0-2.5 \%$ compared with placebo over 78 weeks, along with $2.4-4.1 \mathrm{~kg}$ weight $\operatorname{loss}^{326}$. Addition of placebo, empagliflozin $10 \mathrm{mg}$ or empagliflozin $25 \mathrm{mg}$ to a multiple daily injection insulin regimen reduced $\mathrm{HbA}_{1 c}$ $(-0.81 \pm 0.08 \%,-1.18 \pm 0.08 \%$ and $-1.27 \pm 0.08 \%$, respectively) after 52 weeks ${ }^{327}$. Insulin dose and body weight were reduced (by -9 to -11 international units per day and $-2.4 \mathrm{~kg}$ to $-2.5 \mathrm{~kg}$, respectively) with empagliflozin treatment compared with placebo, without increasing the risk of hypoglycaemia ${ }^{327}$.

In a 12 -week RCT ${ }^{328}$ of patients with T2DM, baseline systolic blood pressure of $130-159 \mathrm{mmHg}$ and diastolic blood pressure of $80-99 \mathrm{mmHg}$, the adjusted mean difference versus placebo in change from baseline in mean 24-h systolic blood pressure was $-4.16 \mathrm{mmHg}$ (95\% CI $-5.50 \mathrm{mmHg}$ to $-2.83 \mathrm{mmHg}$ ), and in diastolic blood pressure was $-1.72 \mathrm{mmHg}(95 \% \mathrm{CI}-2.51 \mathrm{mmHg}$ to $-0.93 \mathrm{mmHg}$ ) with $25 \mathrm{mg}$ empagliflozin (both $P<0.001)$.

Compared with placebo, empagliflozin resulted in an adjusted mean $\mathrm{HbA}_{1 \mathrm{c}}$ difference of $-0.68 \%$ (95\% CI $-0.88 \%$ to $-0.49 \%)$ in patients with eGFR $60-90 \mathrm{ml} /$ $\mathrm{min} / 1.73 \mathrm{~m}^{2}$ and $-0.42 \%(95 \% \mathrm{CI}-0.56 \%$ to $-0.28 \%)$ in patients with eGFR $30-60 \mathrm{ml} / \mathrm{min} / 1.73 \mathrm{~m}^{2}$ over 24 weeks, and the treatment was well tolerated ${ }^{329}$.

\section{Safety and adverse effects}

SGLT2 inhibitors are associated with low risk of hypoglycaemia except when used in combination with insulin or sulfonylureas ${ }^{289}$. This low risk reflects the ability of uninhibited SGLT2 (and SGLT1) to reabsorb all of a reduced filtered glucose load as the blood glucose level declines, emphasizing the self-limiting nature of this mode of action ${ }^{289}$. Compared with the sulfonylurea glipizide, dapagliflozin resulted in significantly lower risk of hypoglycaemia ( $4.2 \%$ versus $45.8 \%$ ) in an RCT involving 814 patients with T2DM over 104 weeks ${ }^{309}$. Canagliflozin treatment was associated with similar rates of hypoglycaemia to placebo when used as monotherapy or as an add-on therapy, except when added to sulfonylurea (RR 1.49, 95\% CI 1.14-1.95, $P=0.004)^{313}$. The percentage of patients having confirmed hypoglycaemic events with empagliflozin treatment has been shown to be $<1 \%$ when used as monotherapy, $1.4-2.4 \%$ when used as add-on to metformin or pioglitazone, $11.5-16.1 \%$ when combined with sulfonylureas and $35-58 \%$ when added to insulin ${ }^{28,239,305}$.

SGLT2 inhibitors are associated with increased risk of genital infections, but an increase in urinary tract infection (UTI) has not been consistently reported ${ }^{289}$. Compared with sulfonylureas, dapagliflozin has been associated with increased risk of genital and urinary tract infections (14.8\% and $13.5 \%$, respectively, with dapagliflozin, $2.9 \%$ and $9.1 \%$, respectively, with glipizide) $)^{309}$. No increased risk of UTIs was observed in patients treated with canagliflozin, but the risk of genital tract infections was increased (RR 3.76, 95\% CI 2.23-6.35, $P<0.00001$ versus placebo, RR 4.95, 95\% CI 3.25-7.52, $P<0.00001$ versus active comparators); the increase was greater in women than in men, but none of the reported infections was severe and all were resolved with simple treatment ${ }^{313}$. In a pooled analysis of RCTs ${ }^{330}$, genital mycotic infection occurred more commonly with canagliflozin $100 \mathrm{mg}$ and $300 \mathrm{mg}$ than with placebo in women $(10.4 \%, 11.4 \%$ and $3.2 \%$, respectively) and in men $(4.2 \%, 3.7 \%$ and $0.6 \%$, respectively). Similar results were found when canagliflozin was compared with active control (14.7\%, 13.9\% and $3.1 \%$ in women, $7.3 \%, 9.3 \%$ and $1.6 \%$ in men $)^{330}$. The infections were generally mild and easy to treat, but laboratory confirmation was lacking for most events ${ }^{330}$. Similarly, a review of the properties of empagliflozin found an association with UTI in some trials, but not others, whereas all trials showed increased risk of genital infections ${ }^{305}$.

SGLT2 inhibitors are associated with small increases in LDL cholesterol, but also corresponding increases in HDL cholesterol; these effects might be slightly greater with canagliflozin than with other SGLT2 inhibitors ${ }^{313,331}$. Results differ with regard to the risk of osmotic diuresis and hypovolaemia ${ }^{289,332}$. In a meta-analysis ${ }^{313}$, the risks of adverse effects related to osmotic diuresis were found to be higher with canagliflozin than with placebo (RR 3.93, 95\% CI 2.25-6.86, $P<0.00001)$ or active comparators (RR 2.57, 95\% CI 1.26-5.25, $P=0.009$ ), whereas volume-related adverse effects did not differ. In a 12-week $\mathrm{RCT}^{333}$, canagliflozin $300 \mathrm{mg}$ resulted in decreased plasma volume at week 1 ( $-5.4 \%$ versus $4.3 \%$ with placebo, 
$P=0.02$ ), along with a modest increase in urinary volume, both of which were attenuated by week 12 . In a pooled analysis $^{334}$ of data from $>11,000$ patients with T2DM, empagliflozin was not associated with the frequency of events related to volume depletion, but a high frequency of such events occurred in patients $\geq 75$ years of age receiving empagliflozin $25 \mathrm{mg}$, and in patients receiving loop diuretics in addition to empagliflozin $10 \mathrm{mg}$.

SGLT2 inhibitors, particularly canagliflozin, might have adverse effects on the risk of fractures. The results of an $\mathrm{RCT}^{335}$ with dapagliflozin showed no effect on markers of bone formation or resorption, or bone mineral density after 50 weeks of treatment in men and postmenopausal women with T2DM inadequately controlled by metformin ${ }^{334,335}$. However, in some studies, canagliflozin has been shown to affect levels of urinary calcium, serum phosphate and 1,25-dihydroxyvitamin $\mathrm{D}^{336}$. In a 26-week RCT ${ }^{336}$ with a 78-week extension that included 716 patients with T2DM aged 55-80 years, canagliflozin treatment was associated with a decrease in total hip bone mineral density over 104 weeks (placebo-subtracted changes $-0.9 \%$ and $-1.2 \%$ for $100 \mathrm{mg}$ and $300 \mathrm{mg}$ canagliflozin, respectively), but no effect was seen at other bone sites. In a pooled analysis of eight studies $(n=5,867)$, the incidence of fractures was similar with (1.7\%) and without (1.5\%) canagliflozin (HR 1.09, 95\% CI 0.71-1.66) . $^{337}$. Separate analysis of results from the CANVAS trial $(n=4,327)$ showed a significant increase in fractures with canagliflozin (4.0\%) compared with placebo $(2.6 \%$; HR 1.51, 95\% CI 1.04-2.19), as well as increased fallrelated adverse effects ${ }^{337}$. However, compared with the non-CANVAS trials, patients in the CANVAS trial were older ( $62.4 \pm 8.0$ years versus $57.6 \pm 9.8$ years), with a high risk of cardiovascular disease, and with lower baseline eGFR and higher diuretic use $\mathrm{e}^{337}$.

Several instances of euglycaemic and hyperglycaemic diabetic ketoacidosis have been reported in patients who received SGLT2 inhibitors ${ }^{338-341}$. The diabetic ketoacidosis prevalence in 17,596 patients from randomized studies of canagliflozin was $0.07 \%(n=12)^{341}$. Many of the affected patients, with T2DM treated with insulin, had reduced or stopped insulin or experienced an intercurrent illness that would increase the demand for glucose $\mathrm{e}^{342}$. A lack of insulin leads to increased lipolysis and conversion of excess fatty acids to ketones, but the hyperglycaemia associated with SGLT2 inhibitors is typically mild, presumably because they reduce blood glucose $e^{338,339,342}$. In many of the occurrences of diabetic ketoacidosis, reduction of insulin dose revealed latent autoimmune diabetes of adults, a form of type 1 diabetes mellitus (T1DM). Other instances of diabetic ketoacidosis resulted from off-label use of SGLT2 inhibitors in patients with T1DM ${ }^{338,339,342}$. Patients treated with insulin and undertaking selfmonitoring of blood glucose should not, therefore, discontinue insulin when they observe a reduction in blood glucose after introduction of an SGLT2 inhibitor. The SGLT2 therapy can improve glycaemic control, but does not obviate the need for insulin.

Pooled analysis of the results of phase II and phase III trials suggests a beneficial effect of dapagliflozin on cardiovascular disease ${ }^{65}$. Cardiovascular outcomes in patients treated with SGLT2 inhibitors are being assessed in a number of RCTs. In a study of 7,020 patients with T2DM at high risk of cardiovascular events, occurrence of a composite end point of nonfatal myocardial infarction, nonfatal stroke and death from cardiovascular causes was lower with empagliflozin than placebo, in addition to standard therapy (HR 0.86, 95\% CI, 0.74-0.99, $P=0.04$ for superiority $)^{343}$. Empagliflozin treatment also reduced the risk of cardiovascular death (HR 0.62, 95\% CI, 0.49-0.77, $P<0.001)$, death from any cause (HR 0.68, 95\% CI, 0.57-0.82, $P<0.001$ ) and hospitalization from heart failure (HR $0.65,95 \%$ CI, 0.50-0.85, $P=0.002)^{343}$. Subgroup analyses showed heterogeneity for the primary outcome; the benefits of empagliflozin were more evident in the Asian population, in patients with $\mathrm{BMI}<30 \mathrm{~kg} / \mathrm{m}^{2}$ and $\mathrm{HbA}_{1 \mathrm{c}}<8.5 \%$, in those not on insulin treatment and in those with nephropathy ${ }^{343}$. The effect of empagliflozin on death from cardiovascular causes was consistent across all subgroups ${ }^{343}$. Results of other cardiovascular outcome trials with dapagliflozin and canagliflozin are awaited with interest.

\section{Other agents \\ Dopamine $D_{2}$ receptor agonists}

Bromocriptine quick release $(\mathrm{QR})$ is a dopamine $\mathrm{D}_{2}$ receptor agonist that is licensed in some countries outside Europe for treatment of T2DM as an adjunct to lifestyle changes ${ }^{344,345}$. The effect of bromocriptine on glycaemic parameters has been noted since 1980 (REF. 346). The drug provides a morning boost to hypothalamic dopamine levels, consistent with normal diurnal glucoregulation, and contributing to a reduction of sympathetic tone, neural suppression of hepatic glucose production and improvement in peripheral glucose disposal, without affecting insulin levels ${ }^{28,344,346,347}$. A meta-analysis showed that bromocriptine QR add-on therapy, compared with placebo, reduced levels of $\mathrm{HbA}_{1 \mathrm{c}}(-6.52 \mathrm{mmol} / \mathrm{mol}, 95 \% \mathrm{CI}-8.07 \mathrm{mmol} / \mathrm{mol}$ to $-4.97 \mathrm{mmol} / \mathrm{mol})$ and FPG $(-1.04 \mathrm{mmol} / \mathrm{l}, 95 \% \mathrm{CI}$ $-1.49 \mathrm{mmol} / \mathrm{l}$ to $-0.59 \mathrm{mmol} / \mathrm{l})$, but had no effect on postprandial glucose ${ }^{348}$. Bromocriptine QR was weight neutral and was not associated with the risk of hypoglycaemia, hypotension or cardiovascular effects ${ }^{348}$. However, bromocriptine QR increased gastrointestinal adverse effects of nausea and vomiting, relative to placebo $^{348}$. In an $\mathrm{RCT}^{349}$ involving 3,095 patients, bromocriptine QR (as monotherapy or add-on to glucoselowering agents, including insulin) was shown to reduce the risk of cardiovascular disease, compared with placebo (HR 0.60, 95\% CI 0.35-0.96) by 52 weeks.

\section{Bile-acid sequestrants}

Bile-acid sequestrants are established treatments for dyslipidaemia and are associated with a reduction in the risk of cardiovascular disease ${ }^{350}$. In 2008, the FDA licensed colesevelam as an adjunct to lifestyle measures to improve glycaemic control in $\mathrm{T}_{2} \mathrm{DM}^{26}$. The mechanism of action might involve the passage of bile acids along the intestine, possibly activating bile-acid receptors on L cells, leading to secretion of GLP-1. Inhibiting the return of bile acids to the liver could also affect 
glucose metabolism by preventing activation of hepatic farnesoid receptors ${ }^{28}$. Colesevelam reduced $\mathrm{HbA}_{1 \mathrm{c}}$ by $0.30-0.54 \%$ compared with placebo, in combination with metformin, sulfonylureas, pioglitazone or insulin, with no increased risk of hypoglycaemia or weight gain $^{350,351}$. Despite its favourable effect on levels of LDL cholesterol and HDL cholesterol, colesevelam increased levels of triglycerides by $11-22 \%{ }^{350}$.

\section{Pramlintide}

Pramlintide, a soluble analogue of islet amyloid polypeptide, was introduced in 2005 as an injectable mealtime adjunct to a basal-bolus insulin regimen ${ }^{352}$. It assists glycaemic control and weight control through a centrally-mediated effect via the area postrema, which activates neural pathways that enhance satiety, suppress pancreatic glucagon secretion and slow gastric emptying ${ }^{352}$. Modest reductions in $\mathrm{HbA}_{1 \mathrm{c}}$, typically $0.3-0.6 \%$, have been reported alongside body-weight reductions of $1-2 \mathrm{~kg}$ and reductions of the bolus insulin requirement ${ }^{352}$. Addition of pramlintide to treatment adds to the burden of mealtime injections and requires care with dose adjustments to minimize risks of nausea and hypoglycaemia ${ }^{352}$.

\section{Treatment algorithm}

The treatment options for patients with T2DM now extend to a variety of drug classes with different mechanisms of action, low risks of hypoglycaemia and favourable effects on body weight. The availability of several agents within most classes offers choice with regard to pharmacokinetics, pharmacodynamics and the timing and mode of delivery. However, direct comparisons can be difficult when long-term head-to-head studies are not available, as can determining suitability for individual patients in the absence of studies in particular patient subgroups. Overall, the choice of treatment must balance efficacy with safety, tolerability with adherence and budgets with resources, as well as considering practical issues relating to realistic targets, monitoring and life situations ${ }^{36}$.

Metformin is firmly established as the preferred first-line pharmacotherapy in patients with $\mathrm{T} 2 \mathrm{DM}^{36}$. Expectations are increasing for SGLT2 inhibitors, and the results of ongoing RCTs will help to determine the positioning of this class in the treatment algorithm. Notably, the choice of metformin as first-line therapy is mainly based on the results of the UKPDS, which included 342 patients assigned to metformin, whereas the efficacy of empagliflozin has been demonstrated in 4,687 patients in the EMPA-REG study ${ }^{343}$. The EMPAREG study included patients with advanced disease and high risk of cardiovascular disease, whereas the UKPDS population had newly diagnosed T2DM. If $\mathrm{HbA}_{1 \mathrm{c}}$ targets are not met with metformin treatment within 3 months, the recommendation from the American Diabetes Association and the European Association for the Study of Diabetes is to add a differently-acting agent ${ }^{36}$. Although oral agents will often have similar efficacy, the injectables (GLP-1RAs and insulin) can have greater effects on $\mathrm{HbA}_{1 c}{ }^{241}$. However, efficacy is not just about
$\mathrm{HbA}_{1 \mathrm{c}}$, but must always take into account a 'package' of effects that includes risk of hypoglycaemia, weight gain, general tolerability and long-term safety. For example, the risks of weight gain and hypoglycaemia are higher with sulfonylureas and insulin than with DPP-4 inhibitors and SGLT2 inhibitors ${ }^{36}$. Thiazolidinediones have a low risk of hypoglycaemia, but increase body weight and the risks of heart failure and bone fractures, compared with placebo ${ }^{36}$. An individualised approach to treatment is important, taking into account patients' circumstances and needs. Therapeutic choice is restricted in people who drive, the elderly, the frail and those with renal, neural and other comorbidities.

If the addition of a second agent fails to achieve or maintain acceptable glycaemic control, adding a third differently acting agent can be indicated ${ }^{36}$. Most classes of agents can be combined with additive efficacy, although addition of DPP-4 inhibitors to GLP-1RAs is unlikely to offer extra control. If triple combinations are inadequate, introduction of insulin (usually basal initially with continued metformin) is needed. If basal insulin is insufficient, addition of meal-time insulin, a GLP-1RA or possibly an SGLT2 inhibitor can be considered ${ }^{36}$. Addition of a GLP-1RA in this context might be a useful treatment strategy, as it has less risk of hypoglycaemia than meal-time insulin, and has a better effect on weight.

The availability of increasing numbers of agents that are given at a frequency less than daily might be attractive for many patients, and might enhance compliance. The outcomes of ongoing cardiovascular safety studies could further clarify the T2DM treatment algorithm, as could the introduction of additional long-acting GLP-1RAs, DPP-4 inhibitors and SGLT2 inhibitors that are in development ${ }^{18,26,353-357}$.

\section{Lessons for future therapies}

Advances in the understanding of the pathogenesis of T2DM have informed the development of different classes of treatments $\mathrm{s}^{358}$. However, treatments are needed with longer lasting metabolic effects than those currently available, and with the ability to improve, or prevent continuing decline in, $\beta$-cell function. Clearly, safety is of paramount importance. Adverse effects have been found with several agents that have now been discontinued, highlighting the importance of maintaining pharmacovigilance. Minimizing hypoglycaemia, weight gain and cardiovascular events while avoiding any increased risk of cancer is crucial for new treatments, particularly as they might need to be taken for many years. In real life, medications will be used in more varied populations than in clinical trials, and they might be prescribed by less-specialized professionals to patients who will not receive the intensive follow-up and monitoring associated with RCTs ${ }^{359}$.

When considering safety, it can be extremely difficult to interpret results from preclinical studies, or to have available the most appropriate models to decide which treatments should be developed further. Another challenge is to identify and interpret adverse signals in clinical trials for extrapolation to real life ${ }^{359}$. Faint signals from preregistration trials can take a decade or 
more to reveal their clinical importance and are often confounded by several biases, including treatment allocation and detection of complications. Pressure to ensure safety is increasing, but regulatory agencies have a difficult task to strike a balance between appropriate caution and making sure that new beneficial treatments are made available in a safe, but timely manner ${ }^{359}$. Understanding the factors responsible for variations in the responses of individuals to particular treatments, and the influence of pharmacogenetics on pharmacokinetics and efficacy will facilitate personalized and patient-centred therapies ${ }^{29}$.

\section{Conclusion}

Many different glucose-lowering therapies are now available to address different aspects of the pathogenesis of T2DM through a range of actions, and these treatments vary in efficacy, convenience, adverse effect profiles and cost. The potential 'value' of a therapy involves more than a cost-benefit analysis, and is based on a 'package' of attributes that takes account of long-term safety, tolerability, risk of hypoglycaemia and weight gain and suitability in the presence of comorbidities and other medications. Individualized therapy must be tailored to patients' needs and preferences, with consideration of their circumstances, understanding and commitment.

DPP-4 inhibitors, GLP-1RAs and SGLT2 inhibitors have low risks of hypoglycaemia (except when combined with insulin or sulfonylurea) and are associated with either weight loss or weight neutrality, but they are more expensive than older agents such as sulfonylureas and meglitinides. Evidence relating to the safety profiles of many of these newer agents is encouraging and suggests their value in the challenge to provide early, effective and sustained glycaemic control in T2DM. Although metformin remains the preferred initial pharmacotherapy (when tolerated), an individualized approach is required to assess treatment targets and to achieve them in the safest possible manner.
1. International Diabetes Federation. IDF Diabetes Atlas 7th edn http://www. diabetesatlas.org/ (2016).

2. de Groot, M., Anderson, R., Freedland, K. E. Clouse, R. E. \& Lustman, P. J. Association of depression and diabetes complications: a metaanalysis. Psychosom. Med. 63, 619-630 (2001).

3. Jacobson, A. M. Impact of improved glycemic control on quality of life in patients with diabetes. Endocr Pract. 10, 502-508 (2004).

4. Stumvoll, M., Goldstein, B. J. \& van Haeften, T. W. Type 2 diabetes: principles of pathogenesis and therapy. Lancet 365, 1333-1346 (2005).

5. Kahn, S. E., Hull, R. L. \& Utzschneider, K. M. Mechanisms linking obesity to insulin resistance and type 2 diabetes. Nature 444, 840-846 (2006).

6. Mulder, H., Nagorny, C. L., Lyssenko, V. \& Groop, L. Melatonin receptors in pancreatic islets: good morning to a novel type 2 diabetes gene. Diabetologia 52, 1240-1249 (2009).

7. Drucker, D. J. \& Nauck, M. A. The incretin system: glucagon-like peptide-1 receptor agonists and dipeptidyl peptidase- 4 inhibitors in type 2 diabetes. Lancet 368, 1696-1705 (2006).

8. Wellen, K. E. \& Hotamisligil, G. S. Inflammation, stress, and diabetes. J. Clin. Invest. 115, 1111-1119 (2005).

9. Yang, Q. et al. Serum retinol binding protein 4 contributes to insulin resistance in obesity and type 2 diabetes. Nature 436, 356-362 (2005).

10. Rui, L., Yuan, M., Frantz, D., Shoelson, S. \& White, M. F. SOCS-1 and SOCS-3 block insulin signaling by ubiquitin-mediated degradation of IRS 1 and IRS2. J. Biol. Chem. 277, 42394-42398 (2002).

11. Marcheva, B. et al. Disruption of the clock components CLOCK and BMAL1 leads to hypoinsulinaemia and diabetes. Nature 466 627-631 (2010)

12. Yang, C. S. et al. Hypothalamic AMP-activated protein kinase regulates glucose production. Diabetes 59 2435-2443 (2010).

13. Marchetti, P. et al. in The Islets of Langerhan (ed. Islam, M. S.) 501-514 (Springer Netherlands, 2010)

14. Campbell, J. E. \& Drucker, D. J. Islet $\alpha$ cells and glucagon - critical regulators of energy homeostasis. Nat. Rev. Endocrinol. 11, 329-338 (2015).

15. Kahn, S. E. et al. Glycemic durability of rosiglitazone metformin, or glyburide monotherapy. N. Engl. J. Med. 355, 2427-2443 (2006).

16. Defronzo, R. A. Banting Lecture. From the triumvirate to the ominous octet: a new paradigm for the treatment of type 2 diabetes mellitus. Diabetes $\mathbf{5 8}$ 773-795 (2009).
17. Bailey, C. J. Treating insulin resistance: future prospects. Diab. Vasc. Dis. Res. 4, 20-31 (2007).

18. Altaf, Q. A., Barnett, A. H. \& Tahrani, A. A. Novel therapeutics for type 2 diabetes: insulin resistance. Diabetes Obes. Metab. 17, 319-334 (2015).

19. Samuel, V. T. \& Shulman, G. I. Mechanisms for insulin resistance: common threads and missing links. Cell 148, 852-871 (2012).

20. Meier, B. C. $\&$ Wagner, B. K. Inhibition of HDAC3 as a strategy for developing novel diabetes therapeutics. Epigenomics 6, 209-214 (2014).

21. Brownlee, M. The pathobiology of diabetic complications: a unifying mechanism. Diabetes $\mathbf{5 4}$, 1615-1625 (2005)

22. UK Prospective Diabetes Study (UKPDS) Group. Intensive blood-glucose control with sulphonylureas or insulin compared with conventional treatment and risk of complications in patients with type 2 diabetes (UKPDS 33). Lancet 352, 837-853 (1998).

23. Holman, R. R., Paul, S. K., Bethel, M. A. Matthews, D. R. \& Neil, H. A. 10-year follow-up of intensive glucose control in type 2 diabetes. $N$. Engl. J. Med. 359, 1577-1589 (2008).

24. The Diabetes Control and Complications Trial Research Group. The effect of intensive treatment of diabetes on the development and progression of longterm complications in insulin-dependent diabetes mellitus. N. Engl. J. Med. 329, 977-986 (1993)

25. Hayward, R. A. et al. Follow-up of glycemic control and cardiovascular outcomes in type 2 diabetes. N. Engl. J. Med. 372, 2197-2206 (2015)

26. Tahrani, A. A., Bailey, C. J., Del Prato, S. \& Barnett, A. H. Management of type 2 diabetes: new and future developments in treatment. Lancet 378 , 182-197 (2011)

27. Tahrani, A. A., Piya, M. K., Kennedy, A. $\delta$ Barnett, A. H. Glycaemic control in type 2 diabetes: targets and new therapies. Pharmacol. Ther. 125 , 328-361 (2010).

28. Bailey, C. J. The current drug treatment landscape for diabetes and perspectives for the future. Clin. Pharmacol. Ther. 98, 170-184 (2015).

29. Maruthur, N. M. et al. The pharmacogenetics of type 2 diabetes: a systematic review. Diabetes Care 37, 876-886 (2014).

30. Home, P. et al. Insulin therapy in people with type 2 diabetes: opportunities and challenges? Diabetes Care 37, 1499-1508 (2014).

31. Ohkubo, Y. et al. Intensive insulin therapy prevents the progression of diabetic microvascular complications in Japanese patients with non-insulindependent diabetes mellitus: a randomized prospective 6-year study. Diabetes Res. Clin. Pract. 28, 103-117 (1995)

32. Dormandy, J. A. et al. Secondary prevention of macrovascular events in patients with type 2 diabetes in the PROactive Study (PROspective
pioglitAzone Clinical Trial In macroVascular Events) a randomised controlled trial. Lancet 366 1279-1289 (2005)

33. Action to Control Cardiovascular Risk in Diabetes Study Group. Effects of intensive glucose lowering in type 2 diabetes. N. Engl. J. Med. 358, 2545-2559 (2008)

34. ADVANCE Collaborative Group. Intensive blood glucose control and vascular outcomes in patients with type 2 diabetes. N. Engl. J. Med. 358, 2560-2572 (2008).

35. Duckworth, W. et al. Glucose control and vascular complications in veterans with type 2 diabetes. N. Engl. J. Med. 360, 129-139 (2009).

36. Inzucchi, S. E. et al. Management of hyperglycemia in type 2 diabetes, 2015: a patient-centered approach: update to a position statement of the American Diabetes Association and the European Association for the Study of Diabetes. Diabetes Care 38, 140-149 (2015).

37. Krentz, A. J. \& Bailey, C. J. Oral antidiabetic agents: current role in type 2 diabetes mellitus. Drugs 65 385-411 (2005).

38. Tahrani, A. A., Varughese, G. I., Scarpello, J. H. \& Hanna, F. W. F. Metformin, heart failure, and lactic acidosis: is metformin absolutely contraindicated? BMJ 335, 508-512 (2007).

39. Bailey, C. J. \& Turner, R. C. Metformin. N. Engl. J. Med. 334, 574-579 (1996).

40. Ferrannini, E. The target of metformin in type 2 diabetes. N. Engl. J. Med. 371, 1547-1548 (2014)

41. Zhou, G. et al. Role of AMP-activated protein kinase in mechanism of metformin action. J. Clin. Invest. 108, 1167-1174 (2001).

42. Viollet, B. et al. Cellular and molecular mechanisms of metformin: an overview. Clin. Sci. (Lond.) 122 253-270 (2012)

43. Bailey, C. J., Wilcock, C. \& Scarpello, J. H. Metformin and the intestine. Diabetologia 51,1552-1553 (2008).

44. Madiraju, A. K. et al. Metformin suppresses gluconeogenesis by inhibiting mitochondrial glycerophosphate dehydrogenase. Nature $\mathbf{5 1 0}$, 542-546 (2014).

45. Buse, J. B. et al. The primary glucose-lowering effect of metformin resides in the gut, not the circulation: results from short-term pharmacokinetic and 12-week dose-ranging studies. Diabetes Care 39, 198-205 (2016).

46. Lindsay, J. R. et al. Inhibition of dipeptidyl peptidase IV activity by oral metformin in type 2 diabetes. Diabet. Med. 22, 654-657 (2005).

47. Mannucci, E. et al. Effect of metformin on glucagonlike peptide 1 (GLP-1) and leptin levels in obese nondiabetic subjects. Diabetes Care 24, 489-494 (2001). 
48. Mannuccl, t. et al. tftects of mettormın on glucagon like peptide- 1 levels in obese patients with and without type 2 diabetes. Diabetes Nutr. Metab. 17 336-342 (2004)

49. Maida, A., Lamont, B. J., Cao, X. \& Drucker, D. J. Metformin regulates the incretin receptor axis via a pathway dependent on peroxisome proliferator activated receptor- $\alpha$ in mice. Diabetologia 54 339-349 (2011)

50. Cho, Y. M. \& Kieffer, T. J. New aspects of an old drug: metformin as a glucagon-like peptide 1 (CLP-1) enhancer and sensitiser. Diabetologia 54, 219-222 (2011).

51. Mulherin, A. J. et al. Mechanisms underlying metformin-induced secretion of glucagon-like peptide-1 from the intestinal L cell. Endocrinology 152, 4610-4619 (2011).

52. Um, J. H et al. Activation of 5'-AMP-activated kinase with diabetes drug metformin induces casein kinase $\mathrm{l} \varepsilon(\mathrm{CK} \mid \varepsilon)$-dependent degradation of clock protein mPer2. J. Biol. Chem. 282, 20794-20798 (2007).

53. Barnea, M. et al. Metformin affects the circadian clock and metabolic rhythms in a tissue-specific manner. Biochim. Biophys. Acta 1822, 1796-1806 (2012).

54. Scheen, A. J. Clinical pharmacokinetics of metformin Clin. Pharmacokinet. 30, 359-371 (1996).

55. Grant, P. J. Beneficial effects of metformin on haemostasis and vascular function in man. Diabetes Metab. 29, 6S44-6S52 (2003).

56. Del Prato, S., Bianchi, C. \& Marchetti, P. $\beta$-cell function and anti-diabetic pharmacotherapy. Diabetes Metab. Res. Rev. 23, 518-527 (2007)

57. Dujic, T. et al. Association of organic cation transporter 1 with intolerance to metformin in type 2 diabetes: a GoDARTS study. Diabetes 64 1786-1793 (2015).

58. Heaf, J. Metformin in chronic kidney disease: time for a rethink. Perit. Dial. Int. 34, 353-357 (2014).

59. Scheen, A. J. \& Paquot, N. Metformin revisited: a critical review of the benefit-risk balance in at-risk patients with type 2 diabetes. Diabetes Metab. 39, 179-190 (2013)

60. Eurich, D. T et al Comparative safety and effectiveness of metformin in patients with diabetes mellitus and heart failure: systematic review of observational studies involving 34,000 patients. Circ. Heart Fail. 6, 395-402 (2013).

61. Hitchings, A. W., Archer, J. R. Srivastava, S. A. \& Baker, E. H. Safety of metformin in patients with chronic obstructive pulmonary disease and type 2 diabetes mellitus. COPD 12, 126-131 (2015).

62. Hung, S. C. et al. Metformin use and mortality in patients with advanced chronic kidney disease: national, retrospective, observational, cohort study. Lancet Diabetes Endocrinol. 3, 605-614 (2015).

63. Salpeter, S. R., Greyber, E., Pasternak, G. A. \& Salpeter, E. E. Risk of fatal and nonfatal lactic acidosis with metformin use in type 2 diabetes mellitus. Cochrane Database Syst. Rev. 4, CD002967 (2010).

64. UK Prospective Diabetes Study (UKPDS) Group. Effect of intensive blood-glucose control with metformin on complications in overweight patients with type 2 diabetes (UKPDS 34). Lancet 352 854-865 (1998)

65. Ferrannini, E. \& DeFronzo, R. A. Impact of glucoselowering drugs on cardiovascular disease in type 2 diabetes. Eur. Heart J. 36, 2288-2296 (2015).

66. Henquin, J. C. The fiftieth anniversary of hypoglycaemic sulphonamides. How did the mother compound work? Diabetologia 35, 907-912 (1992).

67. Ashcroft, F. M. \& Gribble, F. M. ATP-sensitive K channels and insulin secretion: their role in health and disease. Diabetologia 42, 903-919 (1999).

68. Groop, L. C. Sulfonylureas in NIDDM. Diabetes Care 15, 737-754 (1992)

69. Lebovitz, H. E. Insulin secretagogues: old and new. Diabetes Rev. 7, 139-153 (1999).

70. Rendell, M. The role of sulphonylureas in the management of type 2 diabetes mellitus. Drugs 64 1339-1358 (2004)

71. Abe, M., Okada, K. \& Soma, M. Antidiabetic agents in patients with chronic kidney disease and end-stage renal disease on dialysis: metabolism and clinical practice. Curr. Drug Metab. 12, 57-69 (2011).

72. Scheen, A. J. Pharmacokinetic considerations for the treatment of diabetes in patients with chronic kidney disease. Expert Opin. Drug Metab. Toxicol. 9 , 529-550 (2013).
15. Arnouts, $\mathrm{P}$ et al. Gilucose-lowerıng drugs in patıents with chronic kidney disease: a narrative review on pharmacokinetic properties. Nephrol. Dial. Transplant. 29, 1284-1300 (2014)

74. Schernthaner, G. et al. GUIDE study: double-blind comparison of once-daily gliclazide MR and glimepiride in type 2 diabetic patients. Eur. J. Clin Invest. 34, 535-542 (2004).

75. Carlson, R. F., Isley, W. L., Ogrinc, F. G. \& Klobucar, T. R. Efficacy and safety of reformulated, micronized glyburide tablets in patients with noninsulin-dependent diabetes mellitus: a multicenter, double-blind, randomized trial. Clin. Ther. 15, 788-796 (1993).

76. Chung, M. et al. Pharmacokinetics and pharmacodynamics of extended-release glipizide GITS compared with immediate-release glipizide in patients with type II diabetes mellitus. J. Clin. Pharmacol. 42 , 651-657 (2002)

77. UK Hypoglycaemia Study Group. Risk of hypoglycaemia in types 1 and 2 diabetes: effects of treatment modalities and their duration. Diabetologia 50, 1140-1147 (2007)

78. Barnett, A. H. et al. The efficacy of self-monitoring of blood glucose in the management of patients with type 2 diabetes treated with a gliclazide modified release-based regimen. A multicentre, randomized, parallel-group, 6-month evaluation (DINAMIC study). Diabetes Obes. Metab. 10, 1239-1247 (2008).

79. Meinert, C. L., Knatterud, G. L., Prout, T. E. \& Klimt, C. R. A study of the effects of hypoglycemic agents on vascular complications in patients with adult-onset diabetes. II. Mortality results. Diabetes 19 (Suppl.), 789-830 (1970).

80. US National Library of Science. ClinicalTrials.gov https://clinicaltrials.gov/ct2/show/NCT01243424 (2016).

81. Campbell, I. W. Nateglinide - current and future role in the treatment of patients with type 2 diabetes mellitus. Int. J. Clin. Pract. 59, 1218-1228 (2005).

82. Dornhorst, A. Insulinotropic meglitinide analogues. Lancet 358, 1709-1716 (2001)

83. Guardado-Mendoza, R., Prioletta, A., JiménezCeja, L. M., Sosale, A. \& Folli, F. The role of nateglinide and repaglinide, derivatives of meglitinide, in the treatment of type 2 diabetes mellitus. Arch. Med. Sci. 9, 936-943 (2013)

84. Scheen, A. J. Drug-drug and food-drug pharmacokinetic interactions with new insulinotropic agents repaglinide and nateglinide. Clin. Pharmacokinet. 46, 93-108 (2007)

85. Panelo, A. \& Wing, J. R. Repaglinide/bedtime NPH insulin is comparable to twice-daily NPH insulin Diabetes Care 28, 1789-1790 (2005).

86. Lund, S. S. et al. Combining insulin with metformin or an insulin secretagogue in non-obese patients with type 2 diabetes: 12 month, randomised, double blind trial. BMJ 339, b4324 (2009).

87. Rosenstock, J. et al. Repaglinide versus nateglinide monotherapy: a randomized, multicenter study. Diabetes Care 27, 1265-1270 (2004).

88. Madsbad, S., Kilhovd, B., Lager, I., Mustajoki, P. \& Dejgaard, A. Comparison between repaglinide and glipizide in type 2 diabetes mellitus: a 1-year multicentre study. Diabet. Med. 18, 395-401 (2001).

89. Marbury, T., Huang, W. C., Strange, P. \& Lebovitz, H. Repaglinide versus glyburide: a one-year comparison trial. Diabetes Res. Clin. Pract. 43, 155-166 (1999).

90. Meneilly, G. S. Effect of repaglinide versus glyburide on postprandial glucose and insulin values in elderly patients with type 2 diabetes. Diabetes Technol. Ther. 13, 63-65 (2011).

91. Schwarz, S. L. et al. Nateglinide, alone or in combination with metformin, is effective and well tolerated in treatment naïve elderly patients with type 2 diabetes. Diabetes Obes. Metab. 10, 652-660 (2008).

92. Bellomo Damato, A., Stefanelli, G., Laviola, L. Giorgino, R. \& Giorgino, F. Nateglinide provides tighter glycaemic control than glyburide in patients with type 2 diabetes with prevalent postprandial hyperglycaemia. Diabet. Med. 28, 560-566 (2011)

93. Hu, S. et al. Pancreatic $\beta$-cell K(ATP) channel activity and membrane-binding studies with nateglinide: a comparison with sulfonylureas and repaglinide. J. Pharmacol. Exp. Ther. 293, 444-452 (2000)

94. NAVIGATOR Study Group et al. Effect of nateglinide on the incidence of diabetes and cardiovascular events. N. Engl. J. Med. 362, 1463-1476 (2010).

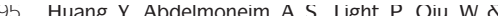
Simpson, S. H. Comparative cardiovascular safety of insulin secretagogues following hospitalization for ischemic heart disease among type 2 diabetes patients: a cohort study. J. Diabetes Compl. 29, 196-202 (2015).

96. Bailey, C. J. Diabetes Therapies: Treating Hyperglycaemia 77-82 (MedEd UK Limited, 2009).

97. Ueno, H. et al. Effects of miglitol, acarbose, and sitagliptin on plasma insulin and gut peptides in type 2 diabetes mellitus: a crossover study. Diabetes Ther. 6, 187-196 (2015)

98. Joshi, S. R. et al. Therapeutic potential of $\alpha$-glucosidase inhibitors in type 2 diabetes mellitus: an evidence-based review. Expert Opin. Pharmacother. 16, 1959-1981 (2015)

99. Yang, W. et al. Acarbose compared with metformin as initial therapy in patients with newly diagnosed type 2 diabetes: an open-label, non-inferiority randomised trial. Lancet Diabetes Endocrinol. 2, 46-55 (2014).

100. van de Laar, F. A. et al. Is acarbose equivalent to tolbutamide as first treatment for newly diagnosed type 2 diabetes in general practice? A randomised controlled trial. Diabetes Res. Clin. Pract. 63, 57-65 (2004).

101. Chiasson, J. L. et al. Acarbose for prevention of type 2 diabetes mellitus: the STOP-NIDDM randomised trial. Lancet 359, 2072-2077 (2002).

102. Chiasson, J. L. et al. Acarbose treatment and the risk of cardiovascular disease and hypertension in patients with impaired glucose tolerance: the STOP-NIDDM trial. JAMA 290, 486-494 (2003).

103. Holman, R. R. et al. Rationale for and design of the Acarbose Cardiovascular Evaluation (ACE) trial. Am. Heart J. 168, 23-29 (2014).

104. Yki-Järvinen, H. Thiazolidinediones. N. Engl. J. Med. 351, 1106-1118 (2004)

105. Hauner, H. The mode of action of thiazolidinediones Diabetes Metab. Res. Rev. 18, S10-S15 (2002).

106. Scheen, A. J. Pharmacokinetic interactions with thiazolidinediones. Clin. Pharmacokinet. 46, 1-12 (2007)

107. Rosenstock, J., Einhorn, D., Hershon, K., Glazer, N. B. $\& Y u$, S. Efficacy and safety of pioglitazone in type 2 diabetes: a randomised, placebo-controlled study in patients receiving stable insulin therapy. Int. J. Clin. Pract. 56, 251-257 (2002).

108. Charbonnel, B. et al. Long-term efficacy and tolerability of add-on pioglitazone therapy to failing monotherapy compared with addition of gliclazide or metformin in patients with type 2 diabetes. Diabetologia 48, 1093-1104 (2005).

109. Punthakee, Z. et al. Impact of rosiglitazone on body composition, hepatic fat, fatty acids, adipokines and glucose in persons with impaired fasting glucose or impaired glucose tolerance: a sub-study of the DREAM trial. Diabet. Med. 31, 1086-1092 (2014).

110. Loke, Y. K., Singh, S. \& Furberg, C. D. Long-term use of thiazolidinediones and fractures in type 2 diabetes: a meta-analysis. CMAJ 180, 32-39 (2009)

111. Schwartz, A. V. et al. Effects of TZD use and discontinuation on fracture rates in ACCORD bone study. J. Clin. Endocrinol. Metab. 100, 4059-4066 (2015).

112. Billington, E. O., Grey, A. \& Bolland, M. J. The effect of thiazolidinediones on bone mineral density and bone turnover: systematic review and meta-analysis. Diabetologia 58, 2238-2246 (2015).

113. Nissen, S. E. \& Wolski, K. Effect of rosiglitazone on the risk of myocardial infarction and death from cardiovascular causes. N. Engl. J. Med. 356 , 2457-2471 (2007)

114. Mahaffey, K. W. et al. Results of a reevaluation of cardiovascular outcomes in the RECORD trial. Am. Heart J. 166, 240-249.e1 (2013).

115. Winkler, K. et al. Pioglitazone reduces atherogenic dense LDL particles in nondiabetic patients with arterial hypertension. Diabetes Care 26, 2588-2594 (2003).

116. Erdmann, E. et al. The effect of pioglitazone on recurrent myocardial infarction in 2,445 patients with type 2 diabetes and previous myocardial infarction: results from the PROactive (PROactive 05) Study. J. Am. Coll. Cardiol. 49, 1772-1780 (2007).

117. Wilcox, R. et al. Effects of pioglitazone in patients with type 2 diabetes with or without previous stroke results from PROactive (PROspective pioglitAzone Clinical Trial In macroVascular Events 04). Stroke 38 , 865-873 (2007)

118. Pfister, R., Cairns, R., Erdmann, E. \& Schneider, C. A A clinical risk score for heart failure in patients with type 2 diabetes and macrovascular disease: an analysis of the PROactive study. Int. J. Cardiol. 162 , 112-116 (2013). 
119. Nissen, S. E. et al. Comparison of pioglitazone versus glimepiride on progression of coronary atherosclerosis in patients with type 2 diabetes: the PERISCOPE randomized controlled trial. JAMA 299, 1561-1573 (2008).

120. Mazzone, T. et al. Effect of pioglitazone compared with glimepiride on carotid intima-media thickness in type 2 diabetes: a randomized trial. JAMA 296 2572-2581 (2006).

121. Hughes, A. D. et al. A randomized placebo controlled double blind crossover study of pioglitazone on left ventricular diastolic function in type 2 diabetes. Int J. Cardiol. 167, 1329-1332 (2013).

122. Straznicky, N. E. et al. A randomized controlled trial of the effects of pioglitazone treatment on sympathetic nervous system activity and cardiovascular function in obese subjects with metabolic syndrome. J. Clin. Endocrinol. Metab. 99, E1701-E1707 (2014).

123. Palalau, A. I., Tahrani, A. A., Piya, M. K. \& Barnett, A. H. DPP-4 inhibitors in clinical practice. Postgrad. Med. 121, 70-100 (2009).

124. McKeage, K. Trelagliptin: first global approval. Drugs 75, 1161-1164 (2015)

125. Burness, C. B. Omarigliptin: first global approval. Drugs 75, 1947-1952 (2015)

126. Elrick, H., Stimmler, L., Hlad, C. J. \& Arai, Y. Plasma insulin response to oral and intravenous glucose administration. J. Clin. Endocrinol. Metab. 24 1076-1082 (1964).

127. Nauck, M. A. et al. Incretin effects of increasing glucose loads in man calculated from venous insulin and C-peptide responses. J. Clin. Endocrinol. Metab. 63, 492-498 (1986)

128. Baggio, L. L. \& Drucker, D. J. Biology of incretins: GLP-1 and GIP. Gastroenterology 132, 2131-2157 (2007).

129. Fehmann, H. C., Göke, R. \& Göke, B. Cell and molecular biology of the incretin hormones glucagonlike peptide-I and glucose-dependent insulin releasing polypeptide. Endocr. Rev. 16, 390-410 (1995).

130. Gautier, J. F., Choukem, S. P. \& Girard, J. Physiology of incretins (GIP and GLP-1) and abnormalities in type 2 diabetes. Diabetes Metab. 34, S65-S72 (2008).

131. Dupre, J., Ross, S. A., Watson, D. \& Brown, J. C. Stimulation of insulin secretion by gastric inhibitory polypeptide in man. J. Clin. Endocrinol. Metab. 37, 826-828 (1973)

132. Trümper, A. et al. Glucose-dependent insulinotropic polypeptide is a growth factor for $\beta$ (INS-1) cells by pleiotropic signaling. Mol. Endocrinol. 15 1559-1570 (2001)

133. Yip, R. G. $\&$ Wolfe, M. M. GIP biology and fat metabolism. Life Sci. 66, 91-103 (2000).

134. Ahrên, B. Gut peptides and type 2 diabetes mellitus treatment. Curr. Diab. Rep. 3, 365-372 (2003).

135. Barnett, A. H. New treatments in type 2 diabetes: a focus on the incretin-based therapies. Clin. Endocrinol. (Oxf.) 70, 343-353 (2009)

136. Drucker, D. J., Philippe, J., Mojsov, S., Chick, W. L. \& Habener, J. F. Glucagon-like peptide I stimulates insulin gene expression and increases cyclic AMP levels in a rat islet cell line. Proc. Natl Acad. Sci. USA 84, 3434-3438 (1987)

137. Drucker, D. J. Glucagon-like peptides: regulators of cell proliferation, differentiation, and apoptosis. $\mathrm{Mol}$. Endocrinol. 17, 161-171 (2003)

138. Malmgren, S. \& Ahrên, B. DPP-4 inhibition contributes to the prevention of hypoglycaemia through a GIP-glucagon counterregulatory axis in mice. Diabetologia 58, 1091-1099 (2015)

139. Farngren, J., Persson, M., Schweizer, A., Foley, J. E. \& Ahrên, B. Vildagliptin reduces glucagon during hyperglycemia and sustains glucagon counterregulation during hypoglycemia in type 1 diabetes. J. Clin. Endocrinol. Metab. 97, 3799-3806 (2012).

140. Hansen, L., Deacon, C. F., Orskov, C. \& Holst, J. J. Glucagon-like peptide-1-(7-36)amide is transformed to glucagon-like peptide-1-(9-36)amide by dipeptidyl peptidase IV in the capillaries supplying the $L$ cells of the porcine intestine. Endocrinology 140, 5356-5363 (1999).

141. Deacon, C. F., Johnsen, A. H. \& Holst, J. J. Degradation of glucagon-like peptide- 1 by human plasma in vitro yields an $\mathrm{N}$-terminally truncated peptide that is a major endogenous metabolite in vivo. J. Clin. Endocrinol. Metab. 80, 952-957 (1995).

142. Mentlein, R. Dipeptidyl-peptidase IV (CD26) - role in the inactivation of regulatory peptides. Regul. Pept. 85, 9-24 (1999).
145. He, Y L et al. Pharmacokinetics and pharmacodynamics of vildagliptin in patients with type 2 diabetes mellitus. Clin. Pharmacokinet. 46 577-588 (2007)

144. Herman, G. A. et al. Pharmacokinetics and pharmacodynamics of sitagliptin, an inhibitor of dipeptidyl peptidase IV, in healthy subjects: results from two randomized, double-blind, placebocontrolled studies with single oral doses. Clin Pharmacol. Ther. 78, 675-688 (2005).

145. Nauck, M. A. \& El-Ouaghlidi, A. The therapeutic actions of DPP-IV inhibition are not mediated by glucagon-like peptide-1. Diabetologia 48, 608-611 (2005).

146. Mearns, E. S. et al. Comparative efficacy and safety of antidiabetic drug regimens added to metformin monotherapy in patients with type 2 diabetes: a network meta-analysis. PLOS ONE 10, e0125879 (2015).

147. Day, C. \& Bailey, C. J. Pharmacotherapies to manage diabesity: an update. Diabes. Pract. 4, 14-23 (2015)

148. Tahrani, A. A., Piya, M. K. \& Barnett, A. H. Saxagliptin: a new DPP-4 inhibitor for the treatment of type 2 diabetes mellitus. Adv. Ther. 26, 249-262 (2009).

149. Tahrani, A. A., Piya, M. K. \& Barnett, A. H. Drug evaluation: vildagliptin-metformin single-tablet combination. Adv. Ther. 26, 138-154 (2009).

150. Deacon, C. F. \& Lebovitz, H. E. Comparative review of dipeptidyl peptidase-4 inhibitors and sulphonylureas. Diabetes Obes. Metab. 18, 333-347 (2016).

151. Deacon, C. F. Dipeptidyl peptidase-4 inhibitors in the treatment of type 2 diabetes: a comparative review. Diabetes Obes. Metab. 13, 7-18 (2011)

152. Scheen, A. J. Dipeptidylpeptidase- 4 inhibitors (gliptins). Clin. Pharmacokinet. 49, 573-588 (2010).

153. Esposito, K. et al. A nomogram to estimate the $\mathrm{HbA} 1 \mathrm{c}$ response to different DPP-4 inhibitors in type 2 diabetes: a systematic review and meta-analysis of 98 trials with 24163 patients. BMJ Open 5 , e005892 (2015).

154. Karagiannis, T., Paschos, P., Paletas, K. Matthews, D. R. \& Tsapas, A. Dipeptidyl peptidase-4 inhibitors for treatment of type 2 diabetes mellitus in the clinical setting: systematic review and metaanalysis. BMJ 344, e 1369 (2012)

155. Zhang, Y. et al. Head-to-head comparison of dipeptidyl peptidase-IV inhibitors and sulfonylureas - a metaanalysis from randomized clinical trials. Diabetes Metab. Res. Rev. 30, 241-256 (2014).

156. Derosa, G. et al. A randomized, double-blind, comparative therapy evaluating sitagliptin versus glibenclamide in type 2 diabetes patients already treated with pioglitazone and metformin: a 3-year study. Diabetes Technol. Ther. 15, 214-222 (2013).

157. Rosenstock, J., Wilson, C. \& Fleck, P. Alogliptin versus glipizide monotherapy in elderly type 2 diabetes mellitus patients with mild hyperglycaemia: a prospective, double-blind, randomized, 1-year study Diabetes Obes. Metab. 15, 906-914 (2013)

158. Gallwitz, B. et al. 2-year efficacy and safety of linagliptin compared with glimepiride in patients with type 2 diabetes inadequately controlled on metformin: a randomised, double-blind, non-inferiority trial. Lancet 380, 475-483 (2012).

159. Filozof, C. \& Gautier, J. F. A comparison of efficacy and safety of vildagliptin and gliclazide in combination with metformin in patients with type 2 diabetes inadequately controlled with metformin alone: a 52-week, randomized study. Diabet. Med. 27 , 318-326 (2010)

160. Matthews, D. R. et al. Vildagliptin add-on to metformin produces similar efficacy and reduced hypoglycaemic risk compared with glimepiride, with no weight gain results from a 2-year study. Diabetes Obes. Metab. 12, 780-789 (2010)

161. Foley, J. E. \& Sreenan, S. Efficacy and safety comparison between the DPP-4 inhibitor vildagliptin and the sulfonylurea gliclazide after two years of monotherapy in drug-naive patients with type 2 diabetes. Horm. Metab. Res. 41, 905-909 (2009).

162. Arjona Ferreira, J. C. et al. Efficacy and safety of sitagliptin in patients with type 2 diabetes and ESRD receiving dialysis: a 54-week randomized trial. $A m$. J. Kidney Dis. 61, 579-587 (2013).

163. Arjona Ferreira, J. C. et al. Efficacy and safety of sitagliptin versus glipizide in patients with type 2 diabetes and moderate-to-severe chronic renal insufficiency. Diabetes Care 36, 1067-1073 (2013).

164. Seck, T. et al. Safety and efficacy of treatment with sitagliptin or glipizide in patients with type 2 diabetes inadequately controlled on mettormin: a 2-year study. Int. J. Clin. Pract. 64, 562-576 (2010).

165. Kim, Y. G. et al. Differences in the glucose-lowering efficacy of dipeptidyl peptidase-4 inhibitors between Asians and non-Asians: a systematic review and metaanalysis. Diabetologia 56, 696-708 (2013).

166. Zimdahl, H. et al. Influence of TCF7L2 gene variants on the therapeutic response to the dipeptidylpeptidase-4 inhibitor linagliptin Diabetologia 57, 1869-1875 (2014).

167. Esposito, K. et al. Glycaemic durability with dipeptidyl peptidase- 4 inhibitors in type 2 diabetes: a systematic review and meta-analysis of long-term randomised controlled trials. BMJ Open 4, e005442 (2014).

168. Scheen, A. J., Charpentier, G., Ostgren, C. J., Hellqvist, A. \& Gause-Nilsson, I. Efficacy and safety of saxagliptin in combination with metformin compared with sitagliptin in combination with metformin in adult patients with type 2 diabetes mellitus. Diabetes Metab. Res. Rev. 26, 540-549 (2010)

169. Kothny, W., Lukashevich, V., Foley, J. E., Rendell, M. S. $\Sigma$ Schweizer, A. Comparison of vildagliptin and sitagliptin in patients with type 2 diabetes and severe renal impairment: a randomised clinical trial. Diabetologia 58, 2020-2026 (2015)

170. Inagaki, N., Onouchi, H., Maezawa, H., Kuroda, S. \& Kaku, K. Once-weekly trelagliptin versus daily alogliptin in Japanese patients with type 2 diabetes: a randomised, double-blind, phase 3, non-inferiority study. Lancet Diabetes Endocrinol. 3, 191-197 (2015).

171. Gantz, I., Okamoto, T., Ito, Y., Okuyama, K. \& Engel, S. S. Effect of omarigliptin, a novel once-weekly DPP-4 inhibitor, in Japanese patients with type 2 diabetes: a placebo-and sitagliptin-controlled trial. Diabetologia 57, S55 (2014)

172. Park, H., Park, C., Kim, Y. \& Rascati, K. L. Efficacy and safety of dipeptidyl peptidase- 4 inhibitors in type 2 diabetes: meta-analysis. Ann. Pharmacother. 46 1453-1469 (2012)

173. Ussher, J. R. \& Drucker, D. J. Cardiovascular biology of the incretin system. Endocr. Rev. 33, 187-215 (2012).

174. Scheen, A. J. Cardiovascular effects of gliptins. Nat Rev. Cardiol. 10, 73-84 (2013)

175. Scirica, B. M. et al. Saxagliptin and cardiovascular outcomes in patients with type 2 diabetes mellitus. N. Engl. J. Med. 369, 1317-1326 (2013).

176. Udell, J. A. et al. Saxagliptin and cardiovascular outcomes in patients with type 2 diabetes and moderate or severe renal impairment: observations from the SAVOR-TIMI 53 trial. Diabetes Care 38, 696-705 (2015).

177. White, W. B. et al. Alogliptin after acute coronary syndrome in patients with type 2 diabetes. N. Engl. J. Med. 369, 1327-1335 (2013)

178. Green, J. B. et al. Effect of sitagliptin on cardiovascular outcomes in type 2 diabetes. N. Engl. J. Med. 373 232-242 (2015)

179. Li, L. et al. Incretin treatment and risk of pancreatitis in patients with type 2 diabetes mellitus: systematic review and meta-analysis of randomised and nonrandomised studies. BMJ 348, g2366 (2014)

180. Roshanov, P. S. \& Dennis, B. B. Incretin-based therapies are associated with acute pancreatitis: meta-analysis of large randomized controlled trials. Diabetes Res. Clin. Pract. 110, e13-e17 (2015).

181. Eng, J., Kleinman, W. A., Singh, L., Singh, G. \& Raufman, J. P. Isolation and characterization of exendin-4, an exendin-3 analogue, from Heloderma suspectum venom. Further evidence for an exendin receptor on dispersed acini from guinea pig pancreas. J. Biol. Chem. 267, 7402-7405 (1992)

182. Barnett, A. Exenatide. Expert. Opin. Pharmacother. 8, 2593-2608 (2007)

183. Drucker, D. J. et al. Exenatide once weekly versus twice daily for the treatment of type 2 diabetes: a randomised, open-label, non-inferiority study. Lancet 372, 1240-1250 (2008)

184. Green, B. D. \& Flatt, P. R. Incretin hormone mimetics and analogues in diabetes therapeutics. Best. Pract. Res. Clin. Endocrinol. Metab. 21, 497-516 (2007).

185. Christensen, M. \& Knop, F. K. Once-weekly GLP-1 agonists: how do they differ from exenatide and liraglutide? Curr. Diab. Rep. 10, 124-132 (2010).

186. Christensen, M., Knop, F. K., Holst, J. J. \& Vilsboll, T. Lixisenatide, a novel GLP-1 receptor agonist for the treatment of type 2 diabetes mellitus. IDrugs 12 . 503-513 (2009)

187. Jimenez-Solem, E., Rasmussen, M. H., Christensen, M. \& Knop, F. K. Dulaglutide, a long-acting GLP-1 analog fused with an Fc antibody fragment for the potential treatment of type 2 diabetes. Curr. Opin. Mol. Ther. 12, 790-797 (2010). 
188. Nauck, M. A Vardarli, I., Deacon, C. F., Holst, J. J. \& Meier, J. J. Secretion of glucagon-like peptide(GLP-1) in type 2 diabetes: what is up, what is down? Diabetologia 54, 10-18 (2011).

189. Kolterman, O. G. et al. Pharmacokinetics, pharmacodynamics, and safety of exenatide in patients with type 2 diabetes mellitus. Am. J. Health Syst. Pharm. 62, 173-181 (2005).

190. Copley, K. et al. Investigation of exenatide elimination and its in vivo and in vitro degradation. Curr. Drug Metab. 7, 367-374 (2006).

191. Edwards, C. M. et al. Exendin-4 reduces fasting and postprandial glucose and decreases energy intake in healthy volunteers. Am. J. Physiol. Endocrinol. Metab. 281, E155-E161 (2001).

192. Simonsen, L., Holst, J. J. \& Deacon, C. F. Exendin-4, but not glucagon-like peptide- 1 , is cleared exclusively by glomerular filtration in anaesthetised pigs. Diabetologia 49, 706-712 (2006).

193. Linnebjerg, H. et al. Effect of renal impairment on the pharmacokinetics of exenatide. Br. J. Clin. Pharmacol. 64, 317-327 (2007).

194. Jose, B., Tahrani, A. A., Piya, M. K. \& Barnett, A. H. Exenatide once weekly: clinical outcomes and patient satisfaction. Patient Prefer. Adherence 4, 313-324 (2010).

195. Elbrønd, B. et al. Pharmacokinetics, pharmacodynamics, safety, and tolerability of a singledose of NN2211, a long-acting glucagon-like peptide derivative, in healthy male subjects. Diabetes Care $\mathbf{2 5}$ 1398-1404 (2002).

196. Juhl, C. B. et al. Bedtime administration of NN2211, a long-acting GLP-1 derivative, substantially reduces fasting and postprandial glycemia in type 2 diabetes. Diabetes 51, 424-429 (2002).

197. Agersø, H., Jensen, L. B., Elbrønd, B., Rolan, P. \& Zdravkovic, M. The pharmacokinetics, pharmacodynamics, safety and tolerability of NN2211, a new long-acting GLP-1 derivative, in healthy men. Diabetologia 45, 195-202 (2002).

198. Barnett, A. H. Lixisenatide: evidence for its potential use in the treatment of type 2 diabetes. Core Evid. 6 , 67-79 (2011)

199. Matthews, J. E. et al. Pharmacodynamics, pharmacokinetics, safety, and tolerability of albiglutide, a long-acting glucagon-like peptide-1 mimetic, in patients with type 2 diabetes. J. Clin Endocrinol. Metab. 93, 4810-4817 (2008).

200. Barrington, P. et al. A 5-week study of the pharmacokinetics and pharmacodynamics of LY2189265, a novel, long-acting glucagon-like peptide- 1 analogue, in patients with type 2 diabetes. Diabetes Obes. Metab. 13, 426-433 (2011).

201. Hurren, K. M. \& Pinelli, N. R. Drug-drug interactions with glucagon-like peptide-1 receptor agonists. Ann. Pharmacother. 46, 710-717 (2012).

202. Buse, J. B. et al. Effects of exenatide (exendin-4) on glycemic control over 30 weeks in sulfonylurea-treated patients with type 2 diabetes. Diabetes Care 27, 2628-2635 (2004).

203. DeFronzo, R. A. et al. Effects of exenatide (exendin-4) on glycemic control and weight over 30 weeks in metformin-treated patients with type 2 diabetes. Diabetes Care 28, 1092-1100 (2005).

204. Kendall, D. M. et al. Effects of exenatide (exendin-4) on glycemic control over 30 weeks in patients with type 2 diabetes treated with metformin and a sulfonylurea. Diabetes Care 28, 1083-1091 (2005).

205. Buse, J. B. et al. Liraglutide once a day versus exenatide twice a day for type 2 diabetes: a 26-week randomised, parallel-group, multinational, open-label trial (LEAD-6). Lancet 374, 39-47 (2009)

206. Garber, A. et al. Liraglutide versus glimepiride monotherapy for type 2 diabetes (LEAD-3 Mono): a randomised, 52-week, phase III, double-blind, paralletreatment trial. Lancet 373, 473-481 (2009).

207. Marre, M. et al. Liraglutide, a once-daily human GLP-1 analogue, added to a sulphonylurea over 26 weeks produces greater improvements in glycaemic and weight control compared with adding rosiglitazone or placebo in subjects with Type 2 diabetes (LEAD-1 SU). Diabet. Med. 26, 268-278 (2009).

208. Nauck, M. et al. Efficacy and safety comparison of liraglutide, glimepiride, and placebo, all in combination with metformin, in type 2 diabetes: the LEAD (liraglutide effect and action in diabetes)-2 study. Diabetes Care 32, 84-90 (2009).

209. Zinman, B. et al. Efficacy and safety of the human glucagon-like peptide-1 analog liraglutide in combination with metformin and thiazolidinedione in patients with type 2 diabetes (LEAD-4 Met + TZD). Diabetes Care 32, 1224-1230 (2009).

210. Bolli, G. B. et al. Efficacy and safety of lixisenatide once daily versus placebo in people with Type-2 diabetes insufficiently controlled on metformin (GetGoal-F1). Diabet. Med. 31, 176-184 (2014).

211. Ahrên, B., Leguizamo Dimas, A., Miossec, P., Saubadu, S. \& Aronson, R. Efficacy and safety of lixisenatide once-daily morning or evening injections in type 2 diabetes inadequately controlled on metformin (GetGoal-M). Diabetes Care 36 , 2543-2550 (2013).

212. Pinget, M. et al. Efficacy and safety of lixisenatide once daily versus placebo in type 2 diabetes insufficiently controlled on pioglitazone (GetGoal-P). Diabetes Obes. Metab. 15, 1000-1007 (2013).

213. Riddle, M. C. et al. Adding once-daily lixisenatide for type 2 diabetes inadequately controlled with newly initiated and continuously titrated basal insulin glargine: a 24-week, randomized, placebo-controlled study (GetGoal-Duo 1). Diabetes Care 36 , 2497-2503 (2013)

214. Seino, Y., Min, K. W., Niemoeller, E. \& Takami, A Randomized, double-blind, placebo-controlled trial of the once-daily GLP-1 receptor agonist lixisenatide in Asian patients with type 2 diabetes insufficiently controlled on basal insulin with or without a sulfonylurea (GetGoal-L-Asia). Diabetes Obes. Metab. 14, 910-917 (2012).

215. Fonseca, V. A. et al. Efficacy and safety of the oncedaily GLP-1 receptor agonist lixisenatide in monotherapy: a randomized, double-blind, placebocontrolled trial in patients with type 2 diabetes (GetGoal-Mono). Diabetes Care 35, 1225-1231 (2012).

216. Rosenstock, J. et al. Efficacy and safety of lixisenatide once daily versus exenatide twice daily in type 2 diabetes inadequately controlled on metformin: a 24-week, randomized, open-label, active-controlled study (GetGoal-X). Diabetes Care 36, 2945-2951 (2013).

217. Ratner, R. E., Rosenstock, J. \& Boka, G. Dosedependent effects of the once-daily GLP-1 receptor agonist lixisenatide in patients with type 2 diabetes inadequately controlled with metformin: a randomized, double-blind, placebo-controlled trial. Diabet. Med. 27, 1024-1032 (2010).

218. Bergenstal, R. M. et al. Efficacy and safety of exenatide once weekly versus sitagliptin or pioglitazone as an adjunct to metformin for treatment of type 2 diabetes (DURATION-2): a randomised trial. Lancet 376, 431-439 (2010).

219. Blevins, T. et al. DURATION-5: exenatide once weekly resulted in greater improvements in glycemic contro compared with exenatide twice daily in patients with type 2 diabetes. J. Clin. Endocrinol. Metab. 96 1301-1310 (2011)

220. Buse, J. B. et al. DURATION-1: exenatide once weekly produces sustained glycemic control and weight loss over 52 weeks. Diabetes Care 33, 1255-1261 (2010)

221. Buse, J. B. et al. Exenatide once weekly versus liraglutide once daily in patients with type 2 diabetes (DURATION-6): a randomised, open-label study. Lancet 381, 117-124 (2013).

222. Diamant, M. et al. Exenatide once weekly versus insulin glargine for type 2 diabetes (DURATION-3) 3 -year results of an open-label randomised trial. Lancet Diabetes Endocrinol. 2, 464-473 (2014).

223. Home, P. D. et al. Efficacy and tolerability of albiglutide versus placebo or pioglitazone over 1 year in people with type 2 diabetes currently taking metformin and glimepiride: HARMONY 5. Diabetes Obes. Metab. 17, 179-187 (2015).

224. Weissman, P. N. et al. HARMONY 4: randomised clinical trial comparing once-weekly albiglutide and insulin glargine in patients with type 2 diabetes inadequately controlled with metformin with or without sulfonylurea. Diabetologia 57, 2475-2484 (2014).

225. Reusch, J. et al. Efficacy and safety of once-weekly glucagon-like peptide 1 receptor agonist albiglutide (HARMONY 1 trial): 52-week primary endpoint results from a randomized, double-blind, placebo-controlled trial in patients with type 2 diabetes mellitus not controlled on pioglitazone, with or without metformin. Diabetes Obes. Metab. 16, 1257-1264 (2014).

226. Ahrén, B. et al. HARMONY 3: 104-week randomized, double-blind, placebo- and active-controlled trial assessing the efficacy and safety of albiglutide compared with placebo, sitagliptin, and glimepiride in patients with type 2 diabetes taking metformin Diabetes Care 37, 2141-2148 (2014).
221. Pratley, R. E et al Once-weekly albiglutide versus once-daily liraglutide in patients with type 2 diabetes inadequately controlled on oral drugs (HARMONY 7) a randomised, open-label, multicentre, non-inferiority phase 3 study. Lancet Diabetes Endocrinol. 2, 289-297 (2014)

228. Reaney, M., Yu, M., Lakshmanan, M., Pechtner, V. \& van Brunt, K. Treatment satisfaction in people with type 2 diabetes mellitus treated with once-weekly dulaglutide: data from the AWARD- 1 and AWARD-3 clinical trials. Diabetes Obes. Metab. 17, 896-903 (2015)

229. Weinstock, R. S. et al. Safety and efficacy of onceweekly dulaglutide versus sitagliptin after 2 years in metformin-treated patients with type 2 diabetes (AWARD-5): a randomized, phase III study. Diabetes Obes. Metab. 17, 849-858 (2015).

230. Dungan, K. M. et al. Once-weekly dulaglutide versus once-daily liraglutide in metformin-treated patients with type 2 diabetes (AWARD-6): a randomised, openlabel, phase 3, non-inferiority trial. Lancet 384, 1349-1357 (2014)

231. Wysham, C. et al. Efficacy and safety of dulaglutide added onto pioglitazone and metformin versus exenatide in type 2 diabetes in a randomized controlled trial (AWARD-1). Diabetes Care 37 2159-2167 (2014).

232. Umpierrez, G., Tofé Povedano, S., Pérez Manghi, F. Shurzinske, L. \& Pechtner, V. Efficacy and safety of dulaglutide monotherapy versus metformin in type 2 diabetes in a randomized controlled trial (AWARD-3) Diabetes Care 37, 2168-2176 (2014).

233. Skrivanek, Z. et al. Dose-finding results in an adaptive, seamless, randomized trial of once-weekly dulaglutide combined with metformin in type 2 diabetes patients (AWARD-5). Diabetes Obes. Metab. 16, 748-756 (2014)

234. Nauck, M. et al. Efficacy and safety of dulaglutide versus sitagliptin after 52 weeks in type 2 diabetes in a randomized controlled trial (AWARD-5). Diabetes Care 37, 2149-2158 (2014)

235. Russell-Jones, D. et al. Liraglutide versus insulin glargine and placebo in combination with metformin and sulfonylurea therapy in type 2 diabetes mellitus (LEAD-5 met + SU): a randomised controlled trial. Diabetologia 52, 2046-2055 (2009).

236. Diamant, M. et al. Once weekly exenatide compared with insulin glargine titrated to target in patients with type 2 diabetes (DURATION-3): an open-label randomised trial. Lancet 375, 2234-2243 (2010).

237. Giorgino, F., Benroubi, M., Sun, J. H. Zimmermann, A. G. \& Pechtner, V. Efficacy and safety of once-weekly dulaglutide versus insulin glargine in patients with type 2 diabetes on metformin and glimepiride (AWARD-2). Diabetes Care 38 , 2241-2249 (2015)

238. Meier, J. J. GLP-1 receptor agonists for individualized treatment of type 2 diabetes mellitus. Nat. Rev. Endocrinol. 8, 728-742 (2012).

239. Harris, K. B. \& McCarty, D. J. Efficacy and tolerability of glucagon-like peptide-1 receptor agonists in patients with type 2 diabetes mellitus. Ther. Adv. Endocrinol. Metab. 6, 3-18 (2015).

240. Klonoff, D. C. et al. Exenatide effects on diabetes, obesity, cardiovascular risk factors and hepatic biomarkers in patients with type 2 diabetes treated for at least 3 years. Curr. Med. Res. Opin. 24 275-286 (2008)

241. Aroda, V. R. et al. Efficacy of GLP-1 receptor agonists and DPP- 4 inhibitors: meta-analysis and systematic review. Clin. Ther. 34, 1247-1258 (2012).

242. Buse, J. B. et al. Use of twice-daily exenatide in Basal insulin-treated patients with type 2 diabetes: a randomized, controlled trial. Ann. Intern. Med. 154, 103-112 (2011).

243. Rosenstock, J. et al. Baseline factors associated with glycemic control and weight loss when exenatide twice daily is added to optimized insulin glargine in patients with type 2 diabetes. Diabetes Care 35, 955-958 (2012)

244. Deacon, C. F., Mannucci, E. \& Ahrén, B. Glycaemic efficacy of glucagon-like peptide-1 receptor agonists and dipeptidyl peptidase- 4 inhibitors as add-on therapy to metformin in subjects with type 2 diabetes - a review and meta analysis. Diabetes Obes. Metab. 14, 762-767 (2012).

245. Henry, R. R. et al. DURATION-1 extension: efficacy and tolerability of exenatide once weekly (OW) over 6 years in patients with T2DM. Diabetes 63, A247 (2014) 
246. Klein, E et al DURATION-1 extension: etticacy and tolerability of exenatide once weekly over 6 years in patients with type 2 diabetes mellitus. Diabetologia 57, S39 (2014).

247. Garber, A. et al. Liraglutide, a once-daily human glucagon-like peptide 1 analogue, provides sustained improvements in glycaemic control and weight for 2 years as monotherapy compared with glimepiride in patients with type 2 diabetes. Diabetes Obes. Metab. 13, 348-356 (2011)

248. Ahmann, A. et al. Efficacy and safety of liraglutide versus placebo added to basal insulin analogues (with or without metformin) in patients with type 2 diabetes: a randomized, placebo-controlled trial. Diabetes Obes. Metab. 17, 1056-1064 (2015).

249. Henry, R. R. et al. Efficacy of anthiyperglycemic therapies and the influence of baseline hemoglobin $A(1 C)$ : a meta-analysis of the liraglutide development program. Endocr. Pract. 17, 906-913 (2011).

250. Tella, S. H. \& Rendell, M. S. Glucagon-like polypeptide agonists in type 2 diabetes mellitus: efficacy and tolerability, a balance. Ther. Adv. Endocrinol. Metab. 6 109-134 (2015).

251. Yu Pan, C. et al. Lixisenatide treatment improves glycaemic control in Asian patients with type 2 diabetes mellitus inadequately controlled on metformin with or without sulfonylurea: a randomized, double-blind, placebo-controlled, 24-week trial (GetGoal-M-Asia). Diabetes Metab. Res. Rev. 30 726-735 (2014)

252. Rosenstock, J. et al. Beneficial effects of once-daily lixisenatide on overall and postprandial glycemic levels without significant excess of hypoglycemia in Type 2 diabetes inadequately controlled on a sulfonylurea with or without metformin (GetGoal-S). J. Diabetes Complications 28, 386-392 (2014).

253. Riddle, M. C. et al. Adding once-daily lixisenatide for type 2 diabetes inadequately controlled by established basal insulin: a 24-week, randomized, placebocontrolled comparison (GetGoal-L). Diabetes Care 36 2489-2496 (2013).

254. Raccah, D., Gourdy, P., Sagnard, L. \& Ceriello, A. Lixisenatide as add-on to oral anti-diabetic therapy: an effective treatment for glycaemic control with body weight benefits in type 2 diabetes. Diabetes Metab. Res. Rev. 30, 742-748 (2014)

255. Schmidt, L. J., Habacher, W., Augustin, T., Krahulec, E. $\S$ Semlitsch, T. A systematic review and meta-analysis of the efficacy of lixisenatide in the treatment of patients with type 2 diabetes. Diabetes Obes. Metab. 16, 769-779 (2014)

256. Ahrén, B. et al. Pronounced reduction of postprandial glucagon by lixisenatide: a meta-analysis of randomized clinical trials. Diabetes Obes. Metab. 16, 861-868 (2014)

257. Charbonnel, B., Bertolini, M., Tinahones, F. J., Domingo, M. P. \& Davies, M. Lixisenatide plus basal insulin in patients with type 2 diabetes mellitus: a meta-analysis. J. Diabetes Complications 28 880-886 (2014)

258. Russell-Jones, D. et al. Efficacy and safety of exenatide once weekly versus metformin, pioglitazone, and sitagliptin used as monotherapy in drug-naive patients with type 2 diabetes (DURATION-4): a 26-week doubleblind study. Diabetes Care 35, 252-258 (2012).

259. Davies, M. et al. Once-weekly exenatide versus onceor twice-daily insulin detemir: randomized, open-label, clinical trial of efficacy and safety in patients with type 2 diabetes treated with metformin alone or in combination with sulfonylureas. Diabetes Care 36, 1368-1376 (2013).

260. Wysham, C. H. et al. Five-year efficacy and safety data of exenatide once weekly: long-term results from the DURATION-1 randomized clinical trial. Mayo Clin. Proc. 90, 356-365 (2015).

261. Rosenstock, J. et al. Potential of albiglutide, a longacting GLP-1 receptor agonist, in type 2 diabetes: a randomized controlled trial exploring weekly, biweekly, and monthly dosing. Diabetes Care 32, 1880-1886 (2009).

262. Karagiannis, T. et al. Efficacy and safety of once-weekly glucagon-like peptide 1 receptor agonists for the management of type 2 diabetes: a systematic review and meta-analysis of randomized controlled trials. Diabetes Obes. Metab. 17, 1065-1074 (2015).

263. Rosenstock, J. et al. Advancing basal insulin replacement in type 2 diabetes inadequately controlled with insulin glargine plus oral agents: a comparison of adding albiglutide, a weekly GLP-1 receptor agonist, versus thrice-daily prandial insulin lispro. Diabetes Care 37, 2317-2325 (2014).
264. Kim, Y G. Hahn, S On, T J., Park, K S \& Cho, Y M Differences in the HbA1c-lowering efficacy of glucagon-like peptide- 1 analogues between Asians and non-Asians: a systematic review and metaanalysis. Diabetes Obes. Metab. 16, 900-909 (2014).

265. Vilsbøll, T., Christensen, M., Junker, A. E., Knop, F. K. \& Gluud, L. L. Effects of glucagon-like peptide-1 receptor agonists on weight loss: systematic review and meta-analyses of randomised controlled trials. BMJ 344, d7771 (2012).

266. Eng, C., Kramer, C. K., Zinman, B. \& Retnakaran, R. Glucagon-like peptide-1 receptor agonist and basal insulin combination treatment for the management of type 2 diabetes: a systematic review and meta-analysis. Lancet $\mathbf{3 8 4}$, 2228-2234 (2014).

267. Potts, J. E. et al. The effect of glucagon-like peptide 1 receptor agonists on weight loss in type 2 diabetes: a systematic review and mixed treatment comparison meta-analysis. PLoS ONE 10, e0126769 (2015).

268. Sun, F. et al. Effect of GLP-1 receptor agonists on waist circumference among type 2 diabetes patients: a systematic review and network meta-analysis. Endocrine 48, 794-803 (2015).

269. Katout, M. et al. Effect of GLP-1 mimetics on blood pressure and relationship to weight loss and glycemia lowering: results of a systematic meta-analysis and meta-regression. Am. J. Hypertens. 27, 130-139 (2014).

270. Sun, F. et al. Impact of GLP-1 receptor agonists on blood pressure, heart rate and hypertension among patients with type 2 diabetes: a systematic review and network meta-analysis. Diabetes Res. Clin. Pract. 110 , 26-37 (2015)

271. Ferdinand, K. C. et al. Effects of the once-weekly glucagon-like peptide- 1 receptor agonist dulaglutide on ambulatory blood pressure and heart rate in patients with type 2 diabetes mellitus. Hypertension 64, 731-737 (2014).

272. Sun, F. et al. Effect of glucagon-like peptide- 1 receptor agonists on lipid profiles among type 2 diabetes: a systematic review and network meta-analysis. Clin. Ther. 37, 225-241 (2015)

273. Egan, A. G. et al. Pancreatic safety of incretin-based drugs - FDA and EMA assessment. N. Engl. J. Med. 370, 794-797 (2014).

274. Wang, T. et al. Using real-world data to evaluate the association of incretin-based therapies with risk of acute pancreatitis: a meta-analysis of $1,324,515$ patients from observational studies. Diabetes Obes. Metab. 17, 32-41 (2015).

275. Giorda, C. B. et al. Incretin-based therapies and acute pancreatitis risk: a systematic review and metaanalysis of observational studies. Endocrine $\mathbf{4 8}$ 461-471 (2015).

276. Pfeffer, M. A. et al. Lixisenatide in patients with type 2 diabetes and acute coronary syndrome. N. Engl. J. Med. 373, 2247-2257 (2015)

277. Lønborg, J. et al. Exenatide reduces reperfusion injury in patients with ST-segment elevation myocardial infarction. Eur. Heart J. 33, 1491-1499 (2012).

278. Gill, A. et al. Effect of exenatide on heart rate and blood pressure in subjects with type 2 diabetes mellitus: a double-blind, placebo-controlled, randomized pilot study. Cardiovasc. Diabetol. 9, 6 (2010).

279. Trujillo, J. M., Nuffer, W. \& Ellis, S. L. GLP-1 receptor agonists: a review of head-to-head clinical studies. Ther. Adv. Endocrinol. Metab. 6, 19-28 (2015).

280. Owens, D. R., Monnier, L. \& Bolli, G. B. Differential effects of GLP-1 receptor agonists on components of dysglycaemia in individuals with type 2 diabetes mellitus. Diabetes Metab. 39, 485-496 (2013)

281. Meier, J. J. et al. Contrasting effects of lixisenatide and liraglutide on postprandial glycemic control, gastric emptying, and safety parameters in patients with type 2 diabetes on optimized insulin glargine with or without metformin: a randomized, open-label trial. Diabetes Care 38, 1263-1273 (2015).

282. Wang, Y. et al. Glucagon-like peptide-1 receptor agonists versus insulin in inadequately controlled patients with type 2 diabetes mellitus: a meta-analysis of clinical trials. Diabetes Obes. Metab. 13, 972-981 (2011).

283. Blonde, L. et al. Once-weekly dulaglutide versus bedtime insulin glargine, both in combination with prandial insulin lispro, in patients with type 2 diabetes (AWARD-4): a randomised, open-label, phase 3, non-inferiority study. Lancet 385 2057-2066 (2015).
284. Gough, S. C. et al. Etticacy and satety of a tixed-ratio combination of insulin degludec and liraglutide (IDegLira) compared with its components given alone results of a phase 3 , open-label, randomised, 26-week, treat-to-target trial in insulin-naive patients with type 2 diabetes. Lancet Diabetes Endocrinol. 2 885-893 (2014).

285. Gough, S. C. et al. One-year efficacy and safety of a fixed combination of insulin degludec and liraglutide in patients with type 2 diabetes: results of a 26-week extension to a 26-week main trial. Diabetes Obes. Metab. 17, 965-973 (2015)

286. Buse, J. B. et al. Contribution of liraglutide in the fixed-ratio combination of insulin degludec and liraglutide (IDegLira). Diabetes Care 37, 2926-2933 (2014).

287. Rosenstock, J. et al. Benefits of a fixed-ratio formulation of once-daily insulin glargine/lixisenatide (LixiLan) versus glargine in type 2 diabetes inadequately controlled on metformin. Diabetologia 57, S108 (2014).

288. [no authors listed.] Sanofi reports positive top-line results in second pivotal LixiLan phase III study. SANOFI http://en.sanofi.com/NasdaO_OMX/local/ press releases/sanofi reports positive toplin 1951405 14-09-2015!07 00 00.aspx (2015)

289. Tahrani, A. A., Barnett, A. H. \& Bailey, C. J. SGLT inhibitors in management of diabetes. Lancet Diabetes Endocrinol. 1, 140-151 (2013).

290. Scheen, A. J. Pharmacodynamics, efficacy and safety of sodium-glucose co-transporter type 2 (SGLT2) inhibitors for the treatment of type 2 diabetes mellitus. Drugs 75, 33-59 (2015)

291. Wright, E. M., Hirayama, B. A. \& Loo, D. F. Active sugar transport in health and disease. J. Intern. Med. 261, 32-43 (2007)

292. Thorens, B. \& Mueckler, M. Glucose transporters in the 21 st Century. Am. J. Physiol. Endocrinol. Metab. 298, E141-E145 (2010).

293. Bailey, C. J. \& Day, C. SGLT2 inhibitors: glucuretic treatment for type 2 diabetes. Br. J. Diabetes Vasc Dis. 10, 193-199 (2010).

294. Bailey, C. J. Renal glucose reabsorption inhibitors to treat diabetes. Trends Pharmacol. Sci. 32, 63-71 (2011).

295. Wright, E. M., Loo, D. D. \& Hirayama, B. A. Biology of human sodium glucose transporters. Physiol. Rev. 91 , 733-794 (2011)

296. Wright, E. M. Renal $\mathrm{Na}^{+}$-glucose cotransporters. Am J. Physiol. Renal Physiol. 280, F10-F18 (2001).

297. Nauck, M. A. et al. Dapagliflozin versus glipizide as add-on therapy in patients with type 2 diabetes who have inadequate glycemic control with metformin: a randomized, 52-week, double-blind, active-controlled noninferiority trial. Diabetes Care 34, 2015-2022 (2011).

298. Ferrannini, G. et al. Energy balance after sodiumglucose cotransporter 2 inhibition. Diabetes Care 38 1730-1735 (2015)

299. Fulcher, G. et al. Efficacy and safety of canagliflozin when used in conjunction with incretin-mimetic therapy in patients with type 2 diabetes. Diabetes Obes. Metab. 18, 82-91 (2016).

300. Obermeier, M. et al. In vitro characterization and pharmacokinetics of dapagliflozin (BMS-512148), a potent sodium-glucose cotransporter type II inhibitor, in animals and humans. Drug Metab. Dispos. 38 , 405-414 (2010)

301. Meng, W. et al. Discovery of dapagliflozin: a potent, selective renal sodium-dependent glucose cotransporter 2 (SGLT2) inhibitor for the treatment of type 2 diabetes. J. Med. Chem. 51, 1145-1149 (2008).

302. Devineni, D. et al. Canagliflozin improves glycaemic control over 28 days in subjects with type 2 diabetes not optimally controlled on insulin. Diabetes Obes. Metab. 14, 539-545 (2012).

303. Heise, T. et al. Safety, tolerability, pharmacokinetics and pharmacodynamics following 4 weeks' treatment with empagliflozin once daily in patients with type 2 diabetes. Diabetes Obes. Metab. 15, 613-621 (2013)

304. Grempler, R et al. Empagliflozin, a novel selective sodium glucose cotransporter-2 (SGLT-2) inhibitor: characterisation and comparison with other SGLT-2 inhibitors. Diabetes Obes. Metab. 14, 83-90 (2012).

305. Jahagirdar, V. \& Barnett, A. H. Empagliflozin for the treatment of type 2 diabetes. Expert Opin. Pharmacother. 15, 2429-2441 (2014). 
306. Scheen, A. J. Drug-drug interactions with sodium glucose cotransporters type 2 (SGLT2) inhibitors, new oral glucose-lowering agents for the management of type 2 diabetes mellitus. Clin. Pharmacokinet. $\mathbf{5 3}$ 295-304 (2014).

307. Ferrannini, E., Ramos, S. J., Salsali, A., Tang, W. \& List, J. F. Dapagliflozin monotherapy in type 2 diabetic patients with inadequate glycemic control by diet and exercise: a randomized, double-blind, placebocontrolled, phase 3 trial. Diabetes Care 33 . 2217-2224 (2010).

308. Sun, Y. N., Zhou, Y. Chen, X., Che, W. S. \& Leung, S. W. The efficacy of dapagliflozin combined with hypoglycaemic drugs in treating type 2 diabetes mellitus: meta-analysis of randomised controlled trials. BMJ Open 4, e004619 (2014).

309. Nauck, M. A. et al. Durability of glycaemic efficacy over 2 years with dapagliflozin versus glipizide as add-on therapies in patients whose type 2 diabetes mellitus is inadequately controlled with metformin. Diabetes Obes. Metab. 16, 1111-1120 (2014).

310. Grandy, S., Hashemi, M., Langkilde, A. M., Parikh, S \& Sjöström, C. D. Changes in weight loss-related quality of life among type 2 diabetes mellitus patients treated with dapagliflozin. Diabetes Obes. Metab. 16 645-650 (2014)

311. Merovci, A. et al. Dapagliflozin improves muscle insulin sensitivity but enhances endogenous glucose production. J. Clin. Invest. 124, 509-514 (2014).

312. Bonner, C. et al. Inhibition of the glucose transporter SGLT2 with dapagliflozin in pancreatic $\alpha$ cells triggers glucagon secretion. Nat. Med. 21, 512-517 (2015)

313. Yang, X. P., Lai, D., Zhong, X. Y., Shen, H. P. \& Huang, Y. L. Efficacy and safety of canagliflozin in subjects with type 2 diabetes: systematic review and meta-analysis. Eur. J. Clin. Pharmacol. 70, 1149-1158 (2014)

314. Neal, B. et al. Efficacy and safety of canagliflozin, an inhibitor of sodium-glucose cotransporter 2, when used in conjunction with insulin therapy in patients with type 2 diabetes. Diabetes Care 38, 403-411 (2015).

315. Stein, P. et al. Canagliflozin, a sodium glucose co-transporter 2 inhibitor, reduces post-meal glucose excursion in patients with type 2 diabetes by a nonrenal mechanism: results of a randomized trial. Metabolism 63, 1296-1303 (2014).

316. Leiter, L. A. et al. Canagliflozin provides durable glycemic improvements and body weight reduction over 104 weeks versus glimepiride in patients with type 2 diabetes on metformin: a randomized, doubleblind, phase 3 study. Diabetes Care 38, 355-364 (2015).

317. Roden, M. et al. Empagliflozin monotherapy with sitagliptin as an active comparator in patients with type 2 diabetes: a randomised, double-blind, placebocontrolled, phase 3 trial. Lancet Diabetes Endocrinol. 1, 208-219 (2013)

318. Häring, H. U. et al. Empagliflozin as add-on to metformin in patients with type 2 diabetes: a 24-week, randomized, double-blind, placebocontrolled trial. Diabetes Care 37, 1650-1659 (2014).

319. Häring, H. U. et al. Empagliflozin as add-on to metformin plus sulfonylurea in patients with type 2 diabetes: a 24-week randomized, double-blind, placebo-controlled trial. Diabetes Care 36 3396-3404 (2013).

320. Kovacs, C. S. et al. Empagliflozin improves glycaemic and weight control as add-on therapy to pioglitazone or pioglitazone plus metformin in patients with type 2 diabetes: a 24-week, randomized, placebocontrolled trial. Diabetes Obes. Metab. 16 147-158 (2014).

321. Roden, M. et al. Empagliflozin (EMPA) monotherapy for $\geq 76$ weeks in drug-naïve patients with type 2 diabetes (T2DM) [abstract 264-OR]. Diabetes 63 (Suppl. 1), A69 (2014).

322. Kovacs, C. S. et al. Empagliflozin as add-on therapy to pioglitazone with or without metformin in patients with type 2 diabetes mellitus. Clin. Ther. 37 , 1773-1788 (2015).

323. Merker, L. et al. Empagliflozin as add-on to metformin in people with type 2 diabetes. Diabet. Med. 32, 1555-1567 (2015).

324. Haering, H. U. et al. Empagliflozin as add-on to metformin plus sulphonylurea in patients with type 2 diabetes. Diabetes Res. Clin. Pract. 110, 82-90 (2015).

325. Ridderstråle, M. et al. Comparison of empagliflozin and glimepiride as add-on to metformin in patients with type 2 diabetes: a 104-week randomised, active- controlled double-blind, phase 5 trial Lancet Diabetes Endocrinol. 2, 691-700 (2014).

326. Rosenstock, J. et al. Impact of empagliflozin added on to basal insulin in type 2 diabetes inadequately controlled on basal insulin: a 78-week randomized, double-blind, placebo-controlled trial. Diabetes Obes. Metab. 17, 936-948 (2015)

327. Rosenstock, J. et al. Improved glucose control with weight loss, lower insulin doses, and no increased hypoglycemia with empagliflozin added to titrated multiple daily injections of insulin in obese inadequately controlled type 2 diabetes. Diabetes Care 37, 1815-1823 (2014).

328. Tikkanen, I. et al. Empagliflozin reduces blood pressure in patients with type 2 diabetes and hypertension. Diabetes Care 38, 420-428 (2015).

329. Barnett, A. H. et al. Efficacy and safety of empagliflozin added to existing antidiabetes treatment in patients with type 2 diabetes and chronic kidney disease: a randomised, double-blind, placebocontrolled trial. Lancet Diabetes Endocrinol. 2, 369-384 (2014).

330. Nyirjesy, P. et al. Genital mycotic infections with canagliflozin, a sodium glucose co-transporter 2 inhibitor, in patients with type 2 diabetes mellitus: a pooled analysis of clinical studies. Curr. Med. Res. Opin. 30, 1109-1119 (2014).

331. Hach, T. et al. Empagliflozin improves glycemic parameters and cardiovascular risk factors in patients with type 2 diabetes (T2DM): pooled data from four pivotal Phase III trials [abstract 69-LB]. Diabetes 62 (Suppl. 1A), LB19 (2013).

332. Ptaszynska, A. et al. Safety profile of dapagliflozin for type 2 diabetes: pooled analysis of clinical studies for overall safety and rare events. Drug Saf. 37, 815-829 (2014).

333. Sha, S. et al. Effect of the sodium glucose co-transporter 2 inhibitor canagliflozin on plasma volume in patients with type 2 diabetes mellitus. Diabetes Obes. Metab 16, 1087-1095 (2014).

334. Toto, R. et al. No overall increase in volume depletion events with empagliflozin (EMPA) in a pooled analysis of more than 11,000 patients with type 2 diabetes (T2DM) [abstract SA-PO373]. J. Am. Soc. Nephrol. 24, 711A (2013)

335. Ljunggren, Ö. et al. Dapagliflozin has no effect on markers of bone formation and resorption or bone mineral density in patients with inadequately controlled type 2 diabetes mellitus on metformin. Diabetes Obes. Metab. 14, 990-999 (2012).

336. Bilezikian, J. P. et al. Evaluation of bone mineral density and bone biomarkers in patients with type 2 diabetes treated with canagliflozin. J. Clin. Endocrinol. Metab. 101, 44-51 (2016)

337. Watts, N. B. et al. Effects of canagliflozin on fracture risk in patients with type 2 diabetes mellitus. J. Clin. Endocrinol. Metab. 101, 157-166 (2015).

338. Kalra, S., Sahay, R. \& Gupta, Y. Sodium glucose transporter 2 (SGLT2) inhibition and ketogenesis. Indian J. Endocrinol. Metab. 19, 524-528 (2015).

339. Storgaard, H., Bagger, J. I., Knop, F. K., Vilsbøll, T. \& Rungby, J. Diabetic ketoacidosis in a patient with type 2 diabetes after initiation of sodium-glucose cotransporter 2 inhibitor treatment. Basic Clin. Pharmacol. Toxicol. 118, 168-170 (2016).

340. Peters, A. L. et al. Euglycemic diabetic ketoacidosis: a potential complication of treatment with sodium glucose cotransporter 2 inhibition. Diabetes Care 38 1687-1693 (2015)

341. Erondu, N., Desai, M., Ways, K. \& Meininger, G. Diabetic ketoacidosis and related events in the canagliflozin type 2 diabetes clinical program. Diabetes Care 38, 1680-1686 (2015).

342. Rosenstock, J. \& Ferrannini, E. Euglycemic diabetic ketoacidosis: a predictable, detectable, and preventable safety concern with SGLT2 inhibitors. Diabetes Care 38, 1638-1642 (2015).

343. Zinman, B. et al. Empagliflozin, cardiovascular outcomes, and mortality in type 2 diabetes. N. Engl. J. Med. 373, 2117-2128 (2015)

344. Holt, R. I., Barnett, A. H. \& Bailey, C. J. Bromocriptine old drug, new formulation and new indication. Diabetes Obes. Metab. 12, 1048-1057 (2010)

345. Cincotta, A. H., Meier, A. H. \& Cincotta, J. M Bromocriptine improves glycaemic control and serum lipid profile in obese Type 2 diabetic subjects: a new approach in the treatment of diabetes. Expert. Opin Investig. Drugs 8, 1683-1707 (1999).

346. Barnett, A. H., Chapman, C., Gailer, K. \& Hayter, C. J. Effect of bromocriptine on maturity onset diabetes. Postgrad. Med. J. 56, 11-14 (1980).
54/. Lam, C. K., Chari, M. \& Lam, T. K. CNS regulation of glucose homeostasis. Physiology (Bethesda) 24, 159-170 (2009)

348. Liang, W. et al. Efficacy and safety of bromocriptine-OR in type 2 diabetes: a systematic review and meta-analysis. Horm. Metab. Res. 47, 805-812 (2015)

349. Gaziano, J. M. et al. Randomized clinical trial of quick-release bromocriptine among patients with type 2 diabetes on overall safety and cardiovascular outcomes. Diabetes Care 33. 1503-1508 (2010).

350. Fonseca, V. A., Handelsman, Y. \& Staels, B. Colesevelam lowers glucose and lipid levels in type 2 diabetes: the clinical evidence. Diabetes Obes. Metab. 12, 384-392 (2010).

351. Rosenstock, J. et al. Efficacy and safety of colesevelam in combination with pioglitazone in patients with type 2 diabetes mellitus. Horm. Metab. Res. 46 943-949 (2014)

352. Younk, L. M., Mikeladze, M. \& Davis, S. N. Pramlintide and the treatment of diabetes: a review of the data since its introduction. Expert Opin. Pharmacother 12 1439-1451 (2011).

353. Henry, R. R. et al. Randomized trial of continuous subcutaneous delivery of exenatide by ITCA 650 versus twice-daily exenatide injections in metformintreated type 2 diabetes. Diabetes Care 36 , 2559-2565 (2013).

354. Nauck, M. A. et al. A phase 2, randomized, dosefinding study of the novel once-weekly human GLP-1 analog, semaglutide, compared with placebo and open-label liraglutide in patients with type 2 diabetes. Diabetes Care 39, 231-241 (2016).

355. Biftu, T. et al. Omarigliptin (MK-3102): a novel longacting DPP-4 inhibitor for once-weekly treatment of type 2 diabetes. J. Med. Chem. 57, 3205-3212 (2014)

356. Amin, N. B et al. Dose-ranging efficacy and safety study of ertugliflozin, a sodium-glucose co-transporter 2 inhibitor, in patients with type 2 diabetes on a background of metformin. Diabetes Obes. Metab. 17, 591-598 (2015)

357. Amin, N. B. et al. Blood pressure lowering effect of the sodium glucose co-transporter (SGLT2) inhibitor, ertugliflozin, assessed via ambulatory blood pressure monitoring (ABPM), in patients with type 2 diabetes and hypertension. Diabetes Obes. Metab. 17 805-808 (2015).

358. van Gaal, L. \& Scheen, A. Weight management in type 2 diabetes: current and emerging approaches to treatment. Diabetes Care 38, 1161-1172 (2015).

359. Bailey, C. J. Interpreting adverse signals in diabetes drug development programs. Diabetes Care 36 2098-2106 (2013).

Author contributions

All authors researched data for the article, made substantial contributions to discussions of content and contributed to writing the article, as well as reviewing and editing the manuscript before submission.

\section{Competing interests statement}

A.A.T. is a clinician scientist supported by the National Institute for Health Research (NIHR) in the UK. The views expressed in this publication are those of the author(s) and not necessarily those of the National Health Service, the NIHR, or the Department of Health. A.A.T. has received honoraria for lectures and advisory work or support for attending conferences from Boehringer-Ingelheim, Bristol-Myers Squibb, Eli Lilly, Novo Nordisk and Sanofi-Aventis. A.A.T. received investigator-led grant support from the Novo Nordisk Research Foundation. A.H.B. has received honoraria for lectures and advisory work from AstraZeneca, Boehringer-Ingelheim, El Lilly, Janssen, MSD, Novartis, Novo Nordisk, Sanofi-Aventis and Takeda. C.J.B. has undertaken ad-hoc consultancy for AstraZeneca, Bristol-Myers Squibb, Elcelyx, Eli Lilly, Janssen, Lexicon, MSD, Novo Nordisk, Roche, Sanofi-Aventis and Takeda. C.J.B. has delivered continuing medical education programmes sponsored by AstraZeneca, Boehringer Ingelheim, Bristol-Myers Squibb, Eli Lilly and MSD, and received travel or accommodation reimbursement from AstraZeneca and Bristol-Myers Squibb.

\section{SUPPLEMENTARY INFORMATION}

See online article: $\underline{\mathrm{S} 1}$ (table) $\mid \underline{\mathrm{S} 2}$ (box) $|\underline{\mathrm{S}} \underline{\text { (table) }}| \underline{\mathrm{S} 4}$ (table) $\mid$

$\underline{\mathrm{S}}$ (table) $\mid \underline{\mathrm{S}} \underline{6}$ (box) $\mid \underline{\mathrm{S} 7}$ (box) 